\title{
How good is your marine protected area at curbing threats?
}

\author{
Zupan Mirta 1, ${ }^{*}$, Bulleri Fabio ${ }^{2}$, Evans Julian ${ }^{3}$, Fraschetti Simonetta ${ }^{4}$, Guidetti Paolo ${ }^{5}$, \\ Garcia-Rubies Antoni ${ }^{6}$, Sostres Marta ${ }^{1}$, Asnaghi Valentina ${ }^{7}$, Caro Anthony ${ }^{1}$, Deudero Salud ${ }^{8}$, \\ Goni Raquel ${ }^{8}$, Guarnieri Giuseppe ${ }^{4}$, Guilhaumon Francois ${ }^{9}$, Kersting Diego ${ }^{10,11}$, Kokkali Athina ${ }^{12}$, \\ Kruschel Claudia ${ }^{13}$, Macic Vesna ${ }^{14}$, Mangialajo Luisa ${ }^{15}, 16$, Mallol Sandra ${ }^{8}$, \\ Macpherson Enrique ${ }^{6}$, Panucci Antonella 12, Radolovic Mirko 17, Ramdani Mohamed ${ }^{18}$, \\ Schembri Patrick J. ${ }^{3}$, Terlizzi Antonio ${ }^{19}, 20$, Villa Elisa ${ }^{21}$, Claudet Joachim ${ }^{22}$
}

\footnotetext{
${ }^{1}$ PSL Res Univ, Natl Ctr Sci Res, CRIOBE, USR 3278,CNRS,EPHE,UPVD, F-66860 Perpignan, France.

2 Univ Pisa, Dipartimento Biol, Via Derna 1, I-56126 Pisa, Italy.

3 Univ Malta, Dept Biol, MSD-2080 Msida, Malta.

${ }^{4}$ Univ Salento, CoNISMa, Dept Biol \& Environm Sci \& Technol, I-73100 Lecce, Italy.

${ }^{5}$ CoNISMa Interuniv Natl Consortium Marine Sci, I-00196 Rome, Italy.

${ }^{6}$ CSIC, CEAB, C Acces Cala S Francesc 14, Blanes 17300, Spain.

7 Univ Genoa, Dept Earth Environm \& Life Sci, CoNISMa, I-16132 Genoa, Italy.

8 Ctr Oceanog Baleares, Inst Espanol Oceanog, Muelle Poniente S-N, Palma De Mallorca 07015, Spain.

9 Univ Montpellier, CNRS, UMR 9190, MARBEC,IRD,IFREMER, F-34095 Montpellier, France.

${ }^{10}$ Free Univ Berlin, Inst Geol Sci, Sect Paleontol, D-12249 Berlin, Germany.

11 Univ Barcelona, Dept Biol Evolut Ecol \& Ciencies Ambientals, E-08028 Barcelona, Spain.

12 Hellen Ctr Marine Res, 46-7 Km Athens Sounio,POB 712, Athens 19013, Greece.

13 Univ Zadar, Dept Ecol Agron \& Aquaculture, Trg Kneza Viseslava 9, Zadar 23000, Croatia.

14 Univ Montenegro, Inst Marine Biol, Kotor 85330, Montenegro.

15 Univ Cote Azur, CNRS, ECOMERS, Parc Valrose 28, F-06108 Nice, France.

${ }^{16}$ UPMC Univ Paris 06, CNRS, LOV, Sorbonne Univ, F-06230 Villefranche Sur Mer, France.

${ }_{17}$ Reg Istria, Adm Dept Sustainable Dev, Flanaticka 29, Pula 52100, Croatia.

18 Inst Sci Rabat, Ave Ibn Batouta, Rabat, Morocco.

19 Univ Trieste, Dept Life Sci, CoNISMa, I-34127 Trieste, Italy.

20 Stn Zool Anton Dohrn, I-80121 Naples, Italy.

21 Observ Oceanol, Microbia Environm, F-66651 Banyuls Sur Mer, France.

22 PSL Univ Paris, Natl Ctr Sci Res, CRIOBE, USR 3278,CNRS, EPHE,UPVD, 195 Rue St Jacques, F75505 Paris, France.
}

* Corresponding author : Mirta Zurpan, email address : mirtazupan@gmail.com

\begin{abstract}
:
Marine protected areas (MPAs) are key tools to mitigate human impacts in coastal environments, promoting sustainable activities to conserve biodiversity. The designation of MPAs alone may not result in the lessening of some human threats, which is highly dependent on management goals and the related
\end{abstract}


specific regulations that are adopted. Here, we develop and operationalize a local threat assessment framework. We develop indices to quantify the effectiveness of MPAs (or individual zones within MPAs in the case of multiple-use MPAs) in reducing anthropogenic extractive and non-extractive threats operating at local scale, focusing specifically on threats that can be managed through MPAs. We apply this framework in 15 Mediterranean MPAs to assess their threat reduction capacity. We show that fully protected areas effectively eliminate extractive activities, whereas the intensity of artisanal and recreational fishing within partially protected areas, paradoxically, is higher than that found outside MPAs, questioning their ability at reaching conservation targets. In addition, both fully and partially protected areas attract non-extractive activities that are potential threats. Overall, only three of the 15 MPAs had lower intensities for the entire set of eight threats considered, in respect to adjacent control unprotected areas. Understanding the intensity and occurrence of human threats operating at the local scale inside and around MPAs is important for assessing MPAs effectiveness in achieving the goals they have been designed for, informing management strategies, and prioritizing specific actions.

\section{Highlights}

- We present and operationalize a cost-effective framework to quantify local threats inside and outside MPAs. We assess how good MPAs are at curbing extractive and non-extractive threats. Fully protected areas effectively eliminate extractive threats. Fully protected areas attract non-extractive threats, when allowed. Small scale fishing intensity is larger in partially protected areas than outside.

Keywords : Fully protected area, Partially protected area, Management, Extractive activities, Nonextractive activities, Marine use 
The effects of human coastal activities often combine into cumulative impacts on many marine ecosystems (Halpern et al., 2015; 2008). Marine protected areas (MPAs) represent the most common tool used in marine spatial planning to mitigate human impacts on marine ecosystems (Lubchenco and Grorud-Colvert, 2015; Lubchenco et al., 2003) and are being increasingly used worldwide both for conservation and fisheries management (Boonzaier and Pauly, 2015). Understanding how MPAs target threats they've been designed to address is essential to inform decision-making and optimize conservation outcomes (Guarderas et al., 2008; Hockings et al., 2004). Some MPAs are located in regions of high cumulative human impact, as shown both in the Mediterranean Sea (Coll et al., 2012; Rodríguez-Rodríguez et al., 2015) and in the Atlantic (Batista et al., 2014). This led to debate about their appropriateness at effectively reducing threats (Agardy et al., 2011; Jameson et al., 2002; Rodríguez-Rodríguez et al., 2015).

Most studies that aimed at evaluating MPAs effectiveness at reducing threat intensities were based on large scale assessments, with resolutions of $500 \mathrm{~m}$ (Batista et al., 2014) or $1 \mathrm{~km}^{2}$ grid cells (Micheli et al., 2013; Portman and Nathan, 2015). Little emphasis has been given on mapping MPAs' specific threats acting at smaller spatial scales -- possibly with some heterogeneity across MPA zones in the case of multiple-use MPAs --, those at which MPAs and their respective management actions are primarily designed to operate in (MPAs being a local spatial management tool; Olsen et al., 2013). This can result in difficulties to translate research findings into management actions, compromising potential benefits of MPAs (Agardy et al., 2011; Freed and Granek, 2014; Kearney et al., 2012; Mills et al., 2010).

The effectiveness of MPAs in reducing threats should be assessed at a local scale, where protection schemes are implemented. To achieve this goal, it is crucial to understand the differences in occurrence and intensity of human activities between the protected and unprotected areas (Claudet and Guidetti, 2010; Portman and Nathan, 2015). This helps to determine whether an MPA is actually successful in mitigating threats or whether the trends observed are merely an indicator of what is occurring outside of the protected area, at larger scales (Hargreaves-Allen et al., 2011).

Two broad types of MPAs exist. First, fully protected areas (FPAs); where all extractive activities (e.g., fishing) are prohibited and where some non-extractive actives (e.g., diving) can be allowed. They are also known as no-take areas or marine reserves. Second, partially protected areas (PPAs); where some activities are prohibited (e.g., spearfishing), others regulated (e.g., fishing with trammel nets) and others allowed (e.g., boating). Those PPAs can be further classified down according to the impact allowed and regulated uses have on species and habitats (Horta e Costa et al., 2016). Different levels of partial protection, together with full protection, can be combined spatially within multiple-use MPAs. Accordingly, the capacity of MPAs to reduce threats will differ depending on their type, design, regulations and level of enforcement (Di Franco et al., 2016; Guidetti et al., 2008; Scianna et al., 2015). Therefore, information on the intensity of threats within each MPA zone and in the surrounding external areas is necessary to assess MPA effectiveness in reducing threats.

Obtaining detailed information on threats is resource demanding, both in terms of time and costs, as the sources of information are largely heterogeneous (Levin et al., 2014). There is a 
need for a reliable, cost-effective method to assess the threat-reduction capacity of MPAs, robust to the heterogeneity of data sources and associated levels of confidence based on data quality. In addition, methods need to be standardized across MPAs as to allow both threat comparisons, among different zones within individual MPAs, and across MPAs.

Here, we developed a cost-effective framework to quantify threats at local scale and assess how MPAs are good (or not) at mitigating extractive and non-extractive local area-based threats (Fig. 1). We trialed the framework on 15 Mediterranean MPAs. MPAs in the Mediterranean Sea are a good model since this basin combines a high intensity of human uses (Claudet and Fraschetti, 2010; Portman and Nathan, 2015) together with a high conservation priority (Coll et al., 2010). This information is essential to inform local management as well as forthcoming regional marine spatial planning (European Commission, 2017).

\section{Materials and methods}

\subsection{Data collection}

We first identified human threats that affect marine ecosystems at a local scale and that can be managed by the MPA staff through regulations. This allowed the identification of 8 threats (Table 1). Threats were either assigned to extractive (i.e., professional and recreational fishing) or non-extractive uses (i.e., activities related to touristic frequentation).

We then developed indicators for each threat accounting for both availability of the data and the quality of the information given. The set of indicators selected was tailored to the data context of the study case, here the Mediterranean, where data availability can be poor in some regions. Data relevant for quantifying threat indicators were collected by means of questionnaires distributed to local managers and scientists. Local expert had to preferably obtain threat indicator values from scientific studies, technical reports or other official documents. When such sources were not available, expert opinion was considered. Three levels of confidence were applied for the estimated threat values (qualitative: high, medium, low). Threat indicator values were considered as high confidence when they were obtained directly from recent quantitative data (e.g., from monitoring data), as medium confidence when estimated from less recent quantitative data and as low confidence when no quantitative data were available and local experts of the particular MPA provided the estimation of the threat indicator value.

Threat indicators were quantified both within and outside 15 coastal MPAs in the Mediterranean Sea (MPAs listed in Appendix A). In case of multiple-use MPAs ( $\mathrm{n}=13$ ), data was obtained for each full (no-take/no-entry or no-take zones) or partial protection level. We used two approaches to delineate the outside area, depending on the characteristics of the threat: i) for commercial fishing with trawlers and purse seiners a $10 \mathrm{~km}$ radius surrounding the MPAs was applied, while ii) for all other threats originating closer to the shore the coastal section at a maximum distance from the shore equal to the MPAs most offshore limit was considered (Fig C.1.). This specific outside areas were chosen following consultations with at least one expert of each MPA. The two approaches aimed to reflect the nature and occurrence of that threat in order to avoid over- or underestimation of threat intensities, respectively, in the outside areas.

The total size of each zone within each MPA was obtained directly from managers and/or 
126 from management plans, whilst the outside surface areas were calculated using QGIS 2.8/1

127 (QGIS Development Team, 2015).

128

129

130

131

132

133

134

135

136

137

138

140

141

142

143

144

145

146

147

148

149

150

151

152

153

154

155

156

157

158

159

160

161

162

163

164

165

All the raw data collected in this study can be found in Appendix B.

\subsection{Threat indices}

\subsubsection{Threat intensity}

Using the raw threat values (Table B.1), we calculated the intensity $T I_{i j k}$ of each threat $i$ within each protection level $j$ (full protection, partial protection and no protection-outside) for each MPA $k$, as follows:

$$
\mathrm{TI}_{i j k}=\mathrm{T}_{i j k} / \mathrm{A}_{j k}
$$

where $T_{i j k}$ is the value of threat $i$ in zone $j$ of MPA $k$, and $A_{j k}$ is the area $\left(\mathrm{km}^{2}\right)$ of zone $j$ in MPA $k$. We have then normalized threat intensity values (TI) by diving each value with the maximum threat intensity value (TI) of each threat, which resulted in a standardized scale of $[0 ; 1]$. These normalized values were then used to calculate the mean threat intensity of each threat in each protection level to explore the variability of threat intensity amongst protection levels. Detailed descriptive statistics of the normalized threat intensity index can be found in Appendix C.

\subsubsection{Threat reduction capacity}

The threat reduction capacity $T R_{i j k}$ of each protection level $j$ (excluding the outside area) of each MPA $k$ was calculated as:

$$
\mathrm{TR}_{i j k}=-\left(1-\mathrm{TI}_{i j k} / \mathrm{TI}_{o, i k}\right)
$$

where $T T_{i j k}$ is the intensity of threat $i$ inside zone $j$ of MPA $k$, and $T I_{o, i k}$ is the threat intensity of threat $i$ outside of the MPA $k$. A negative value of $T R$ indicates that the threat intensity is reduced inside the protected area relative to the outside; a positive value of $T R$ indicates that the threat intensity is higher inside the MPA relative to the outside. The mean threat reduction capacity values $\left(T R_{i j k}\right)$ were used to compare the reduction capacity of the fully and partially protected zones for every threat. Detailed descriptive statistics of the threat reduction capacity index can be found in Appendix C.

\subsubsection{Zone threat reduction score}

The zone threat reduction score $(z T)$ was calculated as:

$$
\mathrm{zT}_{\mathrm{jk}}=\frac{\sum_{\mathrm{i}} \mathrm{TR}_{\mathrm{ijk}} * \mathrm{w}_{\mathrm{i}}}{\sum_{\mathrm{i}}^{\mathrm{w}}{ }_{\mathrm{i}}},
$$

166 where $T R_{i j k}$ is the threat reduction capacity defined above and $w_{i}$ is the weight associated to 167 threat $i$ (Table 1). The weights for each threat were derived from Horta e Costa et al. (2016) 
and were rescaled to values between 0 and 1 , with 1 being the weight assigned to the threat

169 with the greatest ecological impact (i.e. trawling). The weights were used to discriminate

170 between different potential ecological impacts of each threat and were obtained with expert

171 knowledge, but based on previous studies (see detailed explanation in Appendix A of Horta e

172 Costa et al., 2016).

173

174

175

176

177

\subsubsection{MPA threat reduction score}

The MPA threat reduction score mpaT was calculated as:

178

(77)

179

180

181

182

183

184

185

186

187

188

189

190

191

192

193

194

195

$$
\operatorname{mpaT}_{k}=\frac{\sum_{j} \mathrm{zT}_{j k} * \mathrm{~A}_{j k}}{\sum_{j} \mathrm{~A}_{j k}}
$$

where $z T_{j k}$ is the threat reduction score of zone $j$ of MPA $k$, and $A_{j k}$ is the surface area of zone $j$ of MPA $k$. When the zone or MPA threat reduction score is negative, threats are being effectively reduced inside the zone and/or MPA compared to outside. When the threat reduction score is positive the MPA is actually enhancing threats rather than reducing them.

\section{$\underline{2.2 .5 . ~ L o c a l ~ t h r e a t ~ i n d e x ~}$}

To account for the context in which MPAs are sited we calculated a local threat index $l T I$ as follows:

where the $T I_{o, i}$ is the intensity of threat $i$ outside MPA $k$ and max $T I_{o, i}$ is the maximum intensity value of threat $i$ recorded from all the outside areas of all considered MPAs. The local threat index ranges from 0 to 1 , indicating a local low and high intensity, respectively, of a particular threat in the area outside an MPA compared to the broader context.

\subsubsection{MPA local threat index}

Local threat indices were aggregated at each MPA scale to calculate the MPA local threat index mpa.lTI as follows:

$$
l T I_{i k}=\frac{T I_{o, i k}}{\max T I_{o, i}}
$$


outside the MPA, when compared to threat intensities in area outside the other MPAs in the region.

\subsection{Data analyses}

The relationship between the MPA threat reduction score (mpaT) and the MPA local threat index (mpa.lTI) were explored using a linear model. Additionally, the relationship between the threat reduction score, mpaT, and the age and size of the MPA were also tested with a regression to investigate whether these design characteristics affect the threat reduction capacity of MPAs.

The data on the confidence level associated with each threat type and zone protection level was analysed using chi-square tests to assess whether there is an association between data quality and zone type or threat type, respectively.

All analyses were conducted using $\mathrm{R}$ ( $\mathrm{R}$ Development Core Team, 2016). The $\mathrm{R}$ script is available in Appendix D.

\section{Results}

Mean threat intensities (TI) differed amongst protection levels threat type (Fig. 2). Fully protected zones had no extractive threats (by definition), however they had the highest intensity of all non-extractive threats. On average, the intensity of non-extractive threats was 2.6 and 16 times greater in fully protected zones compared to partially protected zones and the area outside of the MPAs, respectively.

All threats were present in partially protected zones, with the highest levels of both recreational and artisanal fishing (Fig. 2). In the area outside MPAs, the intensity of extractive threats was up to 18 times greater than the intensity of non-extractive threats.

The threat reduction capacity (TR) differed across protection level and threat type (Fig. 3). Fully protected areas removed all extractive threats, while on average, partially protected zones did not reduce extractive threats. The intensities of large commercial fisheries (trawling and purse-seine) were reduced in partially protected zones compared to the outside, yet the intensities of artisanal and recreational fishing were approximately 4.9 times greater than in the surrounding areas. All non-extractive threats were increased within fully and partially protected zones, compared to the outside surrounding areas.

The mean zone threat reduction score $(z T)$ for non-extractive threats was, on average, 4.8 greater for fully protected zones compared to partially protected zones, yet this value was highly variable (Fig. 3).

The MPA threat reduction score (mpaT) ranged between -0.8 and 116 (Fig. 4). Overall, only three MPAs reduced all threats relative to the outside. Five MPAs reduced all extractive threats and two MPAs reduced all non-extractive threats relative to their outside area.

The intensity of threats in the areas outside of MPAs varied greatly among MPAs (Fig. C.2 in Appendix C). There were no significant relationship between the MPAs' threat reduction score (mpaT) and the MPA local threat index (mpa.lTI), indicating that the capacity of MPAs to reduce threats was independent on the intensity of threats in their surrounding areas 
248 ( $>0.05$, see Fig. C.3 in Appendix C). Likewise, there were no significant relationships

249 between the MPA threat reduction score and the age or size of the MPA ( $>0.05$, see Fig. C. 4

250 and C.5 in Appendix C).

The confidence levels associated with estimates of threat intensities differed among zones of MPAs and the outside areas (chi-squared test, $\chi^{2}=153.54, \mathrm{p}<0.001$ ). More than half of the values from the areas outside were given low confidence (Fig. 5). In contrast within the MPAs, the majority of threat values had high confidence, $65 \%$ and $50 \%$ in fully and partially protected zones, respectively.

Confidence levels also differed amongst threats (chi-squared test, $\chi^{2}=233.63, p<0.001$ ). For all extractive threats, the greatest proportion of values had high confidence (Fig. 6). Scubadiving and commercial boating were among the non-extractive threats with the highest proportion of high confidence, while the values attributed to private boating and bathing had low confidence.

\section{Discussion}

This study was designed to provide a framework of the effectiveness of MPAs at curbing threats at the scale they are designed, developing indices of the intensity of threats at the scale of single MPAs (Fig. 1). The information provided was scaled to support management actions designed to enhance the success of each MPA in achieving its goals (Hockings et al., 2004).

Our most compelling result is that threats can indeed increase in MPAs compared to outside areas. Even if absent for fully protected zones, many extractive threats were larger in partially protected zones compared to outside. Contrary to fully protected zones, partially protected zones do not necessarily have the objective to eliminate threats (e.g., via a fishing ban), but to regulate their intensity towards sustainable levels. Implementing management strategies that allow and maintain ecologically sustainable uses ensures long-term benefits from ecosystem services benefiting local economies and, hence, local communities (Roberts et al., 2005). In the Mediterranean Sea, the regulatory regimes of partially protected areas vary from MPA to another, however there are some common modalities (Portman et al., 2012).

Artisanal and recreational fishing are permitted in partially protected zones of many MPAs, although most of the time subjected to restrictions in the type of gear allowed. The intensity of artisanal and recreational fishing was up to 4.8 times higher inside partially protected zones compared to outside control areas. While the regulatory regime in partially protected zones may be stricter than in the surrounding outside areas, the former still attract more fishers and hence increase fishing pressure. Most of the partially protected zones considered in this study surround fully protected areas (Appendix A) and may attract fishermen. Full protection enhance fish abundance and size (Guidetti et al., 2014; Sala et al., 2012), often resulting in the spillover of larvae and adults to adjacent unprotected areas (Di Franco et al., 2015; 2012; Di Lorenzo et al., 2016; Garcia-Rubies et al., 2013; Goñi et al., 2010; Stobart et al., 2009), hence concentrating fishing effort (Kellner et al., 2007; Stelzenmüller et al., 2007).

The intensity of non-extractive threats was also higher within MPAs than in the areas outside, and at least 4 times higher in fully protected zones compared to partially protected zones. By definition, fully protected areas are places aiming to protect the full spectrum of biodiversity 
298 by limiting all kinds of extractive and destructive activity within them (Allison et al., 1998),

299 yet this does not exclude all human activity. Indeed, most fully protected zones allow and, as 300 we show here, attract visitation with the intent of non-extractive activities (Thurstan et al., 301 2012). Increasing non-extractive touristic activities are viewed as a positive socioeconomic output of MPAs in the Mediterranean Sea and worldwide (Leisher et al., 2007; Pascual et al., 2016), as they promote education, support employment and generate revenue (HargreavesAllen et al., 2011; Pascual et al., 2016; Spalding et al., 2017). Increasing tourism is, therefore, often listed as a looked-for objective of MPAs (Hargreaves-Allen et al., 2011). Thurstan et al. (2012) suggest that unless all activities are adequately managed, regulation of extractive activities alone may not guarantee the levels of biodiversity protection expected from fully protected zones.

309 Only three MPAs were effective in reducing the intensity of threats in respect to adjacent 310 unprotected areas. Examining the context in which MPAs are established is, nevertheless, 311 central to understanding the capacity of MPAs in addressing threats and their conservation 312 potential (Portman and Nathan, 2015). The majority of MPAs in this study are multiple-use 313 MPAs that accommodate a variety of uses. This type of MPAs is common for densely 314 populated systems (Agardy et al., 2003), such as the Mediterranean Sea, where reducing all 315 threats is unlikely. Portman et al. (2015) showed that the variety of activities occurring within the Mediterranean MPAs is often greater than in the coastal unprotected areas of many Mediterranean countries. Yet, multiple use MPAs and particularly partially protected areas alone are now the most common type of MPAs being implemented worldwide (Claudet, 2017). They are being established to meet the international targets of protection (Agardy et al. 2016), with the stated objectives of biodiversity conservation. Our results point that the achievability of their goals should be questioned, as here, we show that not only the variety, but also intensity of threats is generally greater within MPAs than in the areas outside (see also Mora et al., 2006) that leads to the low threat reduction capacity of MPAs.

324 The capacity to reduce (or not) threats was not dependent on the threat local context, the age

325 or the size of the MPA. This suggests that the relationship between threat-intensity and reduction-capacity is mainly a function of management objectives and capacity (Gill et al., 2017), corresponding regulations (Horta e Costa et al. 2016) and enforcement (Guidetti et al., 2008) of each MPA rather than the magnitude of the outside threat intensities or design features. Hargreaves et al. (2017) examined the differences in threats inside and outside coral reef MPAs and they showed that MPAs with reduced threats had more staff and invested more funds into active management. Indeed, management has been identified as one of the most important factors affecting the effectiveness of MPAs (Gill et al., 2017). Understanding how different management regimes affect the threat reduction capacity of zones in multipleuse MPAs should be further investigated as it could shed light onto the highly variable responses we have observed among protection levels.

Our framework uses threats, and their respective indicators, that are most common and were easily obtained in the Mediterranean MPAs. While we were able to trial our framework using the information available, the assessment of the MPAs threat reduction capacity could be refined with more detailed and robust data. Besides, we do acknowledge that other types of threats may be present in other systems yet this issue can be easily overcome, as our framework can be adapted to suit a variety of systems, by incorporating new threats and their corresponding indicators. 
346 We did not include poaching as one of the threats in our framework. Poaching levels can 347 often be higher than assumed in MPAs (Bergseth et al., 2017) and represent an important 348 threat to the effectiveness of MPAs. While we initially planned to collect data on poaching, 349 we faced strong difficulties to quantitatively standardize this threat across MPAs. If 350 standardized data can be obtained across a range of MPAs, this can easily be added in the framework as an additional threat.

Our results point out that we have greater confidence about what is happening inside MPAs than in their surrounding areas. The low confidence associated with threat values in the unprotected, outside, areas might have affected the precision of our results. The areas outside MPAs are usually less monitored or completely unmonitored and estimating threat values for these areas was challenging. Good management should require regular monitoring, both for the ecological and environmental status of the MPA habitats (Fraschetti et al., 2013), but also should incorporate monitoring of the main activities that can lead to potential threats both inside and beyond the borders of the MPA (Claudet and Guidetti, 2010; Hargreaves-Allen et al., 2017; Parravicini et al., 2013).

Evaluating the success of MPAs is essential to maximize their conservation potential (Agardy et al., 2016; Pomeroy et al., 2005), especially within an adaptive management framework (Scianna et al., 2015). Contrary to previous assessments (Coll et al., 2012; Micheli et al., 2013) our approach uses data specific to each zone of the MPA, where strong heterogeneity among threats intensity can occur, and accounts for manageable threats at manageable scales relevant for MPA managers. We therefore believe this work has general and wide applications, especially for managers and planners who need to assess the success of MPAs at achieving marine spatial planning goals (Partelow et al., 2015).

\section{Management implications}

372 By providing the ability to easily compare threat intensities and the capacity of a given MPA 373 to reduce threats, our proposed framework can help prioritize management actions.

374 Management actions should first be directed towards reducing threats that would prevent 375 achieving the MPA objectives. Besides, the threat assessment framework can help identify 376 unexpected indirect effects of MPA creation, such as increased non-extractive threat due to 377 increase attendance.

By providing the ability to easily compare threat reduction score among zones, in the case of multiple-use MPAs, our proposed framework can help guide local spatial planning. Assigning different uses in different zones can have trade-offs in terms of biodiversity conservation and ecosystem services delivery and threat assessment is a first step towards the identification of acceptable thresholds of uses. When scaled-up regionally, the threat assessment framework can help guide regional spatial planning.

The threat assessment framework could be incorporated into monitoring programs. First, monitoring threat evolution over time helps identify the management actions able to reduce threats. Second, this would necessarily imply to monitor and collect data, which is a condition of proper MPA effectiveness assessments. 
393 Acknowledgments

394 This work was financially supported by the ERA-Net BiodivERsA (BUFFER project) and 395 the EU-FP7 (COCONET project).

396 


\section{References}

Agardy, T., Bridgewater, P., Crosby, M.P., Day, J., Dayton, P.K., Kenchington, R., Laffoley, D., McConney, P., Murray, P.A., Parks, J.E., Peau, L., 2003. Dangerous targets? Unresolved issues and ideological clashes around marine protected areas. Aquatic Conserv: Mar. Freshw. Ecosyst. 13, 353-367. doi:10.1002/aqc.583

Agardy, T., Claudet, J., Day, J.C., 2016. "Dangerous Targets" revisited: Old dangers in new contexts plague marine protected areas. Aquatic Conserv: Mar. Freshw. Ecosyst. 26, $7-$ 23. doi:10.1002/aqc. 2675

Agardy, T., di Sciara, G.N., Christie, P., 2011. Mind the gap: Addressing the shortcomings of marine protected areas through large scale marine spatial planning. Mar. Policy 35, 226232. doi:10.1016/j.marpol.2010.10.006

Allison, G.W., Lubchenco, J., Carr, M.H., 1998. Marine Reserves are Necessary but not Sufficient for Marine Conservation. Ecol. Appl. 8, S79-92

Batista, M.I., Henriques, S., Pais, M.P., Cabral, H.N., 2014. Assessment of cumulative human pressures on a coastal area: Integrating information for MPA planning and management. Ocean Coast. Manag. 102, 248-257. doi:10.1016/j.ocecoaman.2014.09.020

Boonzaier, L., Pauly, D., 2015. Marine protection targets: an updated assessment of global progress. Oryx 50, 27-35. doi:10.1017/S0030605315000848

Bergseth, B.J., 2017 Effective marine protected areas require sea change in compliance management. ICES J. Mar. Sci. doi:10.1093/icesjms/fsx105

Claudet, J., Fraschetti, S., 2010. Human-driven impacts on marine habitats: A regional metaanalysis in the Mediterranean Sea. Biol. Cons. 143, 2195-2206. doi:10.1016/j.biocon.2010.06.004

Claudet, J., Guidetti, P., 2010. Improving assessments of marine protected areas. Aquatic Conserv: Mar. Freshw. Ecosyst. 20, 239-242. doi:10.1002/aqc.1087

Claudet, J., 2017. Six conditions under which MPAs might not appear effective (when they are). ICES J. Mar. Sci. doi: 10.1093/icesjms/fsx074.

Coll, M., Piroddi, C., Albouy, C., Ben Rais Lasram, F., Cheung, W.W.L., Christensen, V., Karpouzi, V.S., Guilhaumon, F., Mouillot, D., Paleczny, M., Palomares, M.L., Steenbeek, J., Trujillo, P., Watson, R., Pauly, D., 2012. The Mediterranean Sea under siege: spatial overlap between marine biodiversity, cumulative threats and marine reserves. Glob. Ecol. and Biogeogr. 21, 465-480. doi:10.1111/j.1466-8238.2011.00697.x

Coll, M., Piroddi, C., Steenbeek, J., Kaschner, K., Ben Rais Lasram, F., Aguzzi, J., Ballesteros, E., Bianchi, C.N., Corbera, J., Dailianis, T., Danovaro, R., Estrada, M., Froglia, C., Galil, B.S., Gasol, J.M., Gertwagen, R., Gil, J., Guilhaumon, F., KesnerReyes, K., Kitsos, M.-S., Koukouras, A., Lampadariou, N., Laxamana, E., López-Fé de la Cuadra, C.M., Lotze, H.K., Martin, D., Mouillot, D., Oro, D., Raicevich, S., RiusBarile, J., Saiz-Salinas, J.I., San Vicente, C., Somot, S., Templado, J., Turon, X., Vafidis, D., Villanueva, R., Voultsiadou, E., 2010. The Biodiversity of the Mediterranean Sea: Estimates, Patterns, and Threats. PLOS ONE 5, e11842-36. doi:10.1371/journal.pone.0011842

Di Franco, A., Calò, A., Pennetta, A., De Benedetto, G., Planes, S., Guidetti, P., 2015. Dispersal of larval and juvenile seabream: Implications for Mediterranean marine protected areas. Biol. Conserv. 192, 361-368. doi:10.1016/j.biocon.2015.10.015

Di Franco, A., Coppini, G., Pujolar, J.M., De Leo, G.A., Gatto, M., Lyubartsev, V., Melià, P., Zane, L., Guidetti, P., 2012. Assessing Dispersal Patterns of Fish Propagules from an Effective Mediterranean Marine Protected Area. PLOS ONE 7, e52108-14. doi:10.1371/journal.pone.0052108

Di Franco, A., Thiriet, P., Di Carlo, G., Dimitriadis, C., Francour, P., Gutiérrez, N.L., de 
Grissac, A.J., Koutsoubas, D., Milazzo, M., del Mar Otero, M., Piante, C., Plass-Johnson, J., Sainz-Trapaga, S., Santarossa, L., Tudela, S., Guidetti, P., 2016. Five key attributes can increase marine protected areas performance for small-scale fisheries management. Sci. Rep. 6, 1-9. doi:10.1038/srep38135

Di Lorenzo, M., Claudet, J., Guidetti, P., 2016. Spillover from marine protected areas to adjacent fisheries has an ecological and a fishery component. J. Nat. Conserv. 32, 62-66. doi:10.1016/j.jnc.2016.04.004

European Commission, 2017. Maritime Affairs, Maritime spatial Planning. https://ec.europa.eu/maritimeaffairs/policy/maritime_spatial_planning_en (accessed 10.07.2017)

Fraschetti, S., Guarnieri, G., Bevilacqua, S., Terlizzi, A., Boero, F., 2013. Protection enhances community and habitat stability: evidence from a mediterranean marine protected area. PLOS ONE 8, e81838. doi:10.1371/journal.pone.0081838

Freed, S., Granek, E.F., 2014. Effects of Human Activities on the World's Most Vulnerable Coral Reefs: Comoros Case Study. Ocean Coast. Manage. 42, 280-296. doi:10.1080/08920753.2014.904261

Garcia-Rubies, A., Hereu, B., Zabala, M., 2013. Long-term recovery patterns and limited spillover of large predatory fish in a Mediterranean MPA. PLOS ONE 8, e 73922. doi:10.1371/journal.pone.0073922

Gill, D.A., Mascia, M.B., Ahmadia, G.N., Glew, L., Lester, S.E., Barnes, M., Craigie, I., Darling, E.S., Free, C.M., Geldmann, J., Holst, S., Jensen, O.P., White, A.T., Basurto, X., Coad, L., Gates, R.D., Guannel, G., Mumby, P.J., Thomas, H., Whitmee, S., Woodley, S., Fox, H.E., 2017. Capacity shortfalls hinder the performance of marine protected areas globally. Nature. 000, 1-16. doi:10.1038/nature21708

Gonson, C., Pelletier, D., Gamp, E., Preuss, B., Jollit, I., Ferraris, J., 2016. Decadal increase in the number of recreational users is concentrated in no-take marine reserves. Mar. Poll. Bull. 107, 1-11. doi:10.1016/j.marpolbul.2016.04.007

Goñi, R., Hilborn, R., D i az, D., Mallol, S., Adlerstein, S., 2010. Net contribution of spillover from a marine reserve to fishery catches. Mar. Ecol. Prog. Ser. 400, 233-243. doi:10.3354/meps08419

Guarderas, A.P., Hacker, S.D., Lubchenco, J., 2008. Current Status of Marine Protected Areas in Latin America and the Caribbean. Conserv. Biol. 22, 1630-1640. doi:10.1111/j.1523-1739.2008.01023.x

Guerrero, A.M., McAllister, R.R.J., Corcoran, J., Wilson, K.A., 2013. Scale Mismatches, Conservation Planning, and the Value of Social-Network Analyses. Conserv. Biol. 27, 35-44. doi:10.1111/j.1523-1739.2012.01964.x

Guidetti, P., Baiata, P., Ballesteros, E., Di Franco, A., Hereu, B., Macpherson, E., Micheli, F., Pais, A., Panzalis, P., Rosenberg, A.A., Zabala, M., Sala, E., 2014. Large-Scale Assessment of Mediterranean Marine Protected Areas Effects on Fish Assemblages. PLOS ONE 9, e91841-14. doi:10.1371/journal.pone.0091841

Guidetti, P., Milazzo, M., Bussotti, S., Molinari, A., Murenu, M., Pais, A., Spanò, N., Balzano, R., Agardy, T., Boero, F., Carrada, G., Cattaneo-Vietti, R., Cau, A., Chemello, R., Greco, S., Manganaro, A., Notarbartolo di Sciara, G., Russo, G.F., Tunesi, L., 2008. Italian marine reserve effectiveness: Does enforcement matter? Biol. Conserv. 141, 699709. doi:10.1016/j.biocon.2007.12.013

Halpern, B.S., Frazier, M., Potapenko, J., Casey, K.S., Koenig, K., Longo, C., Lowndes, J.S., Rockwood, R.C., Selig, E.R., Selkoe, K.A., Walbridge, S., 2015. Spatial and temporal changes in cumulative human impacts on the world's ocean. Nat. Commun. 6, 7615. doi:10.1038/ncomms 8615

Halpern, B.S., Walbridge, S., Selkoe, K.A., Kappel, C.V., Micheli, F., D'Agrosa, C., Bruno, 
J.F., Casey, K.S., Ebert, C., Fox, H.E., Fujita, R., Heinemann, D., Lenihan, H.S., Madin, E.M.P., Perry, M.T., Selig, E.R., Spalding, M., Steneck, R., Watson, R., 2008. A Global Map of Human Impact on Marine Ecosystems. Science 319, 948-952. doi:10.1126/science. 1149345

Hargreaves-Allen, V., Mourato, S., Milner-Gulland, E.J., 2011. A Global Evaluation of Coral Reef Management Performance: Are MPAs Producing Conservation and SocioEconomic Improvements? Environ. Manage. 47, 684-700. doi:10.1007/s00267-0119616-5

Hargreaves-Allen, V.A., Mourato, S., Milner-Gulland, E.J., 2017. Drivers of coral reef marine protected area performance. PLOS ONE 12, e0179394-21. doi:10.1371/journal.pone.0179394

Hockings, M., Stolton, S., Dudley, N., 2004. Management Effectiveness: Assessing Management of Protected Areas? J. Environ. Policy Plan. 6, 157-174. doi:10.1080/1523908042000320731

Horta e Costa, B., Claudet, J., Franco, G., Erzini, K., Caro, A., Gonçalves, E.J., 2016. A regulation-based classification system for Marine Protected Areas (MPAs). Mar. Policy 72, 192-198. doi:10.1016/j.marpol.2016.06.021

Jameson, S.C., Tupper, M.H., Ridley, J.M., 2002. The three screen doors: can marine "protected" areas be effective? Mar. Poll. Bull. 44, 1177-1183. doi:10.1016/S0025326X(02)00258-8

Kearney, R., Buxton, C.D., Farebrother, G., 2012. Australia's no-take marine protected areas Appropriate conservation or inappropriate management of fishing? Mar. Policy 36, 1064-1071. doi:10.1016/j.marpol.2012.02.024

Keller, B.D., Gleason, D.F., McLeod, E., Woodley, C.M., Airame, S., Causey, B.D., Friedlander, A.M., Grober-Dunsmore, R., Johnson, J.E., Miller, S.L., Steneck, R.S., 2009. Climate change, coral reef ecosystems, and management options for marine protected areas. Environ. Manage. 44, 1069-1088. doi:10.1007/s00267-009-9346-0

Kellner, J.B., Tetreault, I., Gaines, S.D., Nisbet, R.M., 2007. Fishing the line near marine reserves in single and multispecies fisheries, Ecol. Appl.. doi:10.1890/05-1845

Leisher, C., Van Beukering, P., Scherl, L.M., 2007. Nature's Investment Bank: How Marine Protected Areas Contribute to Poverty Reduction. Arlington, USA: The Nature Conservancy

Levin, N., Coll, M., Fraschetti, S., Gal, G., Giakoumi, S., Göke, C., Heymans, J.J., Katsanevakis, S., Mazor, T., Öztürk, B., Rilov, G., Gajewski, J., Steenbeek, J., Kark, S., 2014. Biodiversity data requirements for systematic conservation planning in the Mediterranean Sea. Mar. Ecol. Prog. Ser. 508, 261-281. doi:10.3354/meps 10857

Lubchenco, J., Grorud-Colvert, K., 2015. Making waves: The science and politics of ocean protection. Science 350, 382-383. doi:10.1126/science.aad5443

Lubchenco, J., Palumbi, S.R., Gaines, S.D., Andelman, S., 2003. Plugging a hole in the ocean: the emerging science of marine reserves. Ecol. Appl. 13, 3-7. doi:10.1890/10510761(2003)013[0003:PAHITO]2.0.CO;2

Micheli, F., Halpern, B.S., Walbridge, S., Ciriaco, S., Ferretti, F., Fraschetti, S., Lewison, R., Nykjaer, L., Rosenberg, A.A., 2013. Cumulative Human Impacts on Mediterranean and Black Sea Marine Ecosystems: Assessing Current Pressures and Opportunities. PLOS ONE 8, e79889. doi:10.1371/journal.pone.0079889

Mills, M., Pressey, R.L., Weeks, R., Foale, S., Ban, N.C., 2010. A mismatch of scales: challenges in planning for implementation of marine protected areas in the Coral Triangle. Conserv. Lett. 3, 291-303. doi:10.1111/j.1755-263X.2010.00134.x

Mora, C., Andrèfouët, S., Costello, M.J., Kranenburg, C., Rollo, A., Veron, J., Gaston, K.J., Myers, R.A., 2006. Coral reefs and the global network of Marine Protected Areas. 
Olsen, E.M., Fonseca, L., Goni, R., Johnson, D., Katsanevakis, S., Macpherson, E., Pelletier,

D., Rabaut, M., Chantal-Ribeiro, M., Weaver, P., Zaharia, T., 2013. Achieving Ecologically Coherent MPA Networks in Europe: Science Needs and Priorities. European Marine Board Position Paper 18. Larkin, K.E, and McDonough, N. (Eds.). European Marine Board, Ostend, Belgium

Parravicini, V., Micheli, F., Montefalcone, M., Morri, C., Villa, E., Castellano, M., Povero, P., Bianchi, C.N., 2013. Conserving biodiversity in a human-dominated world: degradation of marine sessile communities within a protected area with conflicting human uses. PLOS ONE 8, e75767. doi:10.1371/journal.pone.0075767

Partelow, S., Wehrden, von, H., Horn, O., 2015. Pollution exposure on marine protected areas: A global assessment. Mar. Poll. Bull. 100, 352-358. doi:10.1016/j.marpolbul.2015.08.026

Pascual, M., Rossetto, M., Ojea, E., Milchakova, N., Giakoumi, S., Kark, S., Korolesova, D., Melià, P., 2016. Socioeconomic impacts of marine protected areas in the Mediterranean and Black Seas. Ocean Coast. Manage. 133, 1-10. doi:10.1016/j.ocecoaman.2016.09.001

Pomeroy, R.S., Watson, L.M., Parks, J.E., Cid, G.A., 2005. How is your MPA doing? A methodology for evaluating the management effectiveness of marine protected areas. Ocean Coast. Manage. 48, 485-502. doi:10.1016/j.ocecoaman.2005.05.004

Portman, M.E., Nathan, D., 2015. Conservation "identity" and marine protected areas management: A Mediterranean case study. J. Nat. Conserv. 24, 109-116. doi:10.1016/j.jnc.2014.10.001

Portman, M.E., Nathan, D., Levin, N., 2012. From the Levant to Gibraltar: A Regional Perspective for Marine Conservation in the Mediterranean Sea. Ambio 41, 670-681. doi:10.1007/s13280-012-0298-x

QGIS Development Team, 2015. QGIS Geographic Information System. Open Source Geospatial Foundation. https://qgis.osgeo.orh

R Core Team, 2016. R: A language and environment for statistical computing. Foundation for Statistical Computing, Vienna, Austria

Roberts, C.M., Hawkins, J.P., Gell, F.R., 2005. The role of marine reserves in achieving sustainable fisheries. Philos. Trans. R. Soc. Lond., B, Biol. Sci. 360, 123-132. doi:10.1098/rstb.2004.1578

Rodríguez-Rodríguez, D., Sánchez-Espinosa, A., Schröder, C., Abdul Malak, D., Rodríguez, J., 2015. Cumulative pressures and low protection: a concerning blend for Mediterranean MPAs. Mar. Poll. Bull. 101, 288-295. doi:10.1016/j.marpolbul.2015.09.039

Sala, E., Ballesteros, E., Dendrinos, P., Di Franco, A., Ferretti, F., Foley, D., Fraschetti, S., Friedlander, A., Garrabou, J., Güçlüsoy, H., Guidetti, P., Halpern, B.S., Hereu, B., Karamanlidis, A.A., Kizilkaya, Z., Macpherson, E., Mangialajo, L., Mariani, S., Micheli, F., Pais, A., Riser, K., Rosenberg, A.A., Sales, M., Selkoe, K.A., Starr, R., Tomas, F., Zabala, M., 2012. The Structure of Mediterranean Rocky Reef Ecosystems across Environmental and Human Gradients, and Conservation Implications. PLOS ONE 7, e32742-13. doi:10.1371/journal.pone.0032742

Scianna, C., Niccolini, F., Gaines, S.D., Guidetti, P., 2015. Organization Science': A new prospective to assess marine protected areas effectiveness. Ocean Coast. Manage. 116, 443-448. doi:10.1016/j.ocecoaman.2015.09.005

Spalding, M., Burke, L., Wood, S.A., Ashpole, J., Hutchison, J., zu Ermgassen, P., 2017. Mapping the global value and distribution of coral reef tourism. Mar. Policy 82, 104 113. doi:10.1016/j.marpol.2017.05.014

Stelzenmüller, V., Maynou, F., Mart i n, P., 2007. Spatial assessment of benefits of a coastal Mediterranean Marine Protected Area. Biol. Conserv. 136, 571-583. 
doi:10.1016/j.biocon.2007.01.002

598 Stobart, B., Warwick, R., González, C., Mallol, S., Díaz, D., Reñones, O., Goni, R., 2009.

599 Long-term and spillover effects of a marine protected area on an exploited fish

600 community. Mar. Ecol. Prog. Ser. 384, 47-60. doi:10.3354/meps08007

601 Thurstan, R.H., Hawkins, J.P., Neves, L., Roberts, C.M., 2012. Are marine reserves and non-

602 consumptive activities compatible? A global analysis of marine reserve regulations. Mar.

603 Policy 36, 1096-1104. doi:10.1016/j.marpol.2012.03.006 
604 Tables

605 Table 1. Local threats that can affect marine protected area (MPA) effectiveness and that can 606 be managed by the MPA regulations. Indicators were chosen considering trade-offs between 607 reliability and data availability. Weights reflect the potential impact of a given activity on both 608 species and habitats and were rescaled after Horta e Costa et al. (2016)

609

\begin{tabular}{llc}
\hline Threat & Threat Indicator & $\begin{array}{c}\text { Scaled } \\
\text { weight }\end{array}$ \\
\hline Extractive threats & & \\
\hline Recreational fishing: hook and line & Number of people (nb/year) & 0.56 \\
Recreational fishing: spearfishing & Number of people (nb/year) & 0.33 \\
Artisanal fishing: & Number of boats (nb/year) & 0.82 \\
Professional fishing except trawlers/purse-seiners & &
\end{tabular}

Commercial fishing:

Number of boats (nb/year)

1

Professional fishing trawlers/purse-seiners

Non-extractive threats

Tourism: bathing/trampling

Tourism: scuba-diving

Tourism: private boating

Tourism: commercial boating
Number of people (nb/year)

0.11

Number of dives (nb/year)

0.11

Number of private boats (nb/year)

0.22

Number of commercial touristic boats (nb/year)
0.22 


\section{Figure legends}

615

616 Fig. 1. The framework to assess how good are marine protected areas (MPAs) at curbing 617 threats.

618

619 Fig. 2. Mean threat intensities ( \pm SE) across fully protected, partially protected and outside 620 zones of 15 marine protected areas.

621 Fig. 3. Mean threat reduction capacity ( \pm SE) for each threat across zones of different 622 protection levels. The last bar of each panel represents the zone threat reduction score $(z T)$. 623 Negative values of the threat reduction capacity indicate that the threat is reduced in the marine 624 protected area (MPA) relative to the outside, while positive values indicate that threats are 625 higher inside the MPA relative to the outside.

626 Fig. 4. Threat reduction score of marine protected areas (MPAs) for all threats combined (top 627 panel), extractive (bottom left panel) and non-extractive threats (bottom right panel). Negative 628 values of the threat reduction score indicate that threats are being effectively reduced within an 629 MPA relative to the outside, while positive threat reduction score values indicate that the MPA 630 is not effective at reducing threats compared to the outside.

631

632

633

634

635

636 Fig. 6. Confidence levels (low, medium and high) associated to threat values for each threat.

636 Fig. 6. Confidence levels (low, medium and high) associated to threat values for each threat.
637 The red and blue outlines separate extractive and non-extractive threats.

Fig. 5. Level of confidence (low, medium and high) associated to threat values corresponding to the fully protected zones, partially protected zones and the outside areas of the marine protected areas. 


\section{How good is your MPA at curbing threats?}

\section{Step 1. Identify threats}

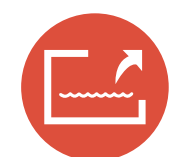

Extractive threats
Artisanal

fishing

Recreational

fishing:

hook and line

Recreational

fishing:

spearfishing

Trawlers \&

purse-seiners

S Others
Bathing, trampling

Commercial

boating

Private

boating

Non

extractive

threats

Scuba diving

Others

Step 2. Quantify threats inside and outside the MPA

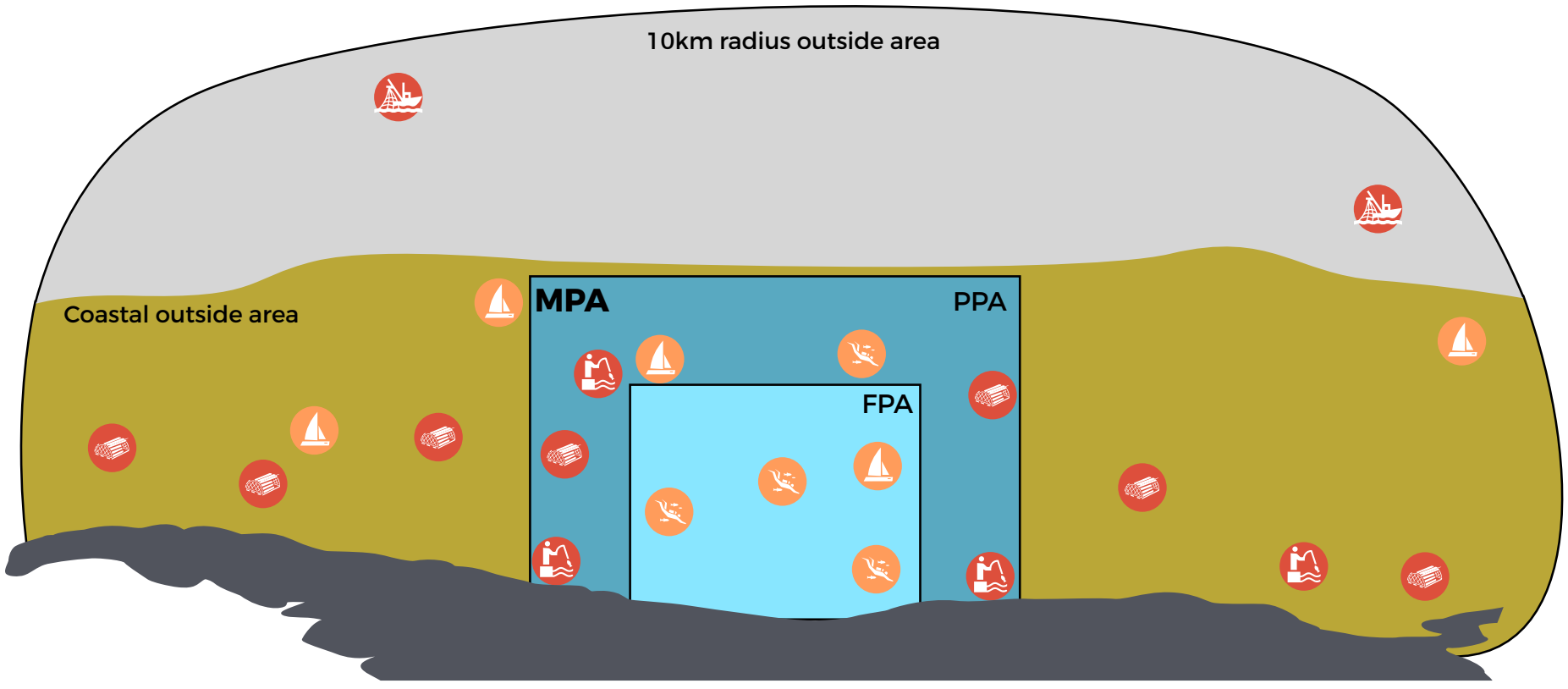

MPA - Marine Protected Area

FPA - Fully Protected Area

PPA - Partially Protected Area

\section{Step 3. Calculate indices}

Threat
intensity

What is each threat intensity in each zone and inside the MPA overall?

\section{TRC Threat Capacity}

Is the threat beeing reduced compared to the outside area?

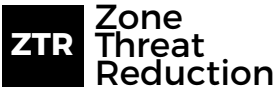

Does the zone reduce threats compared to the outside area?

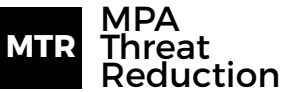

Does the MPA reduce threats compared to the outside area?

\section{Step 4. Management implications}



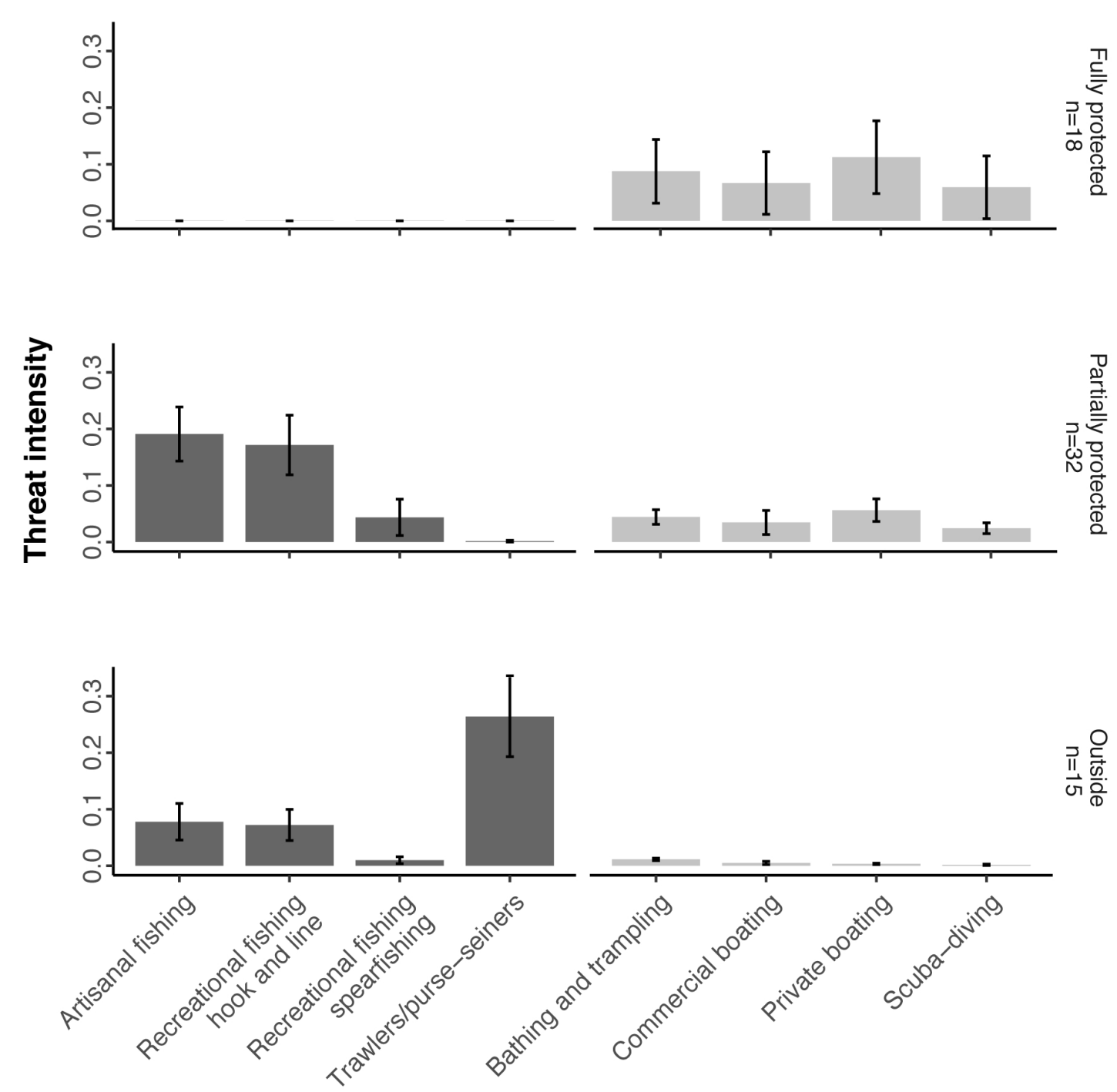

Threats 


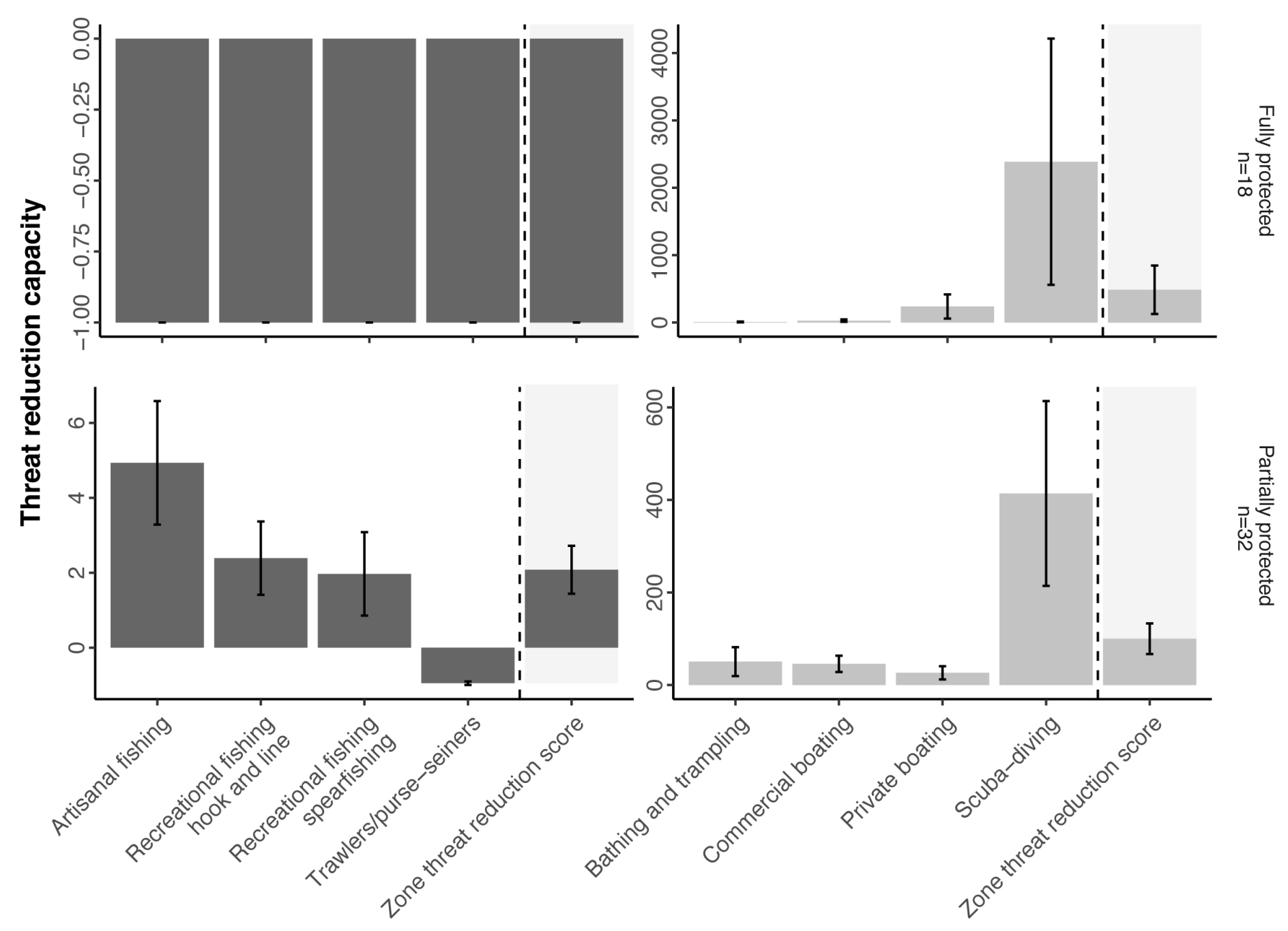



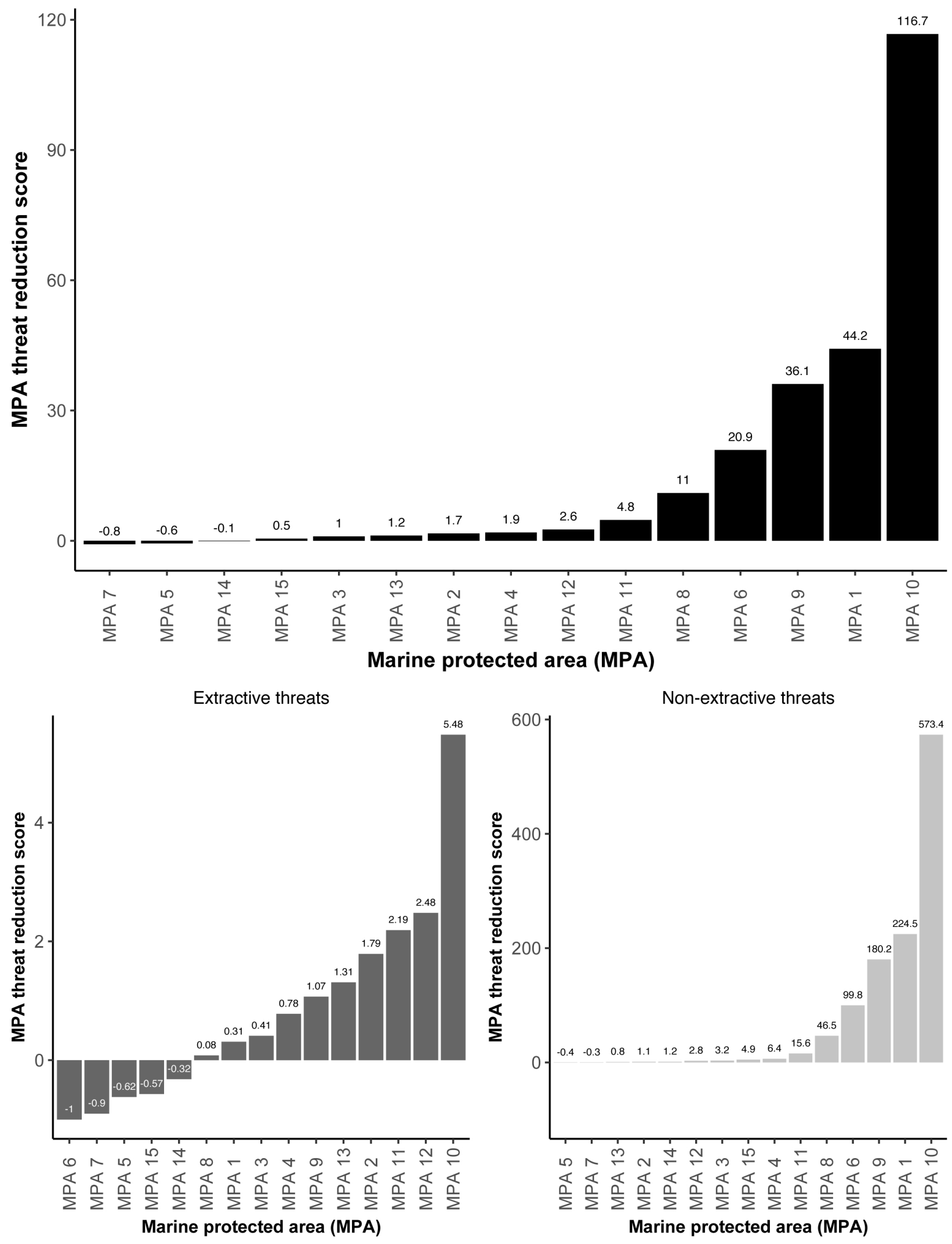


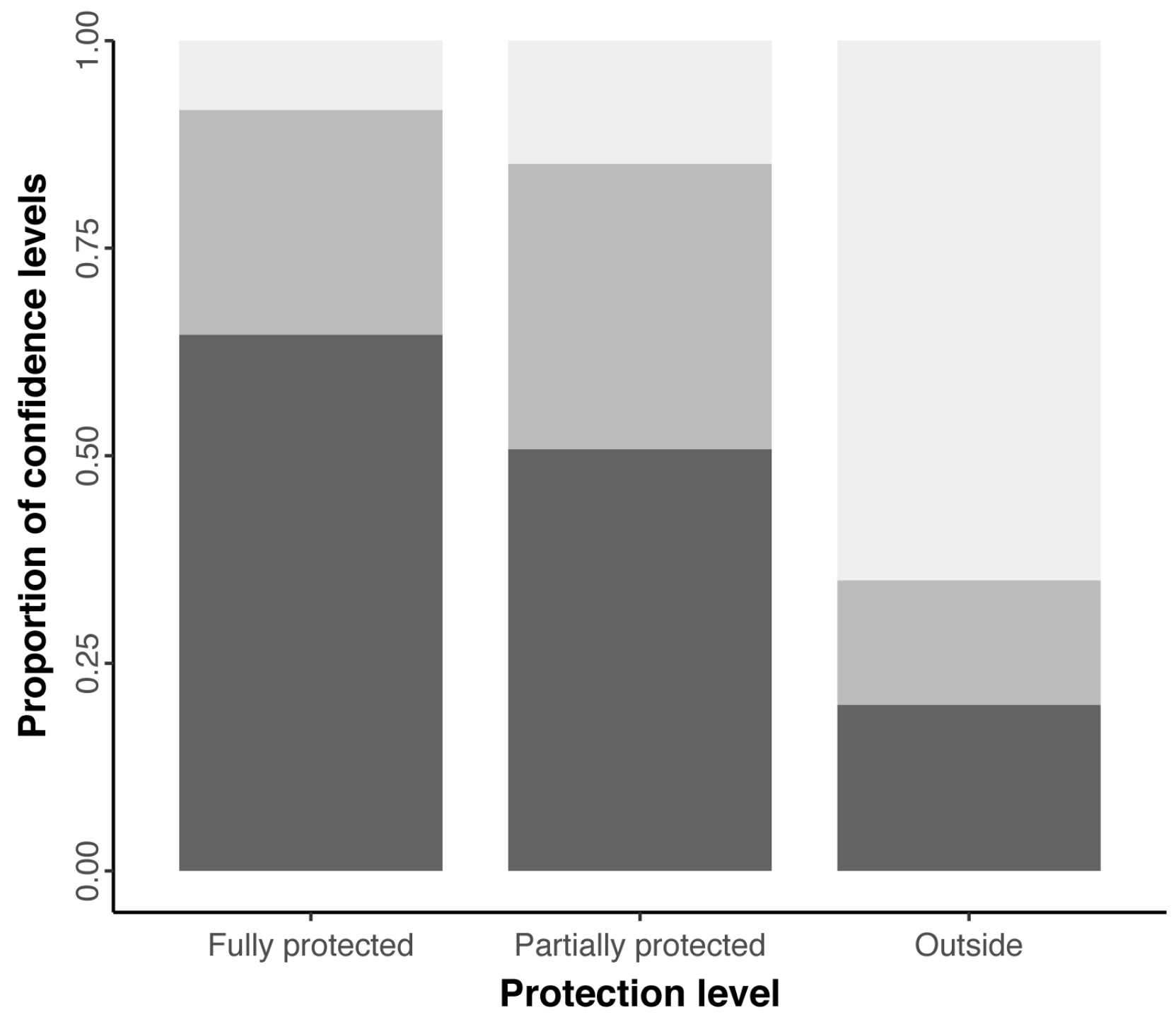

Confidence level Low Medium High 


\section{Extractive threats}

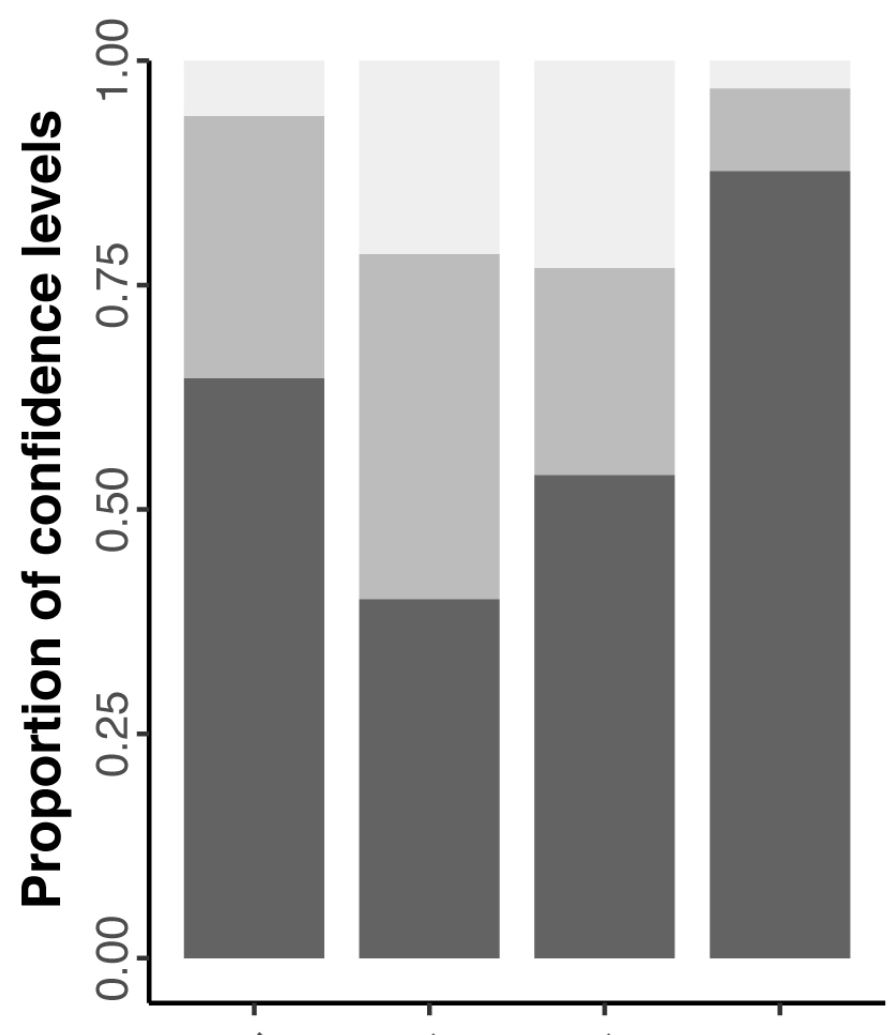

Non-extractive threats

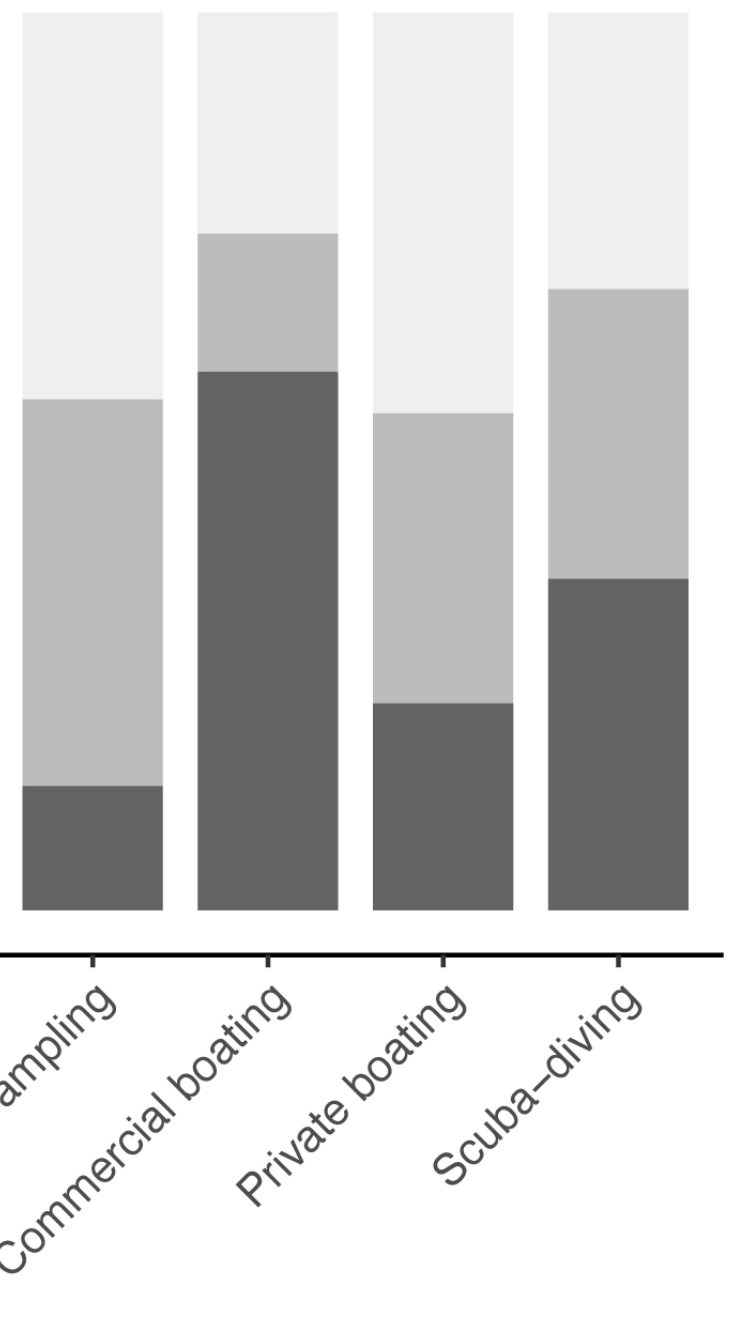

Threats

Confidence level Low Medium High 


\section{Appendix A}

\section{Database of marine protected areas used in the present study}

Table A.1: The characteristics of each of the marine protected areas (MPAs) included in this study. Zone name represents the official name on the basis of the establishment decree. Zones were classified according to the level of protection: fully protected zones (no-entry and no-take areas) and partially protected zones. The size of each zone within the MPA was obtained from managers and/or management plans, whilst the outside surface areas were calculated using QGIS 2.8/1 (QGIS Development Team, 2015). Commercial fisheries using trawlers and purse seiners were assessed in a 10km radius outside area whereas recreational and artisanal fishing and tourism were assessed in the coastal outside area.

\begin{tabular}{|c|c|c|c|c|c|c|c|c|}
\hline $\begin{array}{l}\text { MPA } \\
\text { code }\end{array}$ & MPA name & Zone name & $\begin{array}{l}\text { Protection } \\
\text { level }\end{array}$ & $\begin{array}{l}\text { Zone } \\
\text { size } \\
(\mathbf{k m 2})\end{array}$ & $\begin{array}{l}\text { MPA } \\
\text { size } \\
(\mathbf{k m 2})\end{array}$ & $\begin{array}{l}\text { Year of } \\
\text { establis } \\
\text { hment }\end{array}$ & $\begin{array}{l}\text { Outside area - } \\
\text { coastal }(\mathrm{km} 2)\end{array}$ & $\begin{array}{l}\text { Outside area- } 10 \\
\text { km radius }(\mathbf{k m} 2)\end{array}$ \\
\hline \multirow{3}{*}{$\begin{array}{l}\text { MPA } \\
01\end{array}$} & \multirow[t]{3}{*}{ AMP Portofino } & Zona A & $\begin{array}{l}\text { Fully } \\
\text { protected (no } \\
\text { entry) }\end{array}$ & 0.18 & \multirow[t]{3}{*}{3.94} & \multirow[t]{3}{*}{1998} & \multirow[t]{3}{*}{15.13} & \multirow[t]{3}{*}{190.98} \\
\hline & & Zona B & $\begin{array}{l}\text { Partially } \\
\text { protected }\end{array}$ & 1.95 & & & & \\
\hline & & Zona $\mathrm{C}$ & $\begin{array}{l}\text { Partially } \\
\text { protected }\end{array}$ & 1.81 & & & & \\
\hline \multirow[t]{2}{*}{$\begin{array}{l}\text { MPA } \\
02\end{array}$} & \multirow[t]{2}{*}{ Al Hoceima } & Zona A & $\begin{array}{l}\text { Fully } \\
\text { protected (no } \\
\text { take) }\end{array}$ & 17.8 & \multirow[t]{2}{*}{24.2} & \multirow[t]{2}{*}{2004} & \multirow[t]{2}{*}{183.7} & \multirow[t]{2}{*}{631.53} \\
\hline & & Zona $\mathrm{C}$ & $\begin{array}{l}\text { Partially } \\
\text { protected }\end{array}$ & 6.4 & & & & \\
\hline \multirow{2}{*}{$\begin{array}{l}\text { MPA } \\
03\end{array}$} & \multirow{2}{*}{$\begin{array}{l}\text { Cerbere-Banyuls Natural Marine } \\
\text { Reserve }\end{array}$} & $\begin{array}{l}\text { Zone de protection } \\
\text { renforcée }\end{array}$ & $\begin{array}{l}\text { Fully } \\
\text { protected }\end{array}$ & 0.65 & \multirow[t]{2}{*}{6.5} & \multirow[t]{2}{*}{1974} & \multirow[t]{2}{*}{55.33} & \multirow[t]{2}{*}{194.02} \\
\hline & & $\begin{array}{l}\text { Zone de protection } \\
\text { partielle }\end{array}$ & $\begin{array}{l}\text { Partially } \\
\text { protected }\end{array}$ & 5.85 & & & & \\
\hline $\begin{array}{l}\text { MPA } \\
04\end{array}$ & Dwejra MPA & one zone only & $\begin{array}{l}\text { Partially } \\
\text { protected }\end{array}$ & 2.29 & 2.27 & 2007 & 24.75 & 347.66 \\
\hline \multirow{2}{*}{$\begin{array}{l}\text { MPA } \\
05\end{array}$} & \multirow[t]{2}{*}{ Levante de mallorca-cala Rajada } & Amortiguación & $\begin{array}{l}\text { Partially } \\
\text { protected }\end{array}$ & 93.86 & \multirow[t]{2}{*}{112.86} & \multirow[t]{2}{*}{2007} & \multirow[t]{2}{*}{156.25} & \multirow[t]{2}{*}{684.03} \\
\hline & & Integral & $\begin{array}{l}\text { Fully } \\
\text { protected (no } \\
\text { take) }\end{array}$ & 19 & & & & \\
\hline
\end{tabular}




\begin{tabular}{|c|c|c|c|c|c|c|c|c|}
\hline \multirow[t]{2}{*}{$\begin{array}{l}\text { MPA } \\
06\end{array}$} & \multirow[t]{2}{*}{ Masia Blanca } & Buffer & $\begin{array}{l}\text { Fully } \\
\text { protected (no } \\
\text { take) }\end{array}$ & 2.07 & \multirow[t]{2}{*}{2.50} & \multirow[t]{2}{*}{1999} & \multirow[t]{2}{*}{36.43} & \multirow[t]{2}{*}{196.48} \\
\hline & & Integral & $\begin{array}{l}\text { Fully } \\
\text { protected (no } \\
\text { take) }\end{array}$ & 0.43 & & & & \\
\hline \multirow[t]{2}{*}{$\begin{array}{l}\text { MPA } \\
07\end{array}$} & \multirow[t]{2}{*}{ NP Brijuni } & Zone A & $\begin{array}{l}\text { Fully } \\
\text { protected (no } \\
\text { take) }\end{array}$ & 31.24 & \multirow[t]{2}{*}{34.01} & \multirow[t]{2}{*}{1983} & \multirow[t]{2}{*}{68.1} & \multirow[t]{2}{*}{398.78} \\
\hline & & Zone B & $\begin{array}{l}\text { Partially } \\
\text { protected }\end{array}$ & 2.77 & & & & \\
\hline \multirow{4}{*}{$\begin{array}{l}\text { MPA } \\
08\end{array}$} & \multirow{4}{*}{ National rine Park of Zakynthos } & Peripheral zone & $\begin{array}{l}\text { Partially } \\
\text { protected }\end{array}$ & 31.94 & \multirow{4}{*}{83.31} & \multirow{4}{*}{1999} & \multirow{4}{*}{171.12} & \multirow{4}{*}{1050.33} \\
\hline & & Zone A & $\begin{array}{l}\text { Partially } \\
\text { protected }\end{array}$ & 8.01 & & & & \\
\hline & & Zone B & $\begin{array}{l}\text { Partially } \\
\text { protected }\end{array}$ & 35.95 & & & & \\
\hline & & Zone $\mathrm{C}$ & $\begin{array}{l}\text { Partially } \\
\text { protected }\end{array}$ & 7.40 & & & & \\
\hline \multirow{8}{*}{$\begin{array}{l}\text { MPA } \\
09\end{array}$} & \multirow{8}{*}{ Parc Natural de Cap de Creus } & Parc Natural Cadaques & $\begin{array}{l}\text { Partially } \\
\text { protected }\end{array}$ & 9.6 & \multirow{8}{*}{30.5} & \multirow{8}{*}{1998} & \multirow{8}{*}{76.52} & \multirow{8}{*}{557.97} \\
\hline & & $\begin{array}{l}\text { Parc Natural Cap de } \\
\text { Creus }\end{array}$ & $\begin{array}{l}\text { Partially } \\
\text { protected }\end{array}$ & 2.3 & & & & \\
\hline & & Parc Natural Cap Gros & $\begin{array}{l}\text { Partially } \\
\text { protected }\end{array}$ & 7.1 & & & & \\
\hline & & $\begin{array}{l}\text { Parc Natural Cap } \\
\text { Norfeu }\end{array}$ & $\begin{array}{l}\text { Partially } \\
\text { protected }\end{array}$ & 3.3 & & & & \\
\hline & & $\begin{array}{l}\text { Reserva Natural } \\
\text { Integral des Encalladora }\end{array}$ & $\begin{array}{l}\text { Fully } \\
\text { protected (no } \\
\text { entry) }\end{array}$ & 0.02 & & & & \\
\hline & & $\begin{array}{l}\text { Reserva Natural Parcial } \\
\text { del Cap de Creus }\end{array}$ & $\begin{array}{l}\text { Partially } \\
\text { protected }\end{array}$ & 2.9 & & & & \\
\hline & & $\begin{array}{l}\text { Reserva Natural Parcial } \\
\text { del Cap Norfeu }\end{array}$ & $\begin{array}{l}\text { Partially } \\
\text { protected }\end{array}$ & 2.7 & & & & \\
\hline & & $\begin{array}{l}\text { Reserva Natural Parcial } \\
\text { dels Farallons }\end{array}$ & $\begin{array}{l}\text { Partially } \\
\text { protected }\end{array}$ & 2.6 & & & & \\
\hline
\end{tabular}




\begin{tabular}{|c|c|c|c|c|c|c|c|c|}
\hline \multirow{3}{*}{$\begin{array}{l}\text { MPA } \\
10\end{array}$} & \multirow{3}{*}{$\begin{array}{l}\text { Parc Natural del Montgrí, el baix } \\
\text { Ter i les Medes }\end{array}$} & $\begin{array}{l}\text { Reserva Natural Parcial } \\
\text { de les Illes Medes }\end{array}$ & $\begin{array}{l}\text { Partially } \\
\text { protected }\end{array}$ & 9.4 & \multirow{3}{*}{15.19} & \multirow{3}{*}{2010} & \multirow{3}{*}{94.35} & \multirow{3}{*}{348.87} \\
\hline & & $\begin{array}{l}\text { Reserva Natural Parcial } \\
\text { de les Illes Medes }\end{array}$ & $\begin{array}{l}\text { Fully } \\
\text { protected (no } \\
\text { take) }\end{array}$ & 1 & & & & \\
\hline & & Parc Natural Marí & $\begin{array}{l}\text { Partially } \\
\text { protected }\end{array}$ & 4.79 & & & & \\
\hline \multirow{5}{*}{$\begin{array}{l}\text { MPA } \\
11\end{array}$} & \multirow{5}{*}{$\begin{array}{l}\text { Parque Nacional marítimo terrestre } \\
\text { del Archipiélago de Cabrera }\end{array}$} & Reserva marina & $\begin{array}{l}\text { Fully } \\
\text { protected (no } \\
\text { entry) }\end{array}$ & 2.12 & \multirow{5}{*}{87.05} & \multirow{5}{*}{1991} & \multirow{5}{*}{64.91} & \multirow{5}{*}{800.32} \\
\hline & & Uso especial & $\begin{array}{l}\text { Fully } \\
\text { protected (no } \\
\text { take) }\end{array}$ & 0.71 & & & & \\
\hline & & Uso moderado & $\begin{array}{l}\text { Partially } \\
\text { protected }\end{array}$ & 77.98 & & & & \\
\hline & & Uso restringido & $\begin{array}{l}\text { Fully } \\
\text { protected (no } \\
\text { take) }\end{array}$ & 0.68 & & & & \\
\hline & & $\begin{array}{l}\text { Uso restringido } \\
\text { pesquero }\end{array}$ & $\begin{array}{l}\text { Partially } \\
\text { protected }\end{array}$ & 5.62 & & & & \\
\hline \multirow{3}{*}{$\begin{array}{l}\text { MPA } \\
12\end{array}$} & \multirow[t]{3}{*}{ Porto Cesareo } & Zone A & $\begin{array}{l}\text { Fully } \\
\text { protected (no } \\
\text { take) }\end{array}$ & 1.99 & \multirow[t]{3}{*}{164.87} & \multirow[t]{3}{*}{1997} & \multirow[t]{3}{*}{307.91} & \multirow[t]{3}{*}{407.17} \\
\hline & & Zone B & $\begin{array}{l}\text { Fully } \\
\text { protected (no } \\
\text { take) }\end{array}$ & 30.21 & & & & \\
\hline & & Zone $\mathrm{C}$ & $\begin{array}{l}\text { Partially } \\
\text { protected }\end{array}$ & 132.66 & & & & \\
\hline $\begin{array}{l}\text { MPA } \\
13\end{array}$ & Rdum Majjiesa to Ras ir-Raheb & one zone only & $\begin{array}{l}\text { Partially } \\
\text { protected }\end{array}$ & 8.49 & 8.49 & 2007 & 115.8 & 308.29 \\
\hline \multirow{3}{*}{$\begin{array}{l}\text { MPA } \\
14\end{array}$} & \multirow[t]{3}{*}{ Torre Guaceto } & Zona A & $\begin{array}{l}\text { Fully } \\
\text { protected (no } \\
\text { take) }\end{array}$ & 1.85 & \multirow[t]{3}{*}{22.33} & \multirow[t]{3}{*}{1991} & \multirow[t]{3}{*}{76.87} & \multirow[t]{3}{*}{282.03} \\
\hline & & Zona B & $\begin{array}{l}\text { Fully } \\
\text { protected (no } \\
\text { entry) }\end{array}$ & 18.85 & & & & \\
\hline & & Zona $\mathrm{C}$ & $\begin{array}{l}\text { Partially } \\
\text { protected }\end{array}$ & 22.33 & & & & \\
\hline
\end{tabular}




\begin{tabular}{|c|c|c|c|c|c|c|c|c|}
\hline \multirow{6}{*}{$\begin{array}{l}\text { MPA } \\
15\end{array}$} & \multirow{6}{*}{ Kornati } & Anchoring subzone (3a) & \begin{tabular}{|l} 
Partially \\
natected
\end{tabular} & 1.41 & \multirow{6}{*}{216.78} & \multirow{6}{*}{1994} & \multirow{6}{*}{462.13} & \multirow{6}{*}{1269.35} \\
\hline & & Recreation subzone (2b) & $\begin{array}{l}\text { Partially } \\
\text { protected }\end{array}$ & 2.36 & & & & \\
\hline & & Settlement subzone (3b) & \begin{tabular}{|l|} 
Partially \\
protected
\end{tabular} & 0.64 & & & & \\
\hline & & $\begin{array}{l}\text { Strict protection } \\
\text { subzone (1b) }\end{array}$ & $\begin{array}{l}\text { Fully } \\
\text { protected (no } \\
\text { take) }\end{array}$ & 111.52 & & & & \\
\hline & & $\begin{array}{l}\text { Tradition and culture } \\
\text { subzone (2a) }\end{array}$ & $\begin{array}{l}\text { Partially } \\
\text { protected }\end{array}$ & 82.22 & & & & \\
\hline & & $\begin{array}{l}\text { Very strict protection } \\
\text { subzone (1a) }\end{array}$ & $\begin{array}{l}\text { Fully } \\
\text { protected (no } \\
\text { entry) }\end{array}$ & 18.64 & & & & \\
\hline
\end{tabular}




\section{Appendix B}

\section{Raw threat data collected of marine protected areas used in the present study}

Table B.1. Raw data collected for all threat indicators for each zone of all marine protected areas (MPAs) used in this study. The source of data and confidence level associated to each threat value are also presented. Zone name represents the official name on the basis of the establishment decree. Zones were classified according to the level of protection: fully protected zones (no-entry and no-take areas), partially protected zones and the unprotected-outside areas. The size of each zone within the MPA was obtained from managers and/or management plans, whilst the outside surface areas were calculated using QGIS 2.8/1 (QGIS Development Team, 2015). Commercial fisheries using trawlers and purse seiners were assessed in a $10 \mathrm{~km}$ radius outside area whereas recreational and artisanal fishing and tourism were assessed in the coastal outside area.

\begin{tabular}{|c|c|c|c|c|c|c|c|c|c|}
\hline MPA Code & $\begin{array}{l}\text { Zone } \\
\text { name }\end{array}$ & $\begin{array}{l}\text { Protection } \\
\text { level }\end{array}$ & $\begin{array}{l}\text { Zone size } \\
\left(\mathbf{k m}^{2}\right)\end{array}$ & Threats & Indicators & Value & $\begin{array}{l}\text { Data } \\
\text { source }\end{array}$ & Confidence & Details \\
\hline MPA 01 & Zona A & No-entry & 0.175 & $\begin{array}{l}\text { Artisanal } \\
\text { fishing }\end{array}$ & $\begin{array}{l}\text { Number of } \\
\text { boats (nb/year) }\end{array}$ & 0 & data & high & MPA regulations \\
\hline MPA 01 & Zona A & No-entry & 0.175 & $\begin{array}{l}\text { Recreational } \\
\text { fishing: hook } \\
\text { and line }\end{array}$ & $\begin{array}{l}\text { Number of } \\
\text { people (nb/year) }\end{array}$ & 0 & data & high & MPA regulations \\
\hline MPA 01 & Zona A & No-entry & 0.175 & $\begin{array}{l}\text { Recreational } \\
\text { fishing: } \\
\text { spearfishing }\end{array}$ & $\begin{array}{l}\text { Number of } \\
\text { people (nb/year) }\end{array}$ & 0 & data & high & MPA regulations \\
\hline MPA 01 & Zona $\mathrm{A}$ & No-entry & 0.175 & $\begin{array}{l}\text { Tourism: } \\
\text { bathing/trampl } \\
\text { ing }\end{array}$ & $\begin{array}{l}\text { Number of } \\
\text { people (nb/year) }\end{array}$ & 0 & data & high & MPA regulations \\
\hline MPA 01 & Zona $\mathrm{A}$ & No-entry & 0.175 & $\begin{array}{l}\text { Tourism: } \\
\text { commercial } \\
\text { boating }\end{array}$ & $\begin{array}{l}\text { Number of } \\
\text { commercial } \\
\text { touristic boats } \\
\text { (nb/year) }\end{array}$ & 0 & data & high & MPA regulations \\
\hline MPA 01 & Zona $\mathrm{A}$ & No-entry & 0.175 & $\begin{array}{l}\text { Tourism: } \\
\text { private } \\
\text { boating }\end{array}$ & $\begin{array}{l}\text { Number of } \\
\text { private boats } \\
\text { (nb/year) }\end{array}$ & 0 & data & high & MPA regulations \\
\hline MPA 01 & Zona A & No-entry & 0.175 & $\begin{array}{l}\text { Tourism: } \\
\text { scuba-diving }\end{array}$ & $\begin{array}{l}\text { Number of } \\
\text { dives (nb/year) }\end{array}$ & 0 & data & high & MPA regulations \\
\hline MPA 01 & Zona A & No-entry & 0.175 & $\begin{array}{l}\text { Trawlers/purse } \\
\text {-seiners }\end{array}$ & $\begin{array}{l}\text { Number of } \\
\text { boats (nb/year) }\end{array}$ & 0 & data & high & MPA regulations \\
\hline
\end{tabular}




\begin{tabular}{|c|c|c|c|c|c|c|c|c|c|}
\hline MPA 01 & Zona B & $\begin{array}{l}\text { Partially } \\
\text { protected }\end{array}$ & 1.95 & $\begin{array}{l}\text { Artisanal } \\
\text { fishing }\end{array}$ & $\begin{array}{l}\text { Number of } \\
\text { boats (nb/year) }\end{array}$ & 39 & data & high & $\begin{array}{l}\text { Portofino MPA data of granted } \\
\text { licences }\end{array}$ \\
\hline MPA 01 & Zona B & $\begin{array}{l}\text { Partially } \\
\text { protected }\end{array}$ & 1.95 & $\begin{array}{l}\text { Recreational } \\
\text { fishing: hook } \\
\text { and line }\end{array}$ & $\begin{array}{l}\text { Number of } \\
\text { people (nb/year) }\end{array}$ & 400 & data & medium & $\begin{array}{l}\text { Estimated data (on the basis of } \\
\text { resident population) }\end{array}$ \\
\hline MPA 01 & Zona B & $\begin{array}{l}\text { Partially } \\
\text { protected }\end{array}$ & 1.95 & $\begin{array}{l}\text { Recreational } \\
\text { fishing: } \\
\text { spearfishing }\end{array}$ & $\begin{array}{l}\text { Number of } \\
\text { people (nb/year) }\end{array}$ & 0 & data & medium & MPA regulations \\
\hline MPA 01 & Zona B & $\begin{array}{l}\text { Partially } \\
\text { protected }\end{array}$ & 1.95 & $\begin{array}{l}\text { Tourism: } \\
\text { bathing/trampl } \\
\text { ing }\end{array}$ & $\begin{array}{l}\text { Number of } \\
\text { people (nb/year) }\end{array}$ & 150000 & data & low & Cappanera et al. (2010) \\
\hline MPA 01 & Zona B & $\begin{array}{l}\text { Partially } \\
\text { protected }\end{array}$ & 1.95 & $\begin{array}{l}\text { Tourism: } \\
\text { commercial } \\
\text { boating }\end{array}$ & $\begin{array}{l}\text { Number of } \\
\text { commercial } \\
\text { touristic boats } \\
\text { (nb/year) }\end{array}$ & 0 & data & high & MPA regulations \\
\hline MPA 01 & Zona B & $\begin{array}{l}\text { Partially } \\
\text { protected }\end{array}$ & 1.95 & $\begin{array}{l}\text { Tourism: } \\
\text { private } \\
\text { boating }\end{array}$ & $\begin{array}{l}\text { Number of } \\
\text { private boats } \\
\text { (nb/year) }\end{array}$ & 1924 & data & medium & $\begin{array}{l}\text { Cappanera et al. (2014): } \\
\text { estimated data referred to } 2013 \\
\text { season }\end{array}$ \\
\hline MPA 01 & Zona B & $\begin{array}{l}\text { Partially } \\
\text { protected }\end{array}$ & 1.95 & $\begin{array}{l}\text { Tourism: } \\
\text { scuba-diving }\end{array}$ & $\begin{array}{l}\text { Number of } \\
\text { dives (nb/year) }\end{array}$ & 32306 & data & medium & $\begin{array}{l}\text { Cappanera et al. (2014): } \\
\text { estimated data referred to } 2013 \\
\text { season }\end{array}$ \\
\hline MPA 01 & Zona B & $\begin{array}{l}\text { Partially } \\
\text { protected }\end{array}$ & 1.95 & $\begin{array}{l}\text { Trawlers/purse } \\
\text {-seiners }\end{array}$ & $\begin{array}{l}\text { Number of } \\
\text { boats (nb/year) }\end{array}$ & 0 & data & high & MPA regulations \\
\hline MPA 01 & Zona $\mathrm{C}$ & $\begin{array}{l}\text { Partially } \\
\text { protected }\end{array}$ & 1.811 & $\begin{array}{l}\text { Artisanal } \\
\text { fishing }\end{array}$ & $\begin{array}{l}\text { Number of } \\
\text { boats (nb/year) }\end{array}$ & 39 & data & high & $\begin{array}{l}\text { Portofino MPA data of granted } \\
\text { licences }\end{array}$ \\
\hline MPA 01 & Zona $\mathrm{C}$ & $\begin{array}{l}\text { Partially } \\
\text { protected }\end{array}$ & 1.811 & $\begin{array}{l}\text { Recreational } \\
\text { fishing: hook } \\
\text { and line }\end{array}$ & $\begin{array}{l}\text { Number of } \\
\text { people (nb/year) }\end{array}$ & 349 & data & medium & $\begin{array}{l}\text { Estimated data (on the basis of } \\
\text { resident population) }\end{array}$ \\
\hline MPA 01 & Zona $\mathrm{C}$ & $\begin{array}{l}\text { Partially } \\
\text { protected }\end{array}$ & 1.811 & $\begin{array}{l}\text { Recreational } \\
\text { fishing: } \\
\text { spearfishing }\end{array}$ & $\begin{array}{l}\text { Number of } \\
\text { people (nb/year) }\end{array}$ & 0 & data & high & MPA regulations \\
\hline MPA 01 & Zona $\mathrm{C}$ & $\begin{array}{l}\text { Partially } \\
\text { protected }\end{array}$ & 1.811 & $\begin{array}{l}\text { Tourism: } \\
\text { bathing/trampl } \\
\text { ing }\end{array}$ & $\begin{array}{l}\text { Number of } \\
\text { people (nb/year) }\end{array}$ & 150000 & data & low & $\begin{array}{l}\text { Cappanera et al. (2010): } \\
\text { estimated data referred to the } \\
\text { period from June to September }\end{array}$ \\
\hline MPA 01 & Zona $\mathrm{C}$ & $\begin{array}{l}\text { Partially } \\
\text { protected }\end{array}$ & 1.811 & $\begin{array}{l}\text { Tourism: } \\
\text { commercial } \\
\text { boating }\end{array}$ & $\begin{array}{l}\text { Number of } \\
\text { commercial } \\
\text { touristic boats } \\
\text { (nb/year) }\end{array}$ & 0 & data & high & MPA regulations \\
\hline
\end{tabular}




\begin{tabular}{|c|c|c|c|c|c|c|c|c|c|}
\hline MPA 01 & Zona C & $\begin{array}{l}\text { Partially } \\
\text { protected }\end{array}$ & 1.811 & $\begin{array}{l}\text { Tourism: } \\
\text { private } \\
\text { boating }\end{array}$ & $\begin{array}{l}\text { Number of } \\
\text { private boats } \\
\text { (nb/year) }\end{array}$ & 8767 & data & medium & $\begin{array}{l}\text { Cappanera et al. (2014): } \\
\text { estimated data referred to } 2013 \\
\text { season }\end{array}$ \\
\hline MPA 01 & Zona $\mathrm{C}$ & $\begin{array}{l}\text { Partially } \\
\text { protected }\end{array}$ & 1.811 & $\begin{array}{l}\text { Tourism: } \\
\text { scuba-diving }\end{array}$ & $\begin{array}{l}\text { Number of } \\
\text { dives (nb/year) }\end{array}$ & 2000 & $\begin{array}{l}\text { expert } \\
\text { opinion }\end{array}$ & low & $\begin{array}{l}\text { Cappanera et al. (2014): } \\
\text { estimated data referred to } 2013 \\
\text { season }\end{array}$ \\
\hline MPA 01 & Zona $\mathrm{C}$ & $\begin{array}{l}\text { Partially } \\
\text { protected }\end{array}$ & 1.811 & $\begin{array}{l}\text { Trawlers/purse } \\
\text {-seiners }\end{array}$ & $\begin{array}{l}\text { Number of } \\
\text { boats (nb/year) }\end{array}$ & 0 & data & high & MPA regulations \\
\hline MPA 01 & Outside & Outside & 15.13 & $\begin{array}{l}\text { Artisanal } \\
\text { fishing }\end{array}$ & $\begin{array}{l}\text { Number of } \\
\text { boats (nb/year) }\end{array}$ & 159 & data & high & $\begin{array}{l}\text { Ligurian Region data, } \\
\text { MARTE+ (Cattaneo-Vietti R. } \\
\text { 2013) }\end{array}$ \\
\hline MPA 01 & Outside & Outside & 15.13 & $\begin{array}{l}\text { Recreational } \\
\text { fishing: hook } \\
\text { and line }\end{array}$ & $\begin{array}{l}\text { Number of } \\
\text { people (nb/year) }\end{array}$ & 800 & $\begin{array}{l}\text { expert } \\
\text { opinion }\end{array}$ & low & Estimated \\
\hline MPA 01 & Outside & Outside & 15.13 & $\begin{array}{l}\text { Recreational } \\
\text { fishing: } \\
\text { spearfishing }\end{array}$ & $\begin{array}{l}\text { Number of } \\
\text { people (nb/year) }\end{array}$ & 100 & $\begin{array}{l}\text { expert } \\
\text { opinion }\end{array}$ & low & Estimated \\
\hline MPA 01 & Outside & Outside & 15.13 & $\begin{array}{l}\text { Tourism: } \\
\text { bathing/trampl } \\
\text { ing }\end{array}$ & $\begin{array}{l}\text { Number of } \\
\text { people (nb/year) }\end{array}$ & 100000 & $\begin{array}{l}\text { expert } \\
\text { opinion }\end{array}$ & low & $\begin{array}{l}\text { Estimated data (on the basis of } \\
\text { the number of resident people, } \\
\text { ISTAT 2012) }\end{array}$ \\
\hline MPA 01 & Outside & Outside & 15.13 & $\begin{array}{l}\text { Tourism: } \\
\text { commercial } \\
\text { boating }\end{array}$ & $\begin{array}{l}\text { Number of } \\
\text { commercial } \\
\text { touristic boats } \\
\text { (nb/year) }\end{array}$ & 140 & data & high & $\begin{array}{l}\text { Cappanera et al. (2014): } \\
\text { estimated data referred to } 2013 \\
\text { season }\end{array}$ \\
\hline MPA 01 & Outside & Outside & 15.13 & $\begin{array}{l}\text { Tourism: } \\
\text { private } \\
\text { boating }\end{array}$ & $\begin{array}{l}\text { Number of } \\
\text { private boats } \\
\text { (nb/year) }\end{array}$ & 3600 & $\begin{array}{l}\text { expert } \\
\text { opinion }\end{array}$ & low & Estimated \\
\hline MPA 01 & Outside & Outside & 15.13 & $\begin{array}{l}\text { Tourism: } \\
\text { scuba-diving }\end{array}$ & $\begin{array}{l}\text { Number of } \\
\text { dives (nb/year) }\end{array}$ & 100 & $\begin{array}{l}\text { expert } \\
\text { opinion }\end{array}$ & low & Estimated \\
\hline MPA 01 & Outside & Outside & 190.98 & $\begin{array}{l}\text { Trawlers/purse } \\
\text {-seiners }\end{array}$ & $\begin{array}{l}\text { Number of } \\
\text { boats (nb/year) }\end{array}$ & 53 & data & high & $\begin{array}{l}\text { Fleet register EC - } \\
\text { December } 2013\end{array}$ \\
\hline MPA 02 & Zona A & No-take & 17.8 & $\begin{array}{l}\text { Artisanal } \\
\text { fishing }\end{array}$ & $\begin{array}{l}\text { Number of } \\
\text { boats (nb/year) }\end{array}$ & 0 & data & medium & $\begin{array}{l}\text { Franzosini C. \& Limam A. } \\
\text { (2006); AGIR (2013) }\end{array}$ \\
\hline MPA 02 & Zona A & No-take & 17.8 & $\begin{array}{l}\text { Recreational } \\
\text { fishing: hook } \\
\text { and line }\end{array}$ & $\begin{array}{l}\text { Number of } \\
\text { people (nb/year) }\end{array}$ & 0 & data & medium & $\begin{array}{l}\text { Nibani H. (2010); AGIR } \\
\text { (2013) }\end{array}$ \\
\hline
\end{tabular}




\begin{tabular}{|c|c|c|c|c|c|c|c|c|c|}
\hline MPA 02 & Zona A & No-take & 17.8 & $\begin{array}{l}\text { Recreational } \\
\text { fishing: } \\
\text { spearfishing }\end{array}$ & $\begin{array}{l}\text { Number of } \\
\text { people (nb/year) }\end{array}$ & 0 & data & medium & $\begin{array}{l}\text { Nibani H. (2010), AGIR } \\
\text { (2013) }\end{array}$ \\
\hline MPA 02 & Zona A & No-take & 17.8 & $\begin{array}{l}\text { Tourism: } \\
\text { bathing/trampl } \\
\text { ing }\end{array}$ & $\begin{array}{l}\text { Number of } \\
\text { people (nb/year) }\end{array}$ & 0 & $\begin{array}{l}\text { expert } \\
\text { opinion }\end{array}$ & medium & expert opinion \\
\hline MPA 02 & Zona A & No-take & 17.8 & $\begin{array}{l}\text { Tourism: } \\
\text { commercial } \\
\text { boating }\end{array}$ & $\begin{array}{l}\text { Number of } \\
\text { commercial } \\
\text { touristic boats } \\
\text { (nb/year) }\end{array}$ & 0 & data & low & $\begin{array}{l}\text { Nibani H. (2010), AGIR } \\
\text { (2013) }\end{array}$ \\
\hline MPA 02 & Zona A & No-take & 17.8 & $\begin{array}{l}\text { Tourism: } \\
\text { private } \\
\text { boating }\end{array}$ & $\begin{array}{l}\text { Number of } \\
\text { private boats } \\
\text { (nb/year) }\end{array}$ & 0 & $\begin{array}{l}\text { expert } \\
\text { opinion }\end{array}$ & low & expert opinion \\
\hline MPA 02 & Zona A & No-take & 17.8 & $\begin{array}{l}\text { Tourism: } \\
\text { scuba-diving }\end{array}$ & $\begin{array}{l}\text { Number of } \\
\text { dives (nb/year) }\end{array}$ & 100 & data & medium & $\begin{array}{l}\text { Nibani H. (2010), AGIR } \\
\text { (2013) }\end{array}$ \\
\hline MPA 02 & Zona A & No-take & 17.8 & $\begin{array}{l}\text { Trawlers/purse } \\
\text {-seiners }\end{array}$ & $\begin{array}{l}\text { Number of } \\
\text { boats (nb/year) }\end{array}$ & 0 & data & medium & $\begin{array}{l}\text { Franzosini C. \& Limam A } \\
(2006), \text { AGIR (2013) }\end{array}$ \\
\hline MPA 02 & Zona $\mathrm{C}$ & $\begin{array}{l}\text { Partially } \\
\text { protected }\end{array}$ & 6.4 & $\begin{array}{l}\text { Artisanal } \\
\text { fishing }\end{array}$ & $\begin{array}{l}\text { Number of } \\
\text { boats (nb/year) }\end{array}$ & 130 & data & high & $\begin{array}{l}\text { Franzosini C. \& Limam A } \\
\text { (2006), AGIR (2013) }\end{array}$ \\
\hline MPA 02 & Zona $\mathrm{C}$ & $\begin{array}{l}\text { Partially } \\
\text { protected }\end{array}$ & 6.4 & $\begin{array}{l}\text { Recreational } \\
\text { fishing: hook } \\
\text { and line }\end{array}$ & $\begin{array}{l}\text { Number of } \\
\text { people (nb/year) }\end{array}$ & 1800 & data & medium & $\begin{array}{l}\text { Franzosini C. \& Limam A } \\
\text { (2006), AGIR (2013) }\end{array}$ \\
\hline MPA 02 & Zona C & $\begin{array}{l}\text { Partially } \\
\text { protected }\end{array}$ & 6.4 & $\begin{array}{l}\text { Recreational } \\
\text { fishing: } \\
\text { spearfishing }\end{array}$ & $\begin{array}{l}\text { Number of } \\
\text { people (nb/year) }\end{array}$ & 800 & data & medium & $\begin{array}{l}\text { Franzosini C. \& Limam A. } \\
\text { (2006), AGIR (2013) }\end{array}$ \\
\hline MPA 02 & Zona $\mathrm{C}$ & $\begin{array}{l}\text { Partially } \\
\text { protected }\end{array}$ & 6.4 & $\begin{array}{l}\text { Tourism: } \\
\text { bathing/trampl } \\
\text { ing }\end{array}$ & $\begin{array}{l}\text { Number of } \\
\text { people (nb/year) }\end{array}$ & 1200 & $\begin{array}{l}\text { expert } \\
\text { opinion }\end{array}$ & low & $\begin{array}{l}\text { Nibani H. (2010); AGIR } \\
\text { (2013) }\end{array}$ \\
\hline MPA 02 & Zona C & $\begin{array}{l}\text { Partially } \\
\text { protected }\end{array}$ & 6.4 & $\begin{array}{l}\text { Tourism: } \\
\text { commercial } \\
\text { boating }\end{array}$ & $\begin{array}{l}\text { Number of } \\
\text { commercial } \\
\text { touristic boats } \\
\text { (nb/year) }\end{array}$ & 0 & data & high & $\begin{array}{l}\text { Nibani H. (2010), AGIR } \\
\text { (2013) }\end{array}$ \\
\hline MPA 02 & Zona $\mathrm{C}$ & $\begin{array}{l}\text { Partially } \\
\text { protected }\end{array}$ & 6.4 & $\begin{array}{l}\text { Tourism: } \\
\text { private } \\
\text { boating }\end{array}$ & $\begin{array}{l}\text { Number of } \\
\text { private boats } \\
\text { (nb/year) }\end{array}$ & 50 & $\begin{array}{l}\text { expert } \\
\text { opinion }\end{array}$ & low & $\begin{array}{l}\text { Nibani H. (2010), AGIR } \\
\text { (2013) }\end{array}$ \\
\hline MPA 02 & Zona $\mathrm{C}$ & $\begin{array}{l}\text { Partially } \\
\text { protected }\end{array}$ & 6.4 & $\begin{array}{l}\text { Tourism: } \\
\text { scuba-diving }\end{array}$ & $\begin{array}{l}\text { Number of } \\
\text { dives (nb/year) }\end{array}$ & 850 & data & medium & $\begin{array}{l}\text { Nibani H. (2010), AGIR } \\
(2013)\end{array}$ \\
\hline
\end{tabular}




\begin{tabular}{|c|c|c|c|c|c|c|c|c|c|}
\hline MPA 02 & Zona $\mathrm{C}$ & $\begin{array}{l}\text { Partially } \\
\text { protected }\end{array}$ & 6.4 & $\begin{array}{l}\text { Trawlers/purse } \\
\text {-seiners }\end{array}$ & $\begin{array}{l}\text { Number of } \\
\text { boats (nb/year) }\end{array}$ & 0 & data & high & $\begin{array}{l}\text { Franzosini C. \& Limam A. } \\
(2006)\end{array}$ \\
\hline MPA 02 & Outside & Outside & 183.7 & $\begin{array}{l}\text { Artisanal } \\
\text { fishing }\end{array}$ & $\begin{array}{l}\text { Number of } \\
\text { boats (nb/year) }\end{array}$ & 416 & data & medium & $\begin{array}{l}\text { Franzosini C. \& Limam A. } \\
(2006)\end{array}$ \\
\hline MPA 02 & Outside & Outside & 183.7 & $\begin{array}{l}\text { Recreational } \\
\text { fishing: hook } \\
\text { and line }\end{array}$ & $\begin{array}{l}\text { Number of } \\
\text { people (nb/year) }\end{array}$ & 2250 & $\begin{array}{l}\text { expert } \\
\text { opinion }\end{array}$ & low & expert opinion \\
\hline MPA 02 & Outside & Outside & 183.7 & $\begin{array}{l}\text { Recreational } \\
\text { fishing: } \\
\text { spearfishing }\end{array}$ & $\begin{array}{l}\text { Number of } \\
\text { people (nb/year) }\end{array}$ & 900 & $\begin{array}{l}\text { expert } \\
\text { opinion }\end{array}$ & low & expert opinion \\
\hline MPA 02 & Outside & Outside & 183.7 & $\begin{array}{l}\text { Tourism: } \\
\text { bathing/trampl } \\
\text { ing }\end{array}$ & $\begin{array}{l}\text { Number of } \\
\text { people (nb/year) }\end{array}$ & 4500 & $\begin{array}{l}\text { expert } \\
\text { opinion }\end{array}$ & low & expert opinion \\
\hline MPA 02 & Outside & Outside & 183.7 & $\begin{array}{l}\text { Tourism: } \\
\text { commercial } \\
\text { boating }\end{array}$ & $\begin{array}{l}\text { Number of } \\
\text { commercial } \\
\text { touristic boats } \\
\text { (nb/year) }\end{array}$ & 0 & data & high & $\begin{array}{l}\text { Nibani H. (2010); AGIR } \\
\text { (2013) }\end{array}$ \\
\hline MPA 02 & Outside & Outside & 183.7 & $\begin{array}{l}\text { Tourism: } \\
\text { private } \\
\text { boating }\end{array}$ & $\begin{array}{l}\text { Number of } \\
\text { private boats } \\
\text { (nb/year) }\end{array}$ & 500 & $\begin{array}{l}\text { expert } \\
\text { opinion }\end{array}$ & low & expert opinion \\
\hline MPA 02 & Outside & Outside & 183.7 & $\begin{array}{l}\text { Tourism: } \\
\text { scuba-diving }\end{array}$ & $\begin{array}{l}\text { Number of } \\
\text { dives (nb/year) }\end{array}$ & 1500 & $\begin{array}{l}\text { expert } \\
\text { opinion }\end{array}$ & low & expert opinion \\
\hline MPA 02 & Outside & Outside & 631.53 & $\begin{array}{l}\text { Trawlers/purse } \\
\text {-seiners }\end{array}$ & $\begin{array}{l}\text { Number of } \\
\text { boats (nb/year) }\end{array}$ & 22 & data & medium & $\begin{array}{l}\text { Franzosini C. \& Limam A. } \\
(2006), \text { AGIR (2013) }\end{array}$ \\
\hline MPA 03 & $\begin{array}{l}\text { Zone de } \\
\text { protection } \\
\text { renforcée }\end{array}$ & No-take & 0.65 & $\begin{array}{l}\text { Artisanal } \\
\text { fishing }\end{array}$ & $\begin{array}{l}\text { Number of } \\
\text { boats (nb/year) }\end{array}$ & 0 & data & high & MPA regulations \\
\hline MPA 03 & $\begin{array}{l}\text { Zone de } \\
\text { protection } \\
\text { renforcée }\end{array}$ & No-take & 0.65 & $\begin{array}{l}\text { Recreational } \\
\text { fishing: hook } \\
\text { and line }\end{array}$ & $\begin{array}{l}\text { Number of } \\
\text { people (nb/year) }\end{array}$ & 0 & data & high & MPA regulations \\
\hline MPA 03 & $\begin{array}{l}\text { Zone de } \\
\text { protection } \\
\text { renforcée }\end{array}$ & No-take & 0.65 & $\begin{array}{l}\text { Recreational } \\
\text { fishing: } \\
\text { spearfishing }\end{array}$ & $\begin{array}{l}\text { Number of } \\
\text { people (nb/year) }\end{array}$ & 0 & data & high & MPA regulations \\
\hline MPA 03 & $\begin{array}{l}\text { Zone de } \\
\text { protection } \\
\text { renforcée }\end{array}$ & No-take & 0.65 & $\begin{array}{l}\text { Tourism: } \\
\text { bathing/trampl } \\
\text { ing }\end{array}$ & $\begin{array}{l}\text { Number of } \\
\text { people (nb/year) }\end{array}$ & 2000 & $\begin{array}{l}\text { expert } \\
\text { opinion }\end{array}$ & low & $\begin{array}{l}\text { Estimated: } 5 \% \text { of the total } \\
\text { number of snorkelers in the } \\
\text { Reserve }\end{array}$ \\
\hline
\end{tabular}




\begin{tabular}{|c|c|c|c|c|c|c|c|c|c|}
\hline MPA 03 & $\begin{array}{l}\text { Zone de } \\
\text { protection } \\
\text { renforcée }\end{array}$ & No-take & 0.65 & $\begin{array}{l}\text { Tourism: } \\
\text { commercial } \\
\text { boating }\end{array}$ & $\begin{array}{l}\text { Number of } \\
\text { commercial } \\
\text { touristic boats } \\
\text { (nb/year) }\end{array}$ & 0 & data & high & MPA regulations \\
\hline MPA 03 & $\begin{array}{l}\text { Zone de } \\
\text { protection } \\
\text { renforcée }\end{array}$ & No-take & 0.65 & $\begin{array}{l}\text { Tourism: } \\
\text { private } \\
\text { boating }\end{array}$ & $\begin{array}{l}\text { Number of } \\
\text { private boats } \\
\text { (nb/year) }\end{array}$ & 500 & $\begin{array}{l}\text { expert } \\
\text { opinion }\end{array}$ & low & Estimated \\
\hline MPA 03 & $\begin{array}{l}\text { Zone de } \\
\text { protection } \\
\text { renforcée }\end{array}$ & No-take & 0.65 & $\begin{array}{l}\text { Tourism: } \\
\text { scuba-diving }\end{array}$ & $\begin{array}{l}\text { Number of } \\
\text { dives (nb/year) }\end{array}$ & 0 & data & high & MPA regulations \\
\hline MPA 03 & $\begin{array}{l}\text { Zone de } \\
\text { protection } \\
\text { renforcée }\end{array}$ & No-take & 0.65 & $\begin{array}{l}\text { Trawlers/purse } \\
\text {-seiners }\end{array}$ & $\begin{array}{l}\text { Number of } \\
\text { boats (nb/year) }\end{array}$ & 0 & data & high & MPA regulations \\
\hline MPA 03 & $\begin{array}{l}\text { Zone de } \\
\text { protection } \\
\text { partielle }\end{array}$ & $\begin{array}{l}\text { Partially } \\
\text { protected }\end{array}$ & 5.85 & $\begin{array}{l}\text { Artisanal } \\
\text { fishing }\end{array}$ & $\begin{array}{l}\text { Number of } \\
\text { boats (nb/year) }\end{array}$ & 15 & data & medium & number of fishing licenses \\
\hline MPA 03 & $\begin{array}{l}\text { Zone de } \\
\text { protection } \\
\text { partielle }\end{array}$ & $\begin{array}{l}\text { Partially } \\
\text { protected }\end{array}$ & 5.85 & $\begin{array}{l}\text { Recreational } \\
\text { fishing: hook } \\
\text { and line }\end{array}$ & $\begin{array}{l}\text { Number of } \\
\text { people (nb/year) }\end{array}$ & 1549 & data & high & number of licenses \\
\hline MPA 03 & $\begin{array}{l}\text { Zone de } \\
\text { protection } \\
\text { partielle }\end{array}$ & $\begin{array}{l}\text { Partially } \\
\text { protected }\end{array}$ & 5.85 & $\begin{array}{l}\text { Recreational } \\
\text { fishing: } \\
\text { spearfishing }\end{array}$ & $\begin{array}{l}\text { Number of } \\
\text { people (nb/year) }\end{array}$ & 0 & data & high & MPA regulations \\
\hline MPA 03 & $\begin{array}{l}\text { Zone de } \\
\text { protection } \\
\text { partielle }\end{array}$ & $\begin{array}{l}\text { Partially } \\
\text { protected }\end{array}$ & 5.85 & $\begin{array}{l}\text { Tourism: } \\
\text { bathing/trampl } \\
\text { ing }\end{array}$ & $\begin{array}{l}\text { Number of } \\
\text { people (nb/year) }\end{array}$ & 35857 & data & medium & $\begin{array}{l}\text { Extrapolate value based on the } \\
\text { underwater trail of Peyrefite } \\
\text { ( } 25100 \text { snorkelers per year) } \\
\text { representing } 70 \% \text { of the total } \\
\text { number of snorkelers }\end{array}$ \\
\hline MPA 03 & $\begin{array}{l}\text { Zone de } \\
\text { protection } \\
\text { partielle }\end{array}$ & $\begin{array}{l}\text { Partially } \\
\text { protected }\end{array}$ & 5.85 & $\begin{array}{l}\text { Tourism: } \\
\text { commercial } \\
\text { boating }\end{array}$ & $\begin{array}{l}\text { Number of } \\
\text { commercial } \\
\text { touristic boats } \\
\text { (nb/year) }\end{array}$ & 0 & data & high & $\begin{array}{l}\text { Estimation based on regular } \\
\text { sailing survey ( } 30 \text { boats on the } \\
\text { reserve per day) }\end{array}$ \\
\hline MPA 03 & $\begin{array}{l}\text { Zone de } \\
\text { protection } \\
\text { partielle }\end{array}$ & $\begin{array}{l}\text { Partially } \\
\text { protected }\end{array}$ & 5.85 & $\begin{array}{l}\text { Tourism: } \\
\text { private } \\
\text { boating }\end{array}$ & $\begin{array}{l}\text { Number of } \\
\text { private boats } \\
\text { (nb/year) }\end{array}$ & 1830 & $\begin{array}{l}\text { expert } \\
\text { opinion }\end{array}$ & medium & Estimated \\
\hline MPA 03 & $\begin{array}{l}\text { Zone de } \\
\text { protection } \\
\text { partielle }\end{array}$ & $\begin{array}{l}\text { Partially } \\
\text { protected }\end{array}$ & 5.85 & $\begin{array}{l}\text { Tourism: } \\
\text { scuba-diving }\end{array}$ & $\begin{array}{l}\text { Number of } \\
\text { dives (nb/year) }\end{array}$ & 21862 & data & medium & $\begin{array}{l}\text { Only } 10 \text { scuba-diving center } \\
\text { (on } 18 \text { ) returned their log-book } \\
\text { in } 2013\end{array}$ \\
\hline
\end{tabular}




\begin{tabular}{|c|c|c|c|c|c|c|c|c|c|}
\hline MPA 03 & $\begin{array}{l}\text { Zone de } \\
\text { protection } \\
\text { partielle }\end{array}$ & $\begin{array}{l}\text { Partially } \\
\text { protected }\end{array}$ & 5.85 & $\begin{array}{l}\text { Trawlers/purse } \\
\text {-seiners }\end{array}$ & $\begin{array}{l}\text { Number of } \\
\text { boats (nb/year) }\end{array}$ & 0 & data & high & MPA regulations \\
\hline MPA 03 & Outside & Outside & 55.33 & $\begin{array}{l}\text { Artisanal } \\
\text { fishing }\end{array}$ & $\begin{array}{l}\text { Number of } \\
\text { boats (nb/year) }\end{array}$ & 40 & $\begin{array}{l}\text { expert } \\
\text { opinion }\end{array}$ & medium & $\begin{array}{l}\text { Number of surrounding harbors } \\
\text { Licenses but no data on } \\
\text { Spanish fleet (probably more: } \\
\text { between } 28 \text { and } 50 \text { ) }\end{array}$ \\
\hline MPA 03 & Outside & Outside & 55.33 & $\begin{array}{l}\text { Recreational } \\
\text { fishing: hook } \\
\text { and line }\end{array}$ & $\begin{array}{l}\text { Number of } \\
\text { people (nb/year) }\end{array}$ & 6200 & $\begin{array}{l}\text { expert } \\
\text { opinion }\end{array}$ & low & $\begin{array}{l}\text { Estimation based on } 100 \\
\text { fishing trip per day in summer } \\
\text { but no real data on spanish } \\
\text { situation }\end{array}$ \\
\hline MPA 03 & Outside & Outside & 55.33 & $\begin{array}{l}\text { Recreational } \\
\text { fishing: } \\
\text { spearfishing }\end{array}$ & $\begin{array}{l}\text { Number of } \\
\text { people (nb/year) }\end{array}$ & 620 & $\begin{array}{l}\text { expert } \\
\text { opinion }\end{array}$ & low & $\begin{array}{l}\text { Estimation based on } 10 \% \text { of } \\
\text { the recreational activity is } \\
\text { represented by spearfishes }\end{array}$ \\
\hline MPA 03 & Outside & Outside & 55.33 & $\begin{array}{l}\text { Tourism: } \\
\text { bathing/trampl } \\
\text { ing }\end{array}$ & $\begin{array}{l}\text { Number of } \\
\text { people (nb/year) }\end{array}$ & 500000 & $\begin{array}{l}\text { expert } \\
\text { opinion }\end{array}$ & low & $\begin{array}{l}\text { Estimation data based on sand } \\
\text { beach areas: Racou, Porteils, } \\
\text { Collioure, Port } \\
\text { Vendres,Paulille, Les Elmes, } \\
\text { Banyuls, Aloes, Cerbère, } \\
\text { PortBou, Lanca }\end{array}$ \\
\hline MPA 03 & Outside & Outside & 55.33 & $\begin{array}{l}\text { Tourism: } \\
\text { commercial } \\
\text { boating }\end{array}$ & $\begin{array}{l}\text { Number of } \\
\text { commercial } \\
\text { touristic boats } \\
\text { (nb/year) }\end{array}$ & 26 & data & medium & $\begin{array}{l}\text { in } 2008,13 \text { cruise boats, } 3 \\
\text { tankers ( } 117 \text { trips) and } 10 \\
\text { bottom glass boats }\end{array}$ \\
\hline MPA 03 & Outside & Outside & 55.33 & $\begin{array}{l}\text { Tourism: } \\
\text { private } \\
\text { boating }\end{array}$ & $\begin{array}{l}\text { Number of } \\
\text { private boats } \\
\text { (nb/year) }\end{array}$ & 1830 & data & high & $\begin{array}{l}\text { Data from Google Earth : } 1830 \\
=\text { number of mooring places in } \\
\text { different harbors located inside } \\
\text { the "outside zone" (Collioure, } \\
\text { Port Vendres, Banyuls, } \\
\text { Cerbère, PortBou, Colera, } \\
\text { Llança) }\end{array}$ \\
\hline MPA 03 & Outside & Outside & 55.33 & $\begin{array}{l}\text { Tourism: } \\
\text { scuba-diving }\end{array}$ & $\begin{array}{l}\text { Number of } \\
\text { dives (nb/year) }\end{array}$ & 64000 & data & high & $\begin{array}{l}\text { Data from the Golf of Lion } \\
\text { natural marine park; more } \\
\text { expand than the outside zone } \\
\text { but most of diving spots are } \\
\text { located in the rocky coast }\end{array}$ \\
\hline MPA 03 & Outside & Outside & 194.02 & $\begin{array}{l}\text { Trawlers/purse } \\
\text {-seiners }\end{array}$ & $\begin{array}{l}\text { Number of } \\
\text { boats (nb/year) }\end{array}$ & 10 & $\begin{array}{l}\text { expert } \\
\text { opinion }\end{array}$ & medium & $\begin{array}{l}\text { Number of Licences in Port } \\
\text { Vendre but no data on Spanish }\end{array}$ \\
\hline
\end{tabular}




\begin{tabular}{|c|c|c|c|c|c|c|c|c|c|}
\hline & & & & & & & & & $\begin{array}{l}\text { fleet (probably more : between } \\
5 \text { and } 15 \text { ) }\end{array}$ \\
\hline MPA 04 & Inside & $\begin{array}{l}\text { Partially } \\
\text { protected }\end{array}$ & 2.286 & $\begin{array}{l}\text { Artisanal } \\
\text { fishing }\end{array}$ & $\begin{array}{l}\text { Number of } \\
\text { boats (nb/year) }\end{array}$ & 8 & data & medium & $\begin{array}{l}\text { Registry of fishing vessels held } \\
\text { by Ministry }\end{array}$ \\
\hline MPA 04 & Inside & $\begin{array}{l}\text { Partially } \\
\text { protected }\end{array}$ & 2.286 & $\begin{array}{l}\text { Recreational } \\
\text { fishing: hook } \\
\text { and line }\end{array}$ & $\begin{array}{l}\text { Number of } \\
\text { people (nb/year) }\end{array}$ & 30 & $\begin{array}{l}\text { expert } \\
\text { opinion }\end{array}$ & low & Estimated \\
\hline MPA 04 & Inside & $\begin{array}{l}\text { Partially } \\
\text { protected }\end{array}$ & 2.286 & $\begin{array}{l}\text { Recreational } \\
\text { fishing: } \\
\text { spearfishing }\end{array}$ & $\begin{array}{l}\text { Number of } \\
\text { people (nb/year) }\end{array}$ & 2873 & data & low & $\begin{array}{l}\text { Registry of spear gun licenses } \\
\text { held by Malta Police Force }\end{array}$ \\
\hline MPA 04 & Inside & $\begin{array}{l}\text { Partially } \\
\text { protected }\end{array}$ & 2.286 & $\begin{array}{l}\text { Tourism: } \\
\text { bathing/trampl } \\
\text { ing }\end{array}$ & $\begin{array}{l}\text { Number of } \\
\text { people (nb/year) }\end{array}$ & 5000 & data & low & $\begin{array}{l}\text { Estimated based on logs kept } \\
\text { by Malta Tourism Authority } \\
\text { beach supervisors }\end{array}$ \\
\hline MPA 04 & Inside & $\begin{array}{l}\text { Partially } \\
\text { protected }\end{array}$ & 2.286 & $\begin{array}{l}\text { Tourism: } \\
\text { commercial } \\
\text { boating }\end{array}$ & $\begin{array}{l}\text { Number of } \\
\text { commercial } \\
\text { touristic boats } \\
\text { (nb/year) }\end{array}$ & 17 & data & high & $\begin{array}{l}\text { List of licensed commercial } \\
\text { vessels held by Transport } \\
\text { Malta }\end{array}$ \\
\hline MPA 04 & Inside & $\begin{array}{l}\text { Partially } \\
\text { protected }\end{array}$ & 2.286 & $\begin{array}{l}\text { Tourism: } \\
\text { private } \\
\text { boating }\end{array}$ & $\begin{array}{l}\text { Number of } \\
\text { private boats } \\
\text { (nb/year) }\end{array}$ & NA & & low & NA \\
\hline MPA 04 & Inside & $\begin{array}{l}\text { Partially } \\
\text { protected }\end{array}$ & 2.286 & $\begin{array}{l}\text { Tourism: } \\
\text { scuba-diving }\end{array}$ & $\begin{array}{l}\text { Number of } \\
\text { dives (nb/year) }\end{array}$ & 10000 & $\begin{array}{l}\text { expert } \\
\text { opinion }\end{array}$ & low & Estimated \\
\hline MPA 04 & Inside & $\begin{array}{l}\text { Partially } \\
\text { protected }\end{array}$ & 2.286 & $\begin{array}{l}\text { Trawlers/purse } \\
\text {-seiners }\end{array}$ & $\begin{array}{l}\text { Number of } \\
\text { boats (nb/year) }\end{array}$ & 0 & data & high & $\begin{array}{l}\text { Registry of fishing vessels held } \\
\text { by Ministry }\end{array}$ \\
\hline MPA 04 & Outside & Outside & 24.75 & $\begin{array}{l}\text { Artisanal } \\
\text { fishing }\end{array}$ & $\begin{array}{l}\text { Number of } \\
\text { boats (nb/year) }\end{array}$ & 89 & data & medium & $\begin{array}{l}\text { Registry of fishing vessels held } \\
\text { by Ministry }\end{array}$ \\
\hline MPA 04 & Outside & Outside & 24.75 & $\begin{array}{l}\text { Recreational } \\
\text { fishing: hook } \\
\text { and line }\end{array}$ & $\begin{array}{l}\text { Number of } \\
\text { people (nb/year) }\end{array}$ & 400 & $\begin{array}{l}\text { expert } \\
\text { opinion }\end{array}$ & low & Estimated \\
\hline MPA 04 & Outside & Outside & 24.75 & $\begin{array}{l}\text { Recreational } \\
\text { fishing: } \\
\text { spearfishing }\end{array}$ & $\begin{array}{l}\text { Number of } \\
\text { people (nb/year) }\end{array}$ & 2873 & data & low & $\begin{array}{l}\text { Registry of spear gun licenses } \\
\text { held by Malta Police Force }\end{array}$ \\
\hline MPA 04 & Outside & Outside & 24.75 & $\begin{array}{l}\text { Tourism: } \\
\text { bathing/trampl } \\
\text { ing }\end{array}$ & $\begin{array}{l}\text { Number of } \\
\text { people (nb/year) }\end{array}$ & 60000 & data & low & $\begin{array}{l}\text { Estimated based on logs kept } \\
\text { by Malta Tourism Authority } \\
\text { beach supervisors }\end{array}$ \\
\hline MPA 04 & Outside & Outside & 24.75 & $\begin{array}{l}\text { Tourism: } \\
\text { commercial } \\
\text { boating }\end{array}$ & $\begin{array}{l}\text { Number of } \\
\text { commercial }\end{array}$ & 30 & $\begin{array}{l}\text { expert } \\
\text { opinion }\end{array}$ & low & Estimated \\
\hline
\end{tabular}




\begin{tabular}{|c|c|c|c|c|c|c|c|c|c|}
\hline & & & & & $\begin{array}{l}\text { touristic boats } \\
\text { (nb/year) }\end{array}$ & & & & \\
\hline MPA 04 & Outside & Outside & 24.75 & $\begin{array}{l}\text { Tourism: } \\
\text { private } \\
\text { boating }\end{array}$ & $\begin{array}{l}\text { Number of } \\
\text { private boats } \\
\text { (nb/year) }\end{array}$ & NA & & low & NA \\
\hline MPA 04 & Outside & Outside & 24.75 & $\begin{array}{l}\text { Tourism: } \\
\text { scuba-diving }\end{array}$ & $\begin{array}{l}\text { Number of } \\
\text { dives (nb/year) }\end{array}$ & 3500 & $\begin{array}{l}\text { expert } \\
\text { opinion }\end{array}$ & low & Estimated \\
\hline MPA 04 & Outside & Outside & 347.66 & $\begin{array}{l}\text { Trawlers/purse } \\
\text {-seiners }\end{array}$ & $\begin{array}{l}\text { Number of } \\
\text { boats (nb/year) }\end{array}$ & 39 & data & high & $\begin{array}{l}\text { Registry of fishing vessels held } \\
\text { by Ministry }\end{array}$ \\
\hline MPA 05 & Integral & No-take & 19 & $\begin{array}{l}\text { Artisanal } \\
\text { fishing }\end{array}$ & $\begin{array}{l}\text { Number of } \\
\text { boats (nb/year) }\end{array}$ & 0 & data & high & MPA regulations \\
\hline MPA 05 & Integral & No-take & 19 & $\begin{array}{l}\text { Recreational } \\
\text { fishing: hook } \\
\text { and line }\end{array}$ & $\begin{array}{l}\text { Number of } \\
\text { people (nb/year) }\end{array}$ & 0 & data & high & MPA regulations \\
\hline MPA 05 & Integral & No-take & 19 & $\begin{array}{l}\text { Recreational } \\
\text { fishing: } \\
\text { spearfishing }\end{array}$ & $\begin{array}{l}\text { Number of } \\
\text { people (nb/year) }\end{array}$ & 0 & data & high & MPA regulations \\
\hline MPA 05 & Integral & No-take & 19 & $\begin{array}{l}\text { Tourism: } \\
\text { bathing/trampl } \\
\text { ing }\end{array}$ & $\begin{array}{l}\text { Number of } \\
\text { people (nb/year) }\end{array}$ & 1000 & data & medium & Internal MPA reporting \\
\hline MPA 05 & Integral & No-take & 19 & $\begin{array}{l}\text { Tourism: } \\
\text { commercial } \\
\text { boating }\end{array}$ & $\begin{array}{l}\text { Number of } \\
\text { commercial } \\
\text { touristic boats } \\
\text { (nb/year) }\end{array}$ & 5 & data & high & Harbour Authorities \\
\hline MPA 05 & Integral & No-take & 19 & $\begin{array}{l}\text { Tourism: } \\
\text { private } \\
\text { boating }\end{array}$ & $\begin{array}{l}\text { Number of } \\
\text { private boats } \\
\text { (nb/year) }\end{array}$ & 150 & data & high & Internal MPA reporting \\
\hline MPA 05 & Integral & No-take & 19 & $\begin{array}{l}\text { Tourism: } \\
\text { scuba-diving }\end{array}$ & $\begin{array}{l}\text { Number of } \\
\text { dives (nb/year) }\end{array}$ & 0 & data & high & MPA regulations \\
\hline MPA 05 & Integral & No-take & 19 & $\begin{array}{l}\text { Trawlers/purse } \\
\text {-seiners }\end{array}$ & $\begin{array}{l}\text { Number of } \\
\text { boats (nb/year) }\end{array}$ & 0 & data & high & MPA regulations \\
\hline MPA 05 & $\begin{array}{l}\text { Amortigua } \\
\text { ción }\end{array}$ & $\begin{array}{l}\text { Partially } \\
\text { protected }\end{array}$ & 93.86 & $\begin{array}{l}\text { Artisanal } \\
\text { fishing }\end{array}$ & $\begin{array}{l}\text { Number of } \\
\text { boats (nb/year) }\end{array}$ & 50 & data & high & MPA regulations \\
\hline MPA 05 & $\begin{array}{l}\text { Amortigua } \\
\text { ción }\end{array}$ & $\begin{array}{l}\text { Partially } \\
\text { protected }\end{array}$ & 93.86 & $\begin{array}{l}\text { Recreational } \\
\text { fishing: hook } \\
\text { and line }\end{array}$ & $\begin{array}{l}\text { Number of } \\
\text { people (nb/year) }\end{array}$ & 685 & data & high & Internal MPA reporting \\
\hline
\end{tabular}




\begin{tabular}{|c|c|c|c|c|c|c|c|c|c|}
\hline MPA 05 & $\begin{array}{l}\text { Amortigua } \\
\text { ción }\end{array}$ & $\begin{array}{l}\text { Partially } \\
\text { protected }\end{array}$ & 93.86 & $\begin{array}{l}\text { Recreational } \\
\text { fishing: } \\
\text { spearfishing }\end{array}$ & $\begin{array}{l}\text { Number of } \\
\text { people (nb/year) }\end{array}$ & 64 & data & high & Regional number of Licenses \\
\hline MPA 05 & $\begin{array}{l}\text { Amortigua } \\
\text { ción }\end{array}$ & $\begin{array}{l}\text { Partially } \\
\text { protected }\end{array}$ & 93.86 & $\begin{array}{l}\text { Tourism: } \\
\text { bathing/trampl } \\
\text { ing }\end{array}$ & $\begin{array}{l}\text { Number of } \\
\text { people (nb/year) }\end{array}$ & 180000 & data & medium & Internal MPA reporting \\
\hline MPA 05 & $\begin{array}{l}\text { Amortigua } \\
\text { ción }\end{array}$ & $\begin{array}{l}\text { Partially } \\
\text { protected }\end{array}$ & 93.86 & $\begin{array}{l}\text { Tourism: } \\
\text { commercial } \\
\text { boating }\end{array}$ & $\begin{array}{l}\text { Number of } \\
\text { commercial } \\
\text { touristic boats } \\
\text { (nb/year) }\end{array}$ & 10 & data & high & Internal MPA reporting \\
\hline MPA 05 & $\begin{array}{l}\text { Amortigua } \\
\text { ción }\end{array}$ & $\begin{array}{l}\text { Partially } \\
\text { protected }\end{array}$ & 93.86 & $\begin{array}{l}\text { Tourism: } \\
\text { private } \\
\text { boating }\end{array}$ & $\begin{array}{l}\text { Number of } \\
\text { private boats } \\
\text { (nb/year) }\end{array}$ & 2800 & data & medium & Internal MPA reporting \\
\hline MPA 05 & $\begin{array}{l}\text { Amortigua } \\
\text { ción }\end{array}$ & $\begin{array}{l}\text { Partially } \\
\text { protected }\end{array}$ & 93.86 & $\begin{array}{l}\text { Tourism: } \\
\text { scuba-diving }\end{array}$ & $\begin{array}{l}\text { Number of } \\
\text { dives (nb/year) }\end{array}$ & 4222 & data & high & $\begin{array}{l}\text { Anual Report Regional } \\
\text { Tourism Department }\end{array}$ \\
\hline MPA 05 & $\begin{array}{l}\text { Amortigua } \\
\text { ción }\end{array}$ & $\begin{array}{l}\text { Partially } \\
\text { protected }\end{array}$ & 93.86 & $\begin{array}{l}\text { Trawlers/purse } \\
\text {-seiners }\end{array}$ & $\begin{array}{l}\text { Number of } \\
\text { boats (nb/year) }\end{array}$ & 0 & data & high & MPA regulations \\
\hline MPA 05 & Exterior & Outside & 156.25 & $\begin{array}{l}\text { Artisanal } \\
\text { fishing }\end{array}$ & $\begin{array}{l}\text { Number of } \\
\text { boats (nb/year) }\end{array}$ & 64 & data & high & Regional Boat Census \\
\hline MPA 05 & Exterior & Outside & 156.25 & $\begin{array}{l}\text { Recreational } \\
\text { fishing: hook } \\
\text { and line }\end{array}$ & $\begin{array}{l}\text { Number of } \\
\text { people (nb/year) }\end{array}$ & 7560 & data & medium & Regional number of Licenses \\
\hline MPA 05 & Exterior & Outside & 156.25 & $\begin{array}{l}\text { Recreational } \\
\text { fishing: } \\
\text { spearfishing }\end{array}$ & $\begin{array}{l}\text { Number of } \\
\text { people (nb/year) }\end{array}$ & 380 & data & medium & Regional number of Licenses \\
\hline MPA 05 & Exterior & Outside & 156.25 & $\begin{array}{l}\text { Tourism: } \\
\text { bathing/trampl } \\
\text { ing }\end{array}$ & $\begin{array}{l}\text { Number of } \\
\text { people (nb/year) }\end{array}$ & 340000 & $\begin{array}{l}\text { expert } \\
\text { opinion }\end{array}$ & low & Estimated \\
\hline MPA 05 & Exterior & Outside & 156.25 & $\begin{array}{l}\text { Tourism: } \\
\text { commercial } \\
\text { boating }\end{array}$ & $\begin{array}{l}\text { Number of } \\
\text { commercial } \\
\text { touristic boats } \\
\text { (nb/year) }\end{array}$ & 50 & data & low & $\begin{array}{l}\text { Annual Report Regional } \\
\text { Tourism Department }\end{array}$ \\
\hline MPA 05 & Exterior & Outside & 156.25 & $\begin{array}{l}\text { Tourism: } \\
\text { private } \\
\text { boating }\end{array}$ & $\begin{array}{l}\text { Number of } \\
\text { private boats } \\
\text { (nb/year) }\end{array}$ & 7000 & data & low & $\begin{array}{l}\text { Annual Report Regional } \\
\text { Tourism Department }\end{array}$ \\
\hline MPA 05 & Exterior & Outside & 156.25 & $\begin{array}{l}\text { Tourism: } \\
\text { scuba-diving }\end{array}$ & $\begin{array}{l}\text { Number of } \\
\text { dives (nb/year) }\end{array}$ & 10000 & $\begin{array}{l}\text { expert } \\
\text { opinion }\end{array}$ & low & Estimated \\
\hline
\end{tabular}




\begin{tabular}{|c|c|c|c|c|c|c|c|c|c|}
\hline MPA 05 & Exterior & Outside & 684.03 & $\begin{array}{l}\text { Trawlers/purse } \\
\text {-seiners }\end{array}$ & $\begin{array}{l}\text { Number of } \\
\text { boats (nb/year) }\end{array}$ & 6 & data & high & Regional Boat Census \\
\hline MPA 06 & Integral & No-take & 0.431 & $\begin{array}{l}\text { Artisanal } \\
\text { fishing }\end{array}$ & $\begin{array}{l}\text { Number of } \\
\text { boats (nb/year) }\end{array}$ & 0 & data & medium & MPA regulations \\
\hline MPA 06 & Integral & No-take & 0.431 & $\begin{array}{l}\text { Recreational } \\
\text { fishing: hook } \\
\text { and line }\end{array}$ & $\begin{array}{l}\text { Number of } \\
\text { people (nb/year) }\end{array}$ & 0 & data & medium & MPA regulations \\
\hline MPA 06 & Integral & No-take & 0.431 & $\begin{array}{l}\text { Recreational } \\
\text { fishing: } \\
\text { spearfishing }\end{array}$ & $\begin{array}{l}\text { Number of } \\
\text { people (nb/year) }\end{array}$ & 0 & data & medium & MPA regulations \\
\hline MPA 06 & Integral & No-take & 0.431 & $\begin{array}{l}\text { Tourism: } \\
\text { bathing/trampl } \\
\text { ing }\end{array}$ & $\begin{array}{l}\text { Number of } \\
\text { people (nb/year) }\end{array}$ & 150000 & data & medium & $\begin{array}{l}\text { Allowed. Permit not } \\
\text { required.Data from MPA } \\
\text { wardens for } 2013 \text {. }\end{array}$ \\
\hline MPA 06 & Integral & No-take & 0.431 & $\begin{array}{l}\text { Tourism: } \\
\text { commercial } \\
\text { boating }\end{array}$ & $\begin{array}{l}\text { Number of } \\
\text { commercial } \\
\text { touristic boats } \\
\text { (nb/year) }\end{array}$ & 11 & data & medium & $\begin{array}{l}\text { Allowed. Data from MPA } \\
\text { wardens for } 2013 \text {. }\end{array}$ \\
\hline MPA 06 & Integral & No-take & 0.431 & $\begin{array}{l}\text { Tourism: } \\
\text { private } \\
\text { boating }\end{array}$ & $\begin{array}{l}\text { Number of } \\
\text { private boats } \\
\text { (nb/year) }\end{array}$ & 1193 & data & medium & $\begin{array}{l}\text { Allowed. Data from MPA } \\
\text { wardens for } 2013 \text {. }\end{array}$ \\
\hline MPA 06 & Integral & No-take & 0.431 & $\begin{array}{l}\text { Tourism: } \\
\text { scuba-diving }\end{array}$ & $\begin{array}{l}\text { Number of } \\
\text { dives (nb/year) }\end{array}$ & 0 & data & medium & MPA regulations \\
\hline MPA 06 & Integral & No-take & 0.431 & $\begin{array}{l}\text { Trawlers/purse } \\
\text {-seiners }\end{array}$ & $\begin{array}{l}\text { Number of } \\
\text { boats (nb/year) }\end{array}$ & 0 & data & medium & MPA regulations \\
\hline MPA 06 & Buffer & No-take & 2.0718 & $\begin{array}{l}\text { Artisanal } \\
\text { fishing }\end{array}$ & $\begin{array}{l}\text { Number of } \\
\text { boats (nb/year) }\end{array}$ & 0 & data & medium & MPA regulations \\
\hline MPA 06 & Buffer & No-take & 2.0718 & $\begin{array}{l}\text { Recreational } \\
\text { fishing: hook } \\
\text { and line }\end{array}$ & $\begin{array}{l}\text { Number of } \\
\text { people (nb/year) }\end{array}$ & 0 & data & medium & MPA regulations \\
\hline MPA 06 & Buffer & No-take & 2.0718 & $\begin{array}{l}\text { Recreational } \\
\text { fishing: } \\
\text { spearfishing }\end{array}$ & $\begin{array}{l}\text { Number of } \\
\text { people (nb/year) }\end{array}$ & 0 & data & medium & MPA regulations \\
\hline MPA 06 & Buffer & No-take & 2.0718 & $\begin{array}{l}\text { Tourism: } \\
\text { bathing/trampl } \\
\text { ing }\end{array}$ & $\begin{array}{l}\text { Number of } \\
\text { people (nb/year) }\end{array}$ & 150000 & data & medium & $\begin{array}{l}\text { Allowed. Permit not required. } \\
\text { Data from MPA wardens for } \\
2013 \text {. }\end{array}$ \\
\hline MPA 06 & Buffer & No-take & 2.0718 & $\begin{array}{l}\text { Tourism: } \\
\text { commercial } \\
\text { boating }\end{array}$ & $\begin{array}{l}\text { Number of } \\
\text { commercial }\end{array}$ & 36 & data & medium & $\begin{array}{l}\text { Allowed. Permit not required. } \\
\text { Data from MPA wardens for } \\
2013 \text {. }\end{array}$ \\
\hline
\end{tabular}




\begin{tabular}{|c|c|c|c|c|c|c|c|c|c|}
\hline & & & & & $\begin{array}{l}\text { touristic boats } \\
\text { (nb/year) }\end{array}$ & & & & \\
\hline MPA 06 & Buffer & No-take & 2.0718 & $\begin{array}{l}\text { Tourism: } \\
\text { private } \\
\text { boating }\end{array}$ & $\begin{array}{l}\text { Number of } \\
\text { private boats } \\
\text { (nb/year) }\end{array}$ & 1232 & data & medium & $\begin{array}{l}\text { Allowed. Data from MPA } \\
\text { wardens for } 2013 \text {. }\end{array}$ \\
\hline MPA 06 & Buffer & No-take & 2.0718 & $\begin{array}{l}\text { Tourism: } \\
\text { scuba-diving }\end{array}$ & $\begin{array}{l}\text { Number of } \\
\text { dives (nb/year) }\end{array}$ & 0 & data & low & $\begin{array}{l}\text { Allowed. Data from MPA } \\
\text { wardens for } 2013 \text {. }\end{array}$ \\
\hline MPA 06 & Buffer & No-take & 2.0718 & $\begin{array}{l}\text { Trawlers/purse } \\
\text {-seiners }\end{array}$ & $\begin{array}{l}\text { Number of } \\
\text { boats (nb/year) }\end{array}$ & 0 & data & medium & MPA regulations \\
\hline MPA 06 & Exterior & Outside & 36.43 & $\begin{array}{l}\text { Artisanal } \\
\text { fishing }\end{array}$ & $\begin{array}{l}\text { Number of } \\
\text { boats (nb/year) }\end{array}$ & 6 & data & high & $\begin{array}{l}\text { Allowed. Data from MPA } \\
\text { wardens for } 2013 \text {. }\end{array}$ \\
\hline MPA 06 & Exterior & Outside & 36.43 & $\begin{array}{l}\text { Recreational } \\
\text { fishing: hook } \\
\text { and line }\end{array}$ & $\begin{array}{l}\text { Number of } \\
\text { people (nb/year) }\end{array}$ & 15 & data & medium & $\begin{array}{l}\text { Allowed. Data from MPA } \\
\text { wardens for } 2013 \text {. }\end{array}$ \\
\hline MPA 06 & Exterior & Outside & 36.43 & $\begin{array}{l}\text { Recreational } \\
\text { fishing: } \\
\text { spearfishing }\end{array}$ & $\begin{array}{l}\text { Number of } \\
\text { people (nb/year) }\end{array}$ & 0 & data & medium & $\begin{array}{l}\text { Allowed. Data from MPA } \\
\text { wardens for } 2013 \text {. }\end{array}$ \\
\hline MPA 06 & Exterior & Outside & 36.43 & $\begin{array}{l}\text { Tourism: } \\
\text { bathing/trampl } \\
\text { ing }\end{array}$ & $\begin{array}{l}\text { Number of } \\
\text { people (nb/year) }\end{array}$ & 150000 & $\begin{array}{l}\text { expert } \\
\text { opinion }\end{array}$ & low & $\begin{array}{l}\text { Estimated (Permit not needed. } \\
\text { Unknown.) }\end{array}$ \\
\hline MPA 06 & Exterior & Outside & 36.43 & $\begin{array}{l}\text { Tourism: } \\
\text { commercial } \\
\text { boating }\end{array}$ & $\begin{array}{l}\text { Number of } \\
\text { commercial } \\
\text { touristic boats } \\
\text { (nb/year) }\end{array}$ & 215 & data & medium & $\begin{array}{l}\text { Allowed. Data from MPA } \\
\text { wardens for } 2013 \text {. }\end{array}$ \\
\hline MPA 06 & Exterior & Outside & 36.43 & $\begin{array}{l}\text { Tourism: } \\
\text { private } \\
\text { boating }\end{array}$ & $\begin{array}{l}\text { Number of } \\
\text { private boats } \\
\text { (nb/year) }\end{array}$ & 124 & data & medium & $\begin{array}{l}\text { Allowed. Data from MPA } \\
\text { wardens for } 2013 \text {. }\end{array}$ \\
\hline MPA 06 & Exterior & Outside & 36.43 & $\begin{array}{l}\text { Tourism: } \\
\text { scuba-diving }\end{array}$ & $\begin{array}{l}\text { Number of } \\
\text { dives (nb/year) }\end{array}$ & 1232 & $\begin{array}{l}\text { expert } \\
\text { opinion }\end{array}$ & low & $\begin{array}{l}\text { Permit not needed. Unknown } \\
\text { but high. }\end{array}$ \\
\hline MPA 06 & Exterior & Outside & 196.48 & $\begin{array}{l}\text { Trawlers/purse } \\
\text {-seiners }\end{array}$ & $\begin{array}{l}\text { Number of } \\
\text { boats (nb/year) }\end{array}$ & 24 & data & high & $\begin{array}{l}\text { Allowed. Data from MPA } \\
\text { wardens for } 2013 \text {. }\end{array}$ \\
\hline MPA 07 & Zone A & No-take & 31.24 & $\begin{array}{l}\text { Artisanal } \\
\text { fishing }\end{array}$ & $\begin{array}{l}\text { Number of } \\
\text { boats (nb/year) }\end{array}$ & 0 & data & high & MPA regulations \\
\hline MPA 07 & Zone A & No-take & 31.24 & $\begin{array}{l}\text { Recreational } \\
\text { fishing: hook } \\
\text { and line }\end{array}$ & $\begin{array}{l}\text { Number of } \\
\text { people (nb/year) }\end{array}$ & 0 & data & high & MPA regulations \\
\hline
\end{tabular}




\begin{tabular}{|c|c|c|c|c|c|c|c|c|c|}
\hline MPA 07 & Zone A & No-take & 31.24 & $\begin{array}{l}\text { Recreational } \\
\text { fishing: } \\
\text { spearfishing }\end{array}$ & $\begin{array}{l}\text { Number of } \\
\text { people (nb/year) }\end{array}$ & 0 & data & high & MPA regulations \\
\hline MPA 07 & Zone A & No-take & 31.24 & $\begin{array}{l}\text { Tourism: } \\
\text { bathing/trampl } \\
\text { ing }\end{array}$ & $\begin{array}{l}\text { Number of } \\
\text { people (nb/year) }\end{array}$ & 131516 & data & high & $\begin{array}{l}\text { Total no. of visitors for } 2013 \\
\text { on two main islands (only } \\
\text { around } 1 / 3 \text { are bathing) }\end{array}$ \\
\hline MPA 07 & Zone A & No-take & 31.24 & $\begin{array}{l}\text { Tourism: } \\
\text { commercial } \\
\text { boating }\end{array}$ & $\begin{array}{l}\text { Number of } \\
\text { commercial } \\
\text { touristic boats } \\
\text { (nb/year) }\end{array}$ & 3 & data & high & $\begin{array}{l}\text { Only the boat from NP, and } \\
\text { two other boats have the } \\
\text { permission to take tourists to } \\
\text { the island (the boat from NP } \\
\text { Brijuni makes from } 4 \text { (winter) } \\
\text { to } 14 \text { (summer) trips per day, } \\
\text { and other two boats } 1 \text { trip per } \\
\text { day during the summer) }\end{array}$ \\
\hline MPA 07 & Zone A & No-take & 31.24 & $\begin{array}{l}\text { Tourism: } \\
\text { private } \\
\text { boating }\end{array}$ & $\begin{array}{l}\text { Number of } \\
\text { private boats } \\
\text { (nb/year) }\end{array}$ & 2500 & data & low & $\begin{array}{l}\text { Total no. of boats moored in } \\
\text { the port of the main island for } \\
2013 \text { is } 1830 \text {. }\end{array}$ \\
\hline MPA 07 & Zone A & No-take & 31.24 & $\begin{array}{l}\text { Tourism: } \\
\text { scuba-diving }\end{array}$ & $\begin{array}{l}\text { Number of } \\
\text { dives (nb/year) }\end{array}$ & 1000 & $\begin{array}{l}\text { expert } \\
\text { opinion }\end{array}$ & medium & Estimated \\
\hline MPA 07 & Zone A & No-take & 31.24 & $\begin{array}{l}\text { Trawlers/purse } \\
\text {-seiners }\end{array}$ & $\begin{array}{l}\text { Number of } \\
\text { boats (nb/year) }\end{array}$ & 0 & data & high & MPA regulations \\
\hline MPA 07 & Zone B & $\begin{array}{l}\text { Partially } \\
\text { protected }\end{array}$ & 2.77 & $\begin{array}{l}\text { Artisanal } \\
\text { fishing }\end{array}$ & $\begin{array}{l}\text { Number of } \\
\text { boats (nb/year) }\end{array}$ & 0 & data & high & MPA regulations \\
\hline MPA 07 & Zone B & $\begin{array}{l}\text { Partially } \\
\text { protected }\end{array}$ & 2.77 & $\begin{array}{l}\text { Recreational } \\
\text { fishing: hook } \\
\text { and line }\end{array}$ & $\begin{array}{l}\text { Number of } \\
\text { people (nb/year) }\end{array}$ & 250 & $\begin{array}{l}\text { expert } \\
\text { opinion }\end{array}$ & medium & $\begin{array}{l}\text { There are two types of permits: } \\
\text { monthly and yearly. No. of } \\
\text { issued monthly permits for } \\
\text { 2013. is } 1077 \text { and of yearly } \\
\text { permis } 8 \text {. Only } 2 \text { kg of fish is } \\
\text { allowed per one person per day } \\
\text { for local citizens of three } \\
\text { surrounding municipalities. } \\
\text { Only traditional (recreational) } \\
\text { fishing is allowed for dawn to } \\
\text { dusk. Value in the table is } \\
\text { calculated presuming that } \\
\text { same persons are buying } \\
\text { monthly permits } 5 \text { months } \\
\text { during the year and based on }\end{array}$ \\
\hline
\end{tabular}




\begin{tabular}{|c|c|c|c|c|c|c|c|c|c|}
\hline & & & & & & & & & $\begin{array}{l}\text { the counted small boats in } \\
\text { surrounding ports. }\end{array}$ \\
\hline MPA 07 & Zone B & $\begin{array}{l}\text { Partially } \\
\text { protected }\end{array}$ & 2.77 & $\begin{array}{l}\text { Recreational } \\
\text { fishing: } \\
\text { spearfishing }\end{array}$ & $\begin{array}{l}\text { Number of } \\
\text { people (nb/year) }\end{array}$ & 0 & data & high & MPA regulations \\
\hline MPA 07 & Zone B & $\begin{array}{l}\text { Partially } \\
\text { protected }\end{array}$ & 2.77 & $\begin{array}{l}\text { Tourism: } \\
\text { bathing/trampl } \\
\text { ing }\end{array}$ & $\begin{array}{l}\text { Number of } \\
\text { people (nb/year) }\end{array}$ & 35000 & $\begin{array}{l}\text { expert } \\
\text { opinion }\end{array}$ & medium & $\begin{array}{l}\text { On one of the two islands } \\
\text { (Jerolim) is obligated ticket } \\
\text { buying ( } 17370 \text { visitors for } \\
2013 \text { ), but on the second island } \\
\text { visiting is free of charge. It is } \\
\text { presumed that around same } \\
\text { number of visitor visit the } \\
\text { second island (Kozada). }\end{array}$ \\
\hline MPA 07 & Zone B & $\begin{array}{l}\text { Partially } \\
\text { protected }\end{array}$ & 2.77 & $\begin{array}{l}\text { Tourism: } \\
\text { commercial } \\
\text { boating }\end{array}$ & $\begin{array}{l}\text { Number of } \\
\text { commercial } \\
\text { touristic boats } \\
\text { (nb/year) }\end{array}$ & 20 & $\begin{array}{l}\text { expert } \\
\text { opinion }\end{array}$ & medium & $\begin{array}{l}\text { Around } 20 \text { commercial boats } \\
\text { take visitors to those } 2 \text { islands. }\end{array}$ \\
\hline MPA 07 & Zone B & $\begin{array}{l}\text { Partially } \\
\text { protected }\end{array}$ & 2.77 & $\begin{array}{l}\text { Tourism: } \\
\text { private } \\
\text { boating }\end{array}$ & $\begin{array}{l}\text { Number of } \\
\text { private boats } \\
\text { (nb/year) }\end{array}$ & 1000 & $\begin{array}{l}\text { expert } \\
\text { opinion }\end{array}$ & low & $\begin{array}{l}\text { Around } 1000 \text { boats are counted } \\
\text { on the map in surrounding } \\
\text { ports. }\end{array}$ \\
\hline MPA 07 & Zone B & $\begin{array}{l}\text { Partially } \\
\text { protected }\end{array}$ & 2.77 & $\begin{array}{l}\text { Tourism: } \\
\text { scuba-diving }\end{array}$ & $\begin{array}{l}\text { Number of } \\
\text { dives (nb/year) }\end{array}$ & 100 & $\begin{array}{l}\text { expert } \\
\text { opinion }\end{array}$ & medium & $\begin{array}{l}1 \text { spots in this zone } 2 \text { where } \\
\text { diving is allowed (with permit). } \\
\text { Total number of dives in zone } \\
1 \text { and } 2 \text { for } 2013 \text { is } 497 \text { and for } \\
2012 \text { is } 350 \text {. So the average } \\
\text { number of dives per year is } \\
\text { around } 450 \text { - } 400 \text { for zone } 1 \\
\text { and } 50 \text { for zone } 2 \text {. }\end{array}$ \\
\hline MPA 07 & Zone B & $\begin{array}{l}\text { Partially } \\
\text { protected }\end{array}$ & 2.77 & $\begin{array}{l}\text { Trawlers/purse } \\
\text {-seiners }\end{array}$ & $\begin{array}{l}\text { Number of } \\
\text { boats (nb/year) }\end{array}$ & 0 & data & high & MPA regulations \\
\hline MPA 07 & Outside & Outside & 68.1 & $\begin{array}{l}\text { Artisanal } \\
\text { fishing }\end{array}$ & $\begin{array}{l}\text { Number of } \\
\text { boats (nb/year) }\end{array}$ & 50 & $\begin{array}{l}\text { expert } \\
\text { opinion }\end{array}$ & low & Very rough estimation \\
\hline MPA 07 & Outside & Outside & 68.1 & $\begin{array}{l}\text { Recreational } \\
\text { fishing: hook } \\
\text { and line }\end{array}$ & $\begin{array}{l}\text { Number of } \\
\text { people (nb/year) }\end{array}$ & 1000 & $\begin{array}{l}\text { expert } \\
\text { opinion }\end{array}$ & low & $\begin{array}{l}\text { In this zone there is around } 20 \\
\text { fishing organizations }\end{array}$ \\
\hline MPA 07 & Outside & Outside & 68.1 & $\begin{array}{l}\text { Recreational } \\
\text { fishing: } \\
\text { spearfishing }\end{array}$ & $\begin{array}{l}\text { Number of } \\
\text { people (nb/year) }\end{array}$ & 100 & $\begin{array}{l}\text { expert } \\
\text { opinion }\end{array}$ & low & $\begin{array}{l}\text { The assumption is that } 10 \% \text { of } \\
\text { persons are practicing } \\
\text { spearfishing }\end{array}$ \\
\hline
\end{tabular}




\begin{tabular}{|c|c|c|c|c|c|c|c|c|c|}
\hline MPA 07 & Outside & Outside & 68.1 & $\begin{array}{l}\text { Tourism: } \\
\text { bathing/trampl } \\
\text { ing }\end{array}$ & $\begin{array}{l}\text { Number of } \\
\text { people (nb/year) }\end{array}$ & 400000 & $\begin{array}{l}\text { expert } \\
\text { opinion }\end{array}$ & low & $\begin{array}{l}\text { In this zone lives around } \\
70.000 \text { local citizens and in } \\
2013 \text { in this zone has arrived } \\
430.000 \text { tourists }\end{array}$ \\
\hline MPA 07 & Outside & Outside & 68.1 & $\begin{array}{l}\text { Tourism: } \\
\text { commercial } \\
\text { boating }\end{array}$ & $\begin{array}{l}\text { Number of } \\
\text { commercial } \\
\text { touristic boats } \\
\text { (nb/year) }\end{array}$ & 2000 & $\begin{array}{l}\text { expert } \\
\text { opinion }\end{array}$ & low & $\begin{array}{l}\text { Most of commercial touristic } \\
\text { boats are sailing boats for rent } \\
\text { (other commercial boats } \\
\text { around } 100 \text { ) }\end{array}$ \\
\hline MPA 07 & Outside & Outside & 68.1 & $\begin{array}{l}\text { Tourism: } \\
\text { private } \\
\text { boating }\end{array}$ & $\begin{array}{l}\text { Number of } \\
\text { private boats } \\
\text { (nb/year) }\end{array}$ & 5000 & $\begin{array}{l}\text { expert } \\
\text { opinion }\end{array}$ & low & $\begin{array}{l}\text { In this zone around } 4500 \text { boats } \\
\text { were counted in big and small } \\
\text { ports on Google map }\end{array}$ \\
\hline MPA 07 & Outside & Outside & 68.1 & $\begin{array}{l}\text { Tourism: } \\
\text { scuba-diving }\end{array}$ & $\begin{array}{l}\text { Number of } \\
\text { dives (nb/year) }\end{array}$ & 5000 & $\begin{array}{l}\text { expert } \\
\text { opinion }\end{array}$ & low & $\begin{array}{l}\text { In this zone there is around } 20 \\
\text { diving centers with many } \\
\text { diving sites }\end{array}$ \\
\hline MPA 07 & Outside & Outside & 398.78 & $\begin{array}{l}\text { Trawlers/purse } \\
\text {-seiners }\end{array}$ & $\begin{array}{l}\text { Number of } \\
\text { boats (nb/year) }\end{array}$ & 20 & $\begin{array}{l}\text { expert } \\
\text { opinion }\end{array}$ & low & Very rough estimation \\
\hline MPA 08 & $\begin{array}{l}\text { Peripheral } \\
\text { zone }\end{array}$ & $\begin{array}{l}\text { Partially } \\
\text { protected }\end{array}$ & 31.944 & $\begin{array}{l}\text { Artisanal } \\
\text { fishing }\end{array}$ & $\begin{array}{l}\text { Number of } \\
\text { boats (nb/year) }\end{array}$ & 5 & data & medium & Internal MPA reporting \\
\hline MPA 08 & $\begin{array}{l}\text { Peripheral } \\
\text { zone }\end{array}$ & $\begin{array}{l}\text { Partially } \\
\text { protected }\end{array}$ & 31.944 & $\begin{array}{l}\text { Recreational } \\
\text { fishing: hook } \\
\text { and line }\end{array}$ & $\begin{array}{l}\text { Number of } \\
\text { people (nb/year) }\end{array}$ & 0 & data & high & MPA regulations \\
\hline MPA 08 & $\begin{array}{l}\text { Peripheral } \\
\text { zone }\end{array}$ & $\begin{array}{l}\text { Partially } \\
\text { protected }\end{array}$ & 31.944 & $\begin{array}{l}\text { Recreational } \\
\text { fishing: } \\
\text { spearfishing }\end{array}$ & $\begin{array}{l}\text { Number of } \\
\text { people (nb/year) }\end{array}$ & 0 & data & high & MPA regulations \\
\hline MPA 08 & $\begin{array}{l}\text { Peripheral } \\
\text { zone }\end{array}$ & $\begin{array}{l}\text { Partially } \\
\text { protected }\end{array}$ & 31.944 & $\begin{array}{l}\text { Tourism: } \\
\text { bathing/trampl } \\
\text { ing }\end{array}$ & $\begin{array}{l}\text { Number of } \\
\text { people (nb/year) }\end{array}$ & 0 & data & medium & MPA regulations \\
\hline MPA 08 & $\begin{array}{l}\text { Peripheral } \\
\text { zone }\end{array}$ & $\begin{array}{l}\text { Partially } \\
\text { protected }\end{array}$ & 31.944 & $\begin{array}{l}\text { Tourism: } \\
\text { commercial } \\
\text { boating }\end{array}$ & $\begin{array}{l}\text { Number of } \\
\text { commercial } \\
\text { touristic boats } \\
\text { (nb/year) }\end{array}$ & 200 & $\begin{array}{l}\text { expert } \\
\text { opinion }\end{array}$ & medium & Internal MPA reporting \\
\hline MPA 08 & $\begin{array}{l}\text { Peripheral } \\
\text { zone }\end{array}$ & $\begin{array}{l}\text { Partially } \\
\text { protected }\end{array}$ & 31.944 & $\begin{array}{l}\text { Tourism: } \\
\text { private } \\
\text { boating }\end{array}$ & $\begin{array}{l}\text { Number of } \\
\text { private boats } \\
\text { (nb/year) }\end{array}$ & 500 & $\begin{array}{l}\text { expert } \\
\text { opinion }\end{array}$ & medium & Internal MPA reporting \\
\hline MPA 08 & $\begin{array}{l}\text { Peripheral } \\
\text { zone }\end{array}$ & $\begin{array}{l}\text { Partially } \\
\text { protected }\end{array}$ & 31.944 & $\begin{array}{l}\text { Tourism: } \\
\text { scuba-diving }\end{array}$ & $\begin{array}{l}\text { Number of } \\
\text { dives (nb/year) }\end{array}$ & 7000 & data & medium & Internal MPA reporting \\
\hline MPA 08 & $\begin{array}{l}\text { Peripheral } \\
\text { zone }\end{array}$ & $\begin{array}{l}\text { Partially } \\
\text { protected }\end{array}$ & 31.944 & $\begin{array}{l}\text { Trawlers/purse } \\
\text {-seiners }\end{array}$ & $\begin{array}{l}\text { Number of } \\
\text { boats (nb/year) }\end{array}$ & 0 & data & high & Internal MPA reporting \\
\hline
\end{tabular}




\begin{tabular}{|c|c|c|c|c|c|c|c|c|c|}
\hline MPA 08 & Zone A & $\begin{array}{l}\text { Partially } \\
\text { protected }\end{array}$ & 8.014 & $\begin{array}{l}\text { Artisanal } \\
\text { fishing }\end{array}$ & $\begin{array}{l}\text { Number of } \\
\text { boats (nb/year) }\end{array}$ & 9.93 & data & high & Internal MPA reporting \\
\hline MPA 08 & Zone A & $\begin{array}{l}\text { Partially } \\
\text { protected }\end{array}$ & 8.014 & $\begin{array}{l}\text { Recreational } \\
\text { fishing: hook } \\
\text { and line }\end{array}$ & $\begin{array}{l}\text { Number of } \\
\text { people (nb/year) }\end{array}$ & 0 & data & high & MPA regulations \\
\hline MPA 08 & Zone A & $\begin{array}{l}\text { Partially } \\
\text { protected }\end{array}$ & 8.014 & $\begin{array}{l}\text { Recreational } \\
\text { fishing: } \\
\text { spearfishing }\end{array}$ & $\begin{array}{l}\text { Number of } \\
\text { people (nb/year) }\end{array}$ & 0 & data & high & MPA regulations \\
\hline MPA 08 & Zone A & $\begin{array}{l}\text { Partially } \\
\text { protected }\end{array}$ & 8.014 & $\begin{array}{l}\text { Tourism: } \\
\text { bathing/trampl } \\
\text { ing }\end{array}$ & $\begin{array}{l}\text { Number of } \\
\text { people (nb/year) }\end{array}$ & 180000 & data & medium & MPA regulations \\
\hline MPA 08 & Zone A & $\begin{array}{l}\text { Partially } \\
\text { protected }\end{array}$ & 8.014 & $\begin{array}{l}\text { Tourism: } \\
\text { commercial } \\
\text { boating }\end{array}$ & $\begin{array}{l}\text { Number of } \\
\text { commercial } \\
\text { touristic boats } \\
\text { (nb/year) }\end{array}$ & 0 & & low & Internal MPA reporting \\
\hline MPA 08 & Zone A & $\begin{array}{l}\text { Partially } \\
\text { protected }\end{array}$ & 8.014 & $\begin{array}{l}\text { Tourism: } \\
\text { private } \\
\text { boating }\end{array}$ & $\begin{array}{l}\text { Number of } \\
\text { private boats } \\
\text { (nb/year) }\end{array}$ & 0 & & low & Internal MPA reporting \\
\hline MPA 08 & Zone A & $\begin{array}{l}\text { Partially } \\
\text { protected }\end{array}$ & 8.014 & $\begin{array}{l}\text { Tourism: } \\
\text { scuba-diving }\end{array}$ & $\begin{array}{l}\text { Number of } \\
\text { dives (nb/year) }\end{array}$ & 0 & data & high & Internal MPA reporting \\
\hline MPA 08 & Zone A & $\begin{array}{l}\text { Partially } \\
\text { protected }\end{array}$ & 8.014 & $\begin{array}{l}\text { Trawlers/purse } \\
\text {-seiners }\end{array}$ & $\begin{array}{l}\text { Number of } \\
\text { boats (nb/year) }\end{array}$ & 0 & data & high & Internal MPA reporting \\
\hline MPA 08 & Zone B & $\begin{array}{l}\text { Partially } \\
\text { protected }\end{array}$ & 35.945 & $\begin{array}{l}\text { Artisanal } \\
\text { fishing }\end{array}$ & $\begin{array}{l}\text { Number of } \\
\text { boats (nb/year) }\end{array}$ & 31.5 & data & high & Internal MPA reporting \\
\hline MPA 08 & Zone B & $\begin{array}{l}\text { Partially } \\
\text { protected }\end{array}$ & 35.945 & $\begin{array}{l}\text { Recreational } \\
\text { fishing: hook } \\
\text { and line }\end{array}$ & $\begin{array}{l}\text { Number of } \\
\text { people (nb/year) }\end{array}$ & 0 & data & high & MPA regulations \\
\hline MPA 08 & Zone B & $\begin{array}{l}\text { Partially } \\
\text { protected }\end{array}$ & 35.945 & $\begin{array}{l}\text { Recreational } \\
\text { fishing: } \\
\text { spearfishing }\end{array}$ & $\begin{array}{l}\text { Number of } \\
\text { people (nb/year) }\end{array}$ & 0 & data & high & MPA regulations \\
\hline MPA 08 & Zone B & $\begin{array}{l}\text { Partially } \\
\text { protected }\end{array}$ & 35.945 & $\begin{array}{l}\text { Tourism: } \\
\text { bathing/trampl } \\
\text { ing }\end{array}$ & $\begin{array}{l}\text { Number of } \\
\text { people (nb/year) }\end{array}$ & 310000 & data & medium & MPA regulations \\
\hline MPA 08 & Zone B & $\begin{array}{l}\text { Partially } \\
\text { protected }\end{array}$ & 35.945 & $\begin{array}{l}\text { Tourism: } \\
\text { commercial } \\
\text { boating }\end{array}$ & $\begin{array}{l}\text { Number of } \\
\text { commercial } \\
\text { touristic boats } \\
\text { (nb/year) }\end{array}$ & 200 & $\begin{array}{l}\text { expert } \\
\text { opinion }\end{array}$ & medium & Internal MPA reporting \\
\hline
\end{tabular}




\begin{tabular}{|c|c|c|c|c|c|c|c|c|c|}
\hline MPA 08 & Zone B & $\begin{array}{l}\text { Partially } \\
\text { protected }\end{array}$ & 35.945 & $\begin{array}{l}\text { Tourism: } \\
\text { private } \\
\text { boating }\end{array}$ & $\begin{array}{l}\text { Number of } \\
\text { private boats } \\
\text { (nb/year) }\end{array}$ & 500 & $\begin{array}{l}\text { expert } \\
\text { opinion }\end{array}$ & medium & Internal MPA reporting \\
\hline MPA 08 & Zone B & $\begin{array}{l}\text { Partially } \\
\text { protected }\end{array}$ & 35.945 & $\begin{array}{l}\text { Tourism: } \\
\text { scuba-diving }\end{array}$ & $\begin{array}{l}\text { Number of } \\
\text { dives (nb/year) }\end{array}$ & 3000 & data & medium & Internal MPA reporting \\
\hline MPA 08 & Zone B & $\begin{array}{l}\text { Partially } \\
\text { protected }\end{array}$ & 35.945 & $\begin{array}{l}\text { Trawlers/purse } \\
\text {-seiners }\end{array}$ & $\begin{array}{l}\text { Number of } \\
\text { boats (nb/year) }\end{array}$ & 0 & data & high & Internal MPA reporting \\
\hline MPA 08 & Zone $\mathrm{C}$ & $\begin{array}{l}\text { Partially } \\
\text { protected }\end{array}$ & 7.404 & $\begin{array}{l}\text { Artisanal } \\
\text { fishing }\end{array}$ & $\begin{array}{l}\text { Number of } \\
\text { boats (nb/year) }\end{array}$ & 8.7 & data & high & Internal MPA reporting \\
\hline MPA 08 & Zone $\mathrm{C}$ & $\begin{array}{l}\text { Partially } \\
\text { protected }\end{array}$ & 7.404 & $\begin{array}{l}\text { Recreational } \\
\text { fishing: hook } \\
\text { and line }\end{array}$ & $\begin{array}{l}\text { Number of } \\
\text { people (nb/year) }\end{array}$ & 0 & data & high & MPA regulations \\
\hline MPA 08 & Zone $\mathrm{C}$ & $\begin{array}{l}\text { Partially } \\
\text { protected }\end{array}$ & 7.404 & $\begin{array}{l}\text { Recreational } \\
\text { fishing: } \\
\text { spearfishing }\end{array}$ & $\begin{array}{l}\text { Number of } \\
\text { people (nb/year) }\end{array}$ & 0 & data & high & MPA regulations \\
\hline MPA 08 & Zone $\mathrm{C}$ & $\begin{array}{l}\text { Partially } \\
\text { protected }\end{array}$ & 7.404 & $\begin{array}{l}\text { Tourism: } \\
\text { bathing/trampl } \\
\text { ing }\end{array}$ & $\begin{array}{l}\text { Number of } \\
\text { people (nb/year) }\end{array}$ & 200000 & $\begin{array}{l}\text { expert } \\
\text { opinion }\end{array}$ & medium & MPA regulations \\
\hline MPA 08 & Zone $\mathrm{C}$ & $\begin{array}{l}\text { Partially } \\
\text { protected }\end{array}$ & 7.404 & $\begin{array}{l}\text { Tourism: } \\
\text { commercial } \\
\text { boating }\end{array}$ & $\begin{array}{l}\text { Number of } \\
\text { commercial } \\
\text { touristic boats } \\
\text { (nb/year) }\end{array}$ & 200 & $\begin{array}{l}\text { expert } \\
\text { opinion }\end{array}$ & medium & Internal MPA reporting \\
\hline MPA 08 & Zone $\mathrm{C}$ & $\begin{array}{l}\text { Partially } \\
\text { protected }\end{array}$ & 7.404 & $\begin{array}{l}\text { Tourism: } \\
\text { private } \\
\text { boating }\end{array}$ & $\begin{array}{l}\text { Number of } \\
\text { private boats } \\
\text { (nb/year) }\end{array}$ & 500 & $\begin{array}{l}\text { expert } \\
\text { opinion }\end{array}$ & medium & Internal MPA reporting \\
\hline MPA 08 & Zone $\mathrm{C}$ & $\begin{array}{l}\text { Partially } \\
\text { protected }\end{array}$ & 7.404 & $\begin{array}{l}\text { Tourism: } \\
\text { scuba-diving }\end{array}$ & $\begin{array}{l}\text { Number of } \\
\text { dives (nb/year) }\end{array}$ & 0 & data & high & Internal MPA reporting \\
\hline MPA 08 & Zone $\mathrm{C}$ & $\begin{array}{l}\text { Partially } \\
\text { protected }\end{array}$ & 7.404 & $\begin{array}{l}\text { Trawlers/purse } \\
\text {-seiners }\end{array}$ & $\begin{array}{l}\text { Number of } \\
\text { boats (nb/year) }\end{array}$ & 0 & data & high & Internal MPA reporting \\
\hline MPA 08 & Outside & Outside & 171.12 & $\begin{array}{l}\text { Artisanal } \\
\text { fishing }\end{array}$ & $\begin{array}{l}\text { Number of } \\
\text { boats (nb/year) }\end{array}$ & 40 & data & medium & Internal MPA reporting \\
\hline MPA 08 & Outside & Outside & 171.12 & $\begin{array}{l}\text { Recreational } \\
\text { fishing: hook } \\
\text { and line }\end{array}$ & $\begin{array}{l}\text { Number of } \\
\text { people (nb/year) }\end{array}$ & 0 & $\begin{array}{l}\text { expert } \\
\text { opinion }\end{array}$ & high & Estimated \\
\hline MPA 08 & Outside & Outside & 171.12 & $\begin{array}{l}\text { Recreational } \\
\text { fishing: } \\
\text { spearfishing }\end{array}$ & $\begin{array}{l}\text { Number of } \\
\text { people (nb/year) }\end{array}$ & 500 & $\begin{array}{l}\text { expert } \\
\text { opinion }\end{array}$ & low & Estimated \\
\hline
\end{tabular}




\begin{tabular}{|c|c|c|c|c|c|c|c|c|c|}
\hline MPA 08 & Outside & Outside & 171.12 & $\begin{array}{l}\text { Tourism: } \\
\text { bathing/trampl } \\
\text { ing }\end{array}$ & $\begin{array}{l}\text { Number of } \\
\text { people (nb/year) }\end{array}$ & 500000 & $\begin{array}{l}\text { expert } \\
\text { opinion }\end{array}$ & low & Estimated \\
\hline MPA 08 & Outside & Outside & 171.12 & $\begin{array}{l}\text { Tourism: } \\
\text { commercial } \\
\text { boating }\end{array}$ & $\begin{array}{l}\text { Number of } \\
\text { commercial } \\
\text { touristic boats } \\
\text { (nb/year) }\end{array}$ & 10 & $\begin{array}{l}\text { expert } \\
\text { opinion }\end{array}$ & low & Estimated \\
\hline MPA 08 & Outside & Outside & 171.12 & $\begin{array}{l}\text { Tourism: } \\
\text { private } \\
\text { boating }\end{array}$ & $\begin{array}{l}\text { Number of } \\
\text { private boats } \\
\text { (nb/year) }\end{array}$ & 400 & $\begin{array}{l}\text { expert } \\
\text { opinion }\end{array}$ & low & Estimated \\
\hline MPA 08 & Outside & Outside & 171.12 & $\begin{array}{l}\text { Tourism: } \\
\text { scuba-diving }\end{array}$ & $\begin{array}{l}\text { Number of } \\
\text { dives (nb/year) }\end{array}$ & 1000 & $\begin{array}{l}\text { expert } \\
\text { opinion }\end{array}$ & low & Estimated \\
\hline MPA 08 & Outside & Outside & 1050.33 & $\begin{array}{l}\text { Trawlers/purse } \\
\text {-seiners }\end{array}$ & $\begin{array}{l}\text { Number of } \\
\text { boats (nb/year) }\end{array}$ & 10 & $\begin{array}{l}\text { expert } \\
\text { opinion }\end{array}$ & high & Estimated \\
\hline MPA 09 & $\begin{array}{l}\text { Reserva } \\
\text { Natural } \\
\text { Integral } \\
\text { des } \\
\text { Encallador } \\
\text { a }\end{array}$ & No-entry & 0.02 & $\begin{array}{l}\text { Artisanal } \\
\text { fishing }\end{array}$ & $\begin{array}{l}\text { Number of } \\
\text { boats (nb/year) }\end{array}$ & 0 & data & high & MPA regulations \\
\hline MPA 09 & $\begin{array}{l}\text { Reserva } \\
\text { Natural } \\
\text { Integral } \\
\text { des } \\
\text { Encallador } \\
\text { a }\end{array}$ & No-entry & 0.02 & $\begin{array}{l}\text { Recreational } \\
\text { fishing: hook } \\
\text { and line }\end{array}$ & $\begin{array}{l}\text { Number of } \\
\text { people (nb/year) }\end{array}$ & 0 & data & high & MPA regulations \\
\hline MPA 09 & $\begin{array}{l}\text { Reserva } \\
\text { Natural } \\
\text { Integral } \\
\text { des } \\
\text { Encallador } \\
\text { a } \\
\end{array}$ & No-entry & 0.02 & $\begin{array}{l}\text { Recreational } \\
\text { fishing: } \\
\text { spearfishing }\end{array}$ & $\begin{array}{l}\text { Number of } \\
\text { people (nb/year) }\end{array}$ & 0 & data & high & MPA regulations \\
\hline MPA 09 & $\begin{array}{l}\text { Reserva } \\
\text { Natural } \\
\text { Integral } \\
\text { des } \\
\text { Encallador } \\
\text { a }\end{array}$ & No-entry & 0.02 & $\begin{array}{l}\text { Tourism: } \\
\text { bathing/trampl } \\
\text { ing }\end{array}$ & $\begin{array}{l}\text { Number of } \\
\text { people (nb/year) }\end{array}$ & 0 & data & high & MPA regulations \\
\hline
\end{tabular}




\begin{tabular}{|c|c|c|c|c|c|c|c|c|c|}
\hline MPA 09 & $\begin{array}{l}\text { Reserva } \\
\text { Natural } \\
\text { Integral } \\
\text { des } \\
\text { Encallador } \\
\text { a }\end{array}$ & No-entry & 0.02 & $\begin{array}{l}\text { Tourism: } \\
\text { commercial } \\
\text { boating }\end{array}$ & $\begin{array}{l}\text { Number of } \\
\text { commercial } \\
\text { touristic boats } \\
\text { (nb/year) }\end{array}$ & 0 & data & high & MPA regulations \\
\hline MPA 09 & $\begin{array}{l}\text { Reserva } \\
\text { Natural } \\
\text { Integral } \\
\text { des } \\
\text { Encallador } \\
\text { a }\end{array}$ & No-entry & 0.02 & $\begin{array}{l}\text { Tourism: } \\
\text { private } \\
\text { boating }\end{array}$ & $\begin{array}{l}\text { Number of } \\
\text { private boats } \\
\text { (nb/year) }\end{array}$ & 0 & data & high & MPA regulations \\
\hline MPA 09 & $\begin{array}{l}\text { Reserva } \\
\text { Natural } \\
\text { Integral } \\
\text { des } \\
\text { Encallador } \\
\text { a } \\
\end{array}$ & No-entry & 0.02 & $\begin{array}{l}\text { Tourism: } \\
\text { scuba-diving }\end{array}$ & $\begin{array}{l}\text { Number of } \\
\text { dives (nb/year) }\end{array}$ & 0 & data & high & MPA regulations \\
\hline MPA 09 & $\begin{array}{l}\text { Reserva } \\
\text { Natural } \\
\text { Integral } \\
\text { des } \\
\text { Encallador } \\
\text { a } \\
\end{array}$ & No-entry & 0.02 & $\begin{array}{l}\text { Trawlers/purse } \\
\text {-seiners }\end{array}$ & $\begin{array}{l}\text { Number of } \\
\text { boats (nb/year) }\end{array}$ & 0 & data & high & MPA regulations \\
\hline MPA 09 & $\begin{array}{l}\text { Reserva } \\
\text { Natural } \\
\text { Parcial dels } \\
\text { Farallons }\end{array}$ & $\begin{array}{l}\text { Partially } \\
\text { protected }\end{array}$ & 2.6 & $\begin{array}{l}\text { Artisanal } \\
\text { fishing }\end{array}$ & $\begin{array}{l}\text { Number of } \\
\text { boats (nb/year) }\end{array}$ & 12 & data & high & $\begin{array}{l}\mathrm{N}^{\mathrm{o}} \text { of boats actually fishing } \\
\text { here ( } \mathrm{N}^{\mathrm{o}} \text { of boats in the nearby } \\
\text { ports); } \\
\text { http://parcsnaturals.gencat.cat/c } \\
\text { a/cap-creus/coneix- } \\
\text { nos/centre_de_documentacio/p } \\
\text { nat_cc_fons_documental/biblio } \\
\text { teca_digital/medi_mari/ }\end{array}$ \\
\hline MPA 09 & $\begin{array}{l}\text { Reserva } \\
\text { Natural } \\
\text { Parcial dels } \\
\text { Farallons }\end{array}$ & $\begin{array}{l}\text { Partially } \\
\text { protected }\end{array}$ & 2.6 & $\begin{array}{l}\text { Recreational } \\
\text { fishing: hook } \\
\text { and line }\end{array}$ & $\begin{array}{l}\text { Number of } \\
\text { people (nb/year) }\end{array}$ & 24 & data & medium & $\begin{array}{l}\text { http://parcsnaturals.gencat.cat/c } \\
\text { a/cap-creus/coneix- } \\
\text { nos/centre de documentacio/p } \\
\text { nat cc fons documental/biblio } \\
\text { teca digital/medi mari/ }\end{array}$ \\
\hline
\end{tabular}




\begin{tabular}{|c|c|c|c|c|c|c|c|c|c|}
\hline MPA 09 & $\begin{array}{l}\text { Reserva } \\
\text { Natural } \\
\text { Parcial dels } \\
\text { Farallons } \\
\end{array}$ & $\begin{array}{l}\text { Partially } \\
\text { protected }\end{array}$ & 2.6 & $\begin{array}{l}\text { Recreational } \\
\text { fishing: } \\
\text { spearfishing }\end{array}$ & $\begin{array}{l}\text { Number of } \\
\text { people (nb/year) }\end{array}$ & 0 & data & high & MPA regulations \\
\hline MPA 09 & $\begin{array}{l}\text { Reserva } \\
\text { Natural } \\
\text { Parcial dels } \\
\text { Farallons } \\
\end{array}$ & $\begin{array}{l}\text { Partially } \\
\text { protected }\end{array}$ & 2.6 & $\begin{array}{l}\text { Tourism: } \\
\text { bathing/trampl } \\
\text { ing }\end{array}$ & $\begin{array}{l}\text { Number of } \\
\text { people (nb/year) }\end{array}$ & 2972 & data & medium & $\begin{array}{l}\text { http://catalegclassicbeg.cultura. } \\
\text { gencat.cat/search } \sim \mathrm{S} 50^{*} \text { cat }\end{array}$ \\
\hline MPA 09 & $\begin{array}{l}\text { Reserva } \\
\text { Natural } \\
\text { Parcial dels } \\
\text { Farallons } \\
\end{array}$ & $\begin{array}{l}\text { Partially } \\
\text { protected }\end{array}$ & 2.6 & $\begin{array}{l}\text { Tourism: } \\
\text { commercial } \\
\text { boating }\end{array}$ & $\begin{array}{l}\text { Number of } \\
\text { commercial } \\
\text { touristic boats } \\
\text { (nb/year) }\end{array}$ & 14 & data & high & $\begin{array}{l}\text { http://catalegclassicbeg.cultura. } \\
\text { gencat.cat/search } \sim \text { S50*cat }\end{array}$ \\
\hline MPA 09 & $\begin{array}{l}\text { Reserva } \\
\text { Natural } \\
\text { Parcial dels } \\
\text { Farallons } \\
\end{array}$ & $\begin{array}{l}\text { Partially } \\
\text { protected }\end{array}$ & 2.6 & $\begin{array}{l}\text { Tourism: } \\
\text { private } \\
\text { boating }\end{array}$ & $\begin{array}{l}\text { Number of } \\
\text { private boats } \\
\text { (nb/year) }\end{array}$ & 2362 & data & medium & $\begin{array}{l}\text { http://catalegclassicbeg.cultura. } \\
\text { gencat.cat/search } \sim \text { S50*cat }\end{array}$ \\
\hline MPA 09 & $\begin{array}{l}\text { Reserva } \\
\text { Natural } \\
\text { Parcial dels } \\
\text { Farallons } \\
\end{array}$ & $\begin{array}{l}\text { Partially } \\
\text { protected }\end{array}$ & 2.6 & $\begin{array}{l}\text { Tourism: } \\
\text { scuba-diving }\end{array}$ & $\begin{array}{l}\text { Number of } \\
\text { dives (nb/year) }\end{array}$ & 30100 & data & medium & $\begin{array}{l}\text { http://catalegclassicbeg.cultura. } \\
\text { gencat.cat/search } \sim \text { S50*cat }\end{array}$ \\
\hline MPA 09 & $\begin{array}{l}\text { Reserva } \\
\text { Natural } \\
\text { Parcial dels } \\
\text { Farallons } \\
\end{array}$ & $\begin{array}{l}\text { Partially } \\
\text { protected }\end{array}$ & 2.6 & $\begin{array}{l}\text { Trawlers/purse } \\
\text {-seiners }\end{array}$ & $\begin{array}{l}\text { Number of } \\
\text { boats (nb/year) }\end{array}$ & 0 & data & high & MPA regulations \\
\hline MPA 09 & $\begin{array}{l}\text { Reserva } \\
\text { Natural } \\
\text { Parcial del } \\
\text { Cap de } \\
\text { Creus } \\
\end{array}$ & $\begin{array}{l}\text { Partially } \\
\text { protected }\end{array}$ & 2.9 & $\begin{array}{l}\text { Artisanal } \\
\text { fishing }\end{array}$ & $\begin{array}{l}\text { Number of } \\
\text { boats (nb/year) }\end{array}$ & 12 & data & high & $\begin{array}{l}\mathrm{N}^{o} \text { of boats actually fishing } \\
\text { here }\left(\mathrm{N}^{\mathrm{o}} \text { of boats in the nearby }\right. \\
\text { ports); } \\
\text { http://catalegclassicbeg.cultura. } \\
\text { gencat.cat/search } \sim \mathrm{S} 50^{*} \text { cat }\end{array}$ \\
\hline MPA 09 & $\begin{array}{l}\text { Reserva } \\
\text { Natural } \\
\text { Parcial del } \\
\text { Cap de } \\
\text { Creus } \\
\end{array}$ & $\begin{array}{l}\text { Partially } \\
\text { protected }\end{array}$ & 2.9 & $\begin{array}{l}\text { Recreational } \\
\text { fishing: hook } \\
\text { and line }\end{array}$ & $\begin{array}{l}\text { Number of } \\
\text { people (nb/year) }\end{array}$ & 121 & data & medium & $\begin{array}{l}\text { http://catalegclassicbeg.cultura. } \\
\text { gencat.cat/search } \sim \mathrm{S} 50^{*} \text { cat }\end{array}$ \\
\hline MPA 09 & $\begin{array}{l}\text { Reserva } \\
\text { Natural } \\
\text { Parcial del } \\
\end{array}$ & $\begin{array}{l}\text { Partially } \\
\text { protected }\end{array}$ & 2.9 & $\begin{array}{l}\text { Recreational } \\
\text { fishing: } \\
\text { spearfishing }\end{array}$ & $\begin{array}{l}\text { Number of } \\
\text { people (nb/year) }\end{array}$ & 0 & data & high & MPA regulations \\
\hline
\end{tabular}




\begin{tabular}{|c|c|c|c|c|c|c|c|c|c|}
\hline & $\begin{array}{l}\text { Cap de } \\
\text { Creus }\end{array}$ & & & & & & & & \\
\hline MPA 09 & $\begin{array}{l}\text { Reserva } \\
\text { Natural } \\
\text { Parcial del } \\
\text { Cap de } \\
\text { Creus }\end{array}$ & $\begin{array}{l}\text { Partially } \\
\text { protected }\end{array}$ & 2.9 & $\begin{array}{l}\text { Tourism: } \\
\text { bathing/trampl } \\
\text { ing }\end{array}$ & $\begin{array}{l}\text { Number of } \\
\text { people (nb/year) }\end{array}$ & 6092 & data & medium & https://www.idescat.cat/ \\
\hline MPA 09 & $\begin{array}{l}\text { Reserva } \\
\text { Natural } \\
\text { Parcial del } \\
\text { Cap de } \\
\text { Creus }\end{array}$ & $\begin{array}{l}\text { Partially } \\
\text { protected }\end{array}$ & 2.9 & $\begin{array}{l}\text { Tourism: } \\
\text { commercial } \\
\text { boating }\end{array}$ & $\begin{array}{l}\text { Number of } \\
\text { commercial } \\
\text { touristic boats } \\
\text { (nb/year) }\end{array}$ & 14 & data & high & $\begin{array}{l}\text { http://es.costabrava.org/a- } \\
\text { donde-ir/transportes/cruceros- } \\
\text { maritimos }\end{array}$ \\
\hline MPA 09 & $\begin{array}{l}\text { Reserva } \\
\text { Natural } \\
\text { Parcial del } \\
\text { Cap de } \\
\text { Creus }\end{array}$ & $\begin{array}{l}\text { Partially } \\
\text { protected }\end{array}$ & 2.9 & $\begin{array}{l}\text { Tourism: } \\
\text { private } \\
\text { boating }\end{array}$ & $\begin{array}{l}\text { Number of } \\
\text { private boats } \\
\text { (nb/year) }\end{array}$ & 4841 & data & medium & http://ports.gencat.cat/es/ \\
\hline MPA 09 & $\begin{array}{l}\text { Reserva } \\
\text { Natural } \\
\text { Parcial del } \\
\text { Cap de } \\
\text { Creus } \\
\end{array}$ & $\begin{array}{l}\text { Partially } \\
\text { protected }\end{array}$ & 2.9 & $\begin{array}{l}\text { Tourism: } \\
\text { scuba-diving }\end{array}$ & $\begin{array}{l}\text { Number of } \\
\text { dives (nb/year) }\end{array}$ & 4900 & data & medium & $\begin{array}{l}\text { http://nautica.gencat.cat/ca/bus } \\
\text { seig-esbarjo/centres_immersio/ }\end{array}$ \\
\hline MPA 09 & $\begin{array}{l}\text { Reserva } \\
\text { Natural } \\
\text { Parcial del } \\
\text { Cap de } \\
\text { Creus } \\
\end{array}$ & $\begin{array}{l}\text { Partially } \\
\text { protected }\end{array}$ & 2.9 & $\begin{array}{l}\text { Trawlers/purse } \\
\text {-seiners }\end{array}$ & $\begin{array}{l}\text { Number of } \\
\text { boats (nb/year) }\end{array}$ & 0 & data & high & MPA regulations \\
\hline MPA 09 & $\begin{array}{l}\text { Reserva } \\
\text { Natural } \\
\text { Parcial del } \\
\text { Cap } \\
\text { Norfeu }\end{array}$ & $\begin{array}{l}\text { Partially } \\
\text { protected }\end{array}$ & 2.7 & $\begin{array}{l}\text { Artisanal } \\
\text { fishing }\end{array}$ & $\begin{array}{l}\text { Number of } \\
\text { boats (nb/year) }\end{array}$ & 12 & data & high & $\begin{array}{l}\mathrm{N}^{\circ} \text { of boats actually fishing } \\
\text { here ( } \mathrm{N}^{\circ} \text { of boats in the nearby } \\
\text { ports); } \\
\text { http://agricultura.gencat.cat/ca/ } \\
\text { ambits/pesca/dar_flota_pesquer } \\
\text { a/dar_estadistiques/dar_detall_ } \\
\text { flota_pesquera_per_ports/ }\end{array}$ \\
\hline MPA 09 & $\begin{array}{l}\text { Reserva } \\
\text { Natural } \\
\text { Parcial del }\end{array}$ & $\begin{array}{l}\text { Partially } \\
\text { protected }\end{array}$ & 2.7 & $\begin{array}{l}\text { Recreational } \\
\text { fishing: hook } \\
\text { and line }\end{array}$ & $\begin{array}{l}\text { Number of } \\
\text { people (nb/year) }\end{array}$ & 34 & data & medium & $\begin{array}{l}\text { http://parcsnaturals.gencat.cat/c } \\
\text { a/cap-creus/coneix- } \\
\text { nos/normativa especifica/ }\end{array}$ \\
\hline
\end{tabular}




\begin{tabular}{|c|c|c|c|c|c|c|c|c|c|}
\hline & $\begin{array}{l}\text { Cap } \\
\text { Norfeu }\end{array}$ & & & & & & & & \\
\hline MPA 09 & $\begin{array}{l}\text { Reserva } \\
\text { Natural } \\
\text { Parcial del } \\
\text { Cap } \\
\text { Norfeu }\end{array}$ & $\begin{array}{l}\text { Partially } \\
\text { protected }\end{array}$ & 2.7 & $\begin{array}{l}\text { Recreational } \\
\text { fishing: } \\
\text { spearfishing }\end{array}$ & $\begin{array}{l}\text { Number of } \\
\text { people (nb/year) }\end{array}$ & 0 & data & high & MPA regulations \\
\hline MPA 09 & $\begin{array}{l}\text { Reserva } \\
\text { Natural } \\
\text { Parcial del } \\
\text { Cap } \\
\text { Norfeu }\end{array}$ & $\begin{array}{l}\text { Partially } \\
\text { protected }\end{array}$ & 2.7 & $\begin{array}{l}\text { Tourism: } \\
\text { bathing/trampl } \\
\text { ing }\end{array}$ & $\begin{array}{l}\text { Number of } \\
\text { people (nb/year) }\end{array}$ & 2229 & data & medium & https://www.idescat.cat/ \\
\hline MPA 09 & $\begin{array}{l}\text { Reserva } \\
\text { Natural } \\
\text { Parcial del } \\
\text { Cap } \\
\text { Norfeu }\end{array}$ & $\begin{array}{l}\text { Partially } \\
\text { protected }\end{array}$ & 2.7 & $\begin{array}{l}\text { Tourism: } \\
\text { commercial } \\
\text { boating }\end{array}$ & $\begin{array}{l}\text { Number of } \\
\text { commercial } \\
\text { touristic boats } \\
\text { (nb/year) }\end{array}$ & 14 & data & high & $\begin{array}{l}\text { http://es.costabrava.org/a- } \\
\text { donde-ir/transportes/cruceros- } \\
\underline{\text { maritimos }}\end{array}$ \\
\hline MPA 09 & $\begin{array}{l}\text { Reserva } \\
\text { Natural } \\
\text { Parcial del } \\
\text { Cap } \\
\text { Norfeu }\end{array}$ & $\begin{array}{l}\text { Partially } \\
\text { protected }\end{array}$ & 2.7 & $\begin{array}{l}\text { Tourism: } \\
\text { private } \\
\text { boating }\end{array}$ & $\begin{array}{l}\text { Number of } \\
\text { private boats } \\
\text { (nb/year) }\end{array}$ & $\begin{array}{r}1771.2 \\
76596\end{array}$ & data & medium & http://ports.gencat.cat/es/ \\
\hline MPA 09 & $\begin{array}{l}\text { Reserva } \\
\text { Natural } \\
\text { Parcial del } \\
\text { Cap } \\
\text { Norfeu }\end{array}$ & $\begin{array}{l}\text { Partially } \\
\text { protected }\end{array}$ & 2.7 & $\begin{array}{l}\text { Tourism: } \\
\text { scuba-diving }\end{array}$ & $\begin{array}{l}\text { Number of } \\
\text { dives (nb/year) }\end{array}$ & 4200 & data & medium & $\begin{array}{l}\text { http://nautica.gencat.cat/ca/bus } \\
\underline{\text { seig-esbarjo/centres immersio/ }}\end{array}$ \\
\hline MPA 09 & $\begin{array}{l}\text { Reserva } \\
\text { Natural } \\
\text { Parcial del } \\
\text { Cap } \\
\text { Norfeu }\end{array}$ & $\begin{array}{l}\text { Partially } \\
\text { protected }\end{array}$ & 2.7 & $\begin{array}{l}\text { Trawlers/purse } \\
\text {-seiners }\end{array}$ & $\begin{array}{l}\text { Number of } \\
\text { boats (nb/year) }\end{array}$ & 0 & data & high & MPA regulations \\
\hline MPA 09 & $\begin{array}{l}\text { Parc } \\
\text { Natural } \\
\text { Cap Gros }\end{array}$ & $\begin{array}{l}\text { Partially } \\
\text { protected }\end{array}$ & 7.1 & $\begin{array}{l}\text { Artisanal } \\
\text { fishing }\end{array}$ & $\begin{array}{l}\text { Number of } \\
\text { boats (nb/year) }\end{array}$ & 12 & data & high & $\begin{array}{l}\mathrm{N}^{\circ} \text { of boats actually fishing } \\
\text { here }\left(\mathrm{N}^{\circ} \text { of boats in the nearby }\right. \\
\text { ports); } \\
\text { http://parcsnaturals.gencat.cat/c } \\
\text { a/cap-creus/coneix- } \\
\text { nos/normativa_especifica/ }\end{array}$ \\
\hline
\end{tabular}




\begin{tabular}{|c|c|c|c|c|c|c|c|c|c|}
\hline MPA 09 & $\begin{array}{l}\text { Parc } \\
\text { Natural } \\
\text { Cap Gros }\end{array}$ & $\begin{array}{l}\text { Partially } \\
\text { protected }\end{array}$ & 7.1 & $\begin{array}{l}\text { Recreational } \\
\text { fishing: hook } \\
\text { and line }\end{array}$ & $\begin{array}{l}\text { Number of } \\
\text { people (nb/year) }\end{array}$ & 89 & data & medium & $\begin{array}{l}\text { http://parcsnaturals.gencat.cat/c } \\
\text { a/cap-creus/coneix- } \\
\text { nos/normativa especifica/ }\end{array}$ \\
\hline MPA 09 & $\begin{array}{l}\text { Parc } \\
\text { Natural } \\
\text { Cap Gros }\end{array}$ & $\begin{array}{l}\text { Partially } \\
\text { protected }\end{array}$ & 7.1 & $\begin{array}{l}\text { Recreational } \\
\text { fishing: } \\
\text { spearfishing }\end{array}$ & $\begin{array}{l}\text { Number of } \\
\text { people (nb/year) }\end{array}$ & 17 & data & high & $\begin{array}{l}\text { http://parcsnaturals.gencat.cat/c } \\
\text { a/cap-creus/coneix- } \\
\text { nos/normativa especifica/ }\end{array}$ \\
\hline MPA 09 & $\begin{array}{l}\text { Parc } \\
\text { Natural } \\
\text { Cap Gros }\end{array}$ & $\begin{array}{l}\text { Partially } \\
\text { protected }\end{array}$ & 7.1 & $\begin{array}{l}\text { Tourism: } \\
\text { bathing/trampl } \\
\text { ing }\end{array}$ & $\begin{array}{l}\text { Number of } \\
\text { people (nb/year) }\end{array}$ & 7429 & data & medium & https://www.idescat.cat/ \\
\hline MPA 09 & $\begin{array}{l}\text { Parc } \\
\text { Natural } \\
\text { Cap Gros }\end{array}$ & $\begin{array}{l}\text { Partially } \\
\text { protected }\end{array}$ & 7.1 & $\begin{array}{l}\text { Tourism: } \\
\text { commercial } \\
\text { boating }\end{array}$ & $\begin{array}{l}\text { Number of } \\
\text { commercial } \\
\text { touristic boats } \\
\text { (nb/year) }\end{array}$ & 14 & data & high & $\begin{array}{l}\text { http://es.costabrava.org/a- } \\
\text { donde-ir/transportes/cruceros- } \\
\underline{\text { maritimos }}\end{array}$ \\
\hline MPA 09 & $\begin{array}{l}\text { Parc } \\
\text { Natural } \\
\text { Cap Gros }\end{array}$ & $\begin{array}{l}\text { Partially } \\
\text { protected }\end{array}$ & 7.1 & $\begin{array}{l}\text { Tourism: } \\
\text { private } \\
\text { boating }\end{array}$ & $\begin{array}{l}\text { Number of } \\
\text { private boats } \\
\text { (nb/year) }\end{array}$ & $\begin{array}{r}5904.2 \\
55319\end{array}$ & data & medium & http://ports.gencat.cat/es/ \\
\hline MPA 09 & $\begin{array}{l}\text { Parc } \\
\text { Natural } \\
\text { Cap Gros } \\
\end{array}$ & $\begin{array}{l}\text { Partially } \\
\text { protected }\end{array}$ & 7.1 & $\begin{array}{l}\text { Tourism: } \\
\text { scuba-diving }\end{array}$ & $\begin{array}{l}\text { Number of } \\
\text { dives (nb/year) }\end{array}$ & 7000 & data & medium & $\begin{array}{l}\text { http://nautica.gencat.cat/ca/bus } \\
\text { seig-esbarjo/centres_immersio/ }\end{array}$ \\
\hline MPA 09 & $\begin{array}{l}\text { Parc } \\
\text { Natural } \\
\text { Cap Gros }\end{array}$ & $\begin{array}{l}\text { Partially } \\
\text { protected }\end{array}$ & 7.1 & $\begin{array}{l}\text { Trawlers/purse } \\
\text {-seiners }\end{array}$ & $\begin{array}{l}\text { Number of } \\
\text { boats (nb/year) }\end{array}$ & 0 & data & high & MPA regulations \\
\hline MPA 09 & $\begin{array}{l}\text { Parc } \\
\text { Natural } \\
\text { Cap de } \\
\text { Creus }\end{array}$ & $\begin{array}{l}\text { Partially } \\
\text { protected }\end{array}$ & 2.3 & $\begin{array}{l}\text { Artisanal } \\
\text { fishing }\end{array}$ & $\begin{array}{l}\text { Number of } \\
\text { boats (nb/year) }\end{array}$ & 12 & data & high & $\begin{array}{l}\mathrm{N}^{\mathrm{o}} \text { of boats actually fishing } \\
\text { here }\left(\mathrm{N}^{\mathrm{o}} \text { of boats in the nearby }\right. \\
\text { ports); } \\
\text { http://parcsnaturals.gencat.cat/c } \\
\text { a/cap-creus/coneix- } \\
\text { nos/normativa_especifica/ }\end{array}$ \\
\hline MPA 09 & $\begin{array}{l}\text { Parc } \\
\text { Natural } \\
\text { Cap de } \\
\text { Creus } \\
\end{array}$ & $\begin{array}{l}\text { Partially } \\
\text { protected }\end{array}$ & 2.3 & $\begin{array}{l}\text { Recreational } \\
\text { fishing: hook } \\
\text { and line }\end{array}$ & $\begin{array}{l}\text { Number of } \\
\text { people (nb/year) }\end{array}$ & 26 & data & medium & $\begin{array}{l}\text { http://parcsnaturals.gencat.cat/c } \\
\text { a/cap-creus/coneix- } \\
\text { nos/normativa_especifica/ }\end{array}$ \\
\hline MPA 09 & $\begin{array}{l}\text { Parc } \\
\text { Natural } \\
\text { Cap de } \\
\text { Creus } \\
\end{array}$ & $\begin{array}{l}\text { Partially } \\
\text { protected }\end{array}$ & 2.3 & $\begin{array}{l}\text { Recreational } \\
\text { fishing: } \\
\text { spearfishing }\end{array}$ & $\begin{array}{l}\text { Number of } \\
\text { people (nb/year) }\end{array}$ & 13 & data & high & $\begin{array}{l}\text { http://parcsnaturals.gencat.cat/c } \\
\text { a/cap-creus/coneix- } \\
\text { nos/normativa_especifica/ }\end{array}$ \\
\hline
\end{tabular}




\begin{tabular}{|c|c|c|c|c|c|c|c|c|c|}
\hline MPA 09 & $\begin{array}{l}\text { Parc } \\
\text { Natural } \\
\text { Cap de } \\
\text { Creus }\end{array}$ & $\begin{array}{l}\text { Partially } \\
\text { protected }\end{array}$ & 2.3 & $\begin{array}{l}\text { Tourism: } \\
\text { bathing/trampl } \\
\text { ing }\end{array}$ & $\begin{array}{l}\text { Number of } \\
\text { people (nb/year) }\end{array}$ & 3269 & data & medium & https://www.idescat.cat/ \\
\hline MPA 09 & $\begin{array}{l}\text { Parc } \\
\text { Natural } \\
\text { Cap de } \\
\text { Creus } \\
\end{array}$ & $\begin{array}{l}\text { Partially } \\
\text { protected }\end{array}$ & 2.3 & $\begin{array}{l}\text { Tourism: } \\
\text { commercial } \\
\text { boating }\end{array}$ & $\begin{array}{l}\text { Number of } \\
\text { commercial } \\
\text { touristic boats } \\
\text { (nb/year) }\end{array}$ & 14 & data & high & $\begin{array}{l}\text { http://es.costabrava.org/a- } \\
\underline{\text { donde-ir/transportes/cruceros- }} \\
\underline{\text { maritimos }}\end{array}$ \\
\hline MPA 09 & $\begin{array}{l}\text { Parc } \\
\text { Natural } \\
\text { Cap de } \\
\text { Creus } \\
\end{array}$ & $\begin{array}{l}\text { Partially } \\
\text { protected }\end{array}$ & 2.3 & $\begin{array}{l}\text { Tourism: } \\
\text { private } \\
\text { boating }\end{array}$ & $\begin{array}{l}\text { Number of } \\
\text { private boats } \\
\text { (nb/year) }\end{array}$ & $\begin{array}{r}2597.8 \\
7234\end{array}$ & data & medium & $\underline{\text { http://ports.gencat.cat/es/ }}$ \\
\hline MPA 09 & $\begin{array}{l}\text { Parc } \\
\text { Natural } \\
\text { Cap de } \\
\text { Creus } \\
\end{array}$ & $\begin{array}{l}\text { Partially } \\
\text { protected }\end{array}$ & 2.3 & $\begin{array}{l}\text { Tourism: } \\
\text { scuba-diving }\end{array}$ & $\begin{array}{l}\text { Number of } \\
\text { dives (nb/year) }\end{array}$ & 0 & data & medium & $\begin{array}{l}\text { http://nautica.gencat.cat/ca/bus } \\
\text { seig-esbarjo/centres immersio/ }\end{array}$ \\
\hline MPA 09 & $\begin{array}{l}\text { Parc } \\
\text { Natural } \\
\text { Cap de } \\
\text { Creus } \\
\end{array}$ & $\begin{array}{l}\text { Partially } \\
\text { protected }\end{array}$ & 2.3 & $\begin{array}{l}\text { Trawlers/purse } \\
\text {-seiners }\end{array}$ & $\begin{array}{l}\text { Number of } \\
\text { boats (nb/year) }\end{array}$ & 0 & data & high & MPA regulations \\
\hline MPA 09 & $\begin{array}{l}\text { arc Natural } \\
\text { Cadaques }\end{array}$ & $\begin{array}{l}\text { Partially } \\
\text { protected }\end{array}$ & 9.6 & $\begin{array}{l}\text { Artisanal } \\
\text { fishing }\end{array}$ & $\begin{array}{l}\text { Number of } \\
\text { boats (nb/year) }\end{array}$ & 12 & data & high & $\begin{array}{l}\mathrm{N}^{\mathrm{o}} \text { of boats actually fishing } \\
\text { here }\left(\mathrm{N}^{\mathrm{o}} \text { of boats in the nearby }\right. \\
\text { ports); } \\
\text { http://parcsnaturals.gencat.cat/c } \\
\text { a/cap-creus/coneix- } \\
\text { nos/normativa_especifica/ }\end{array}$ \\
\hline MPA 09 & $\begin{array}{l}\text { arc Natural } \\
\text { Cadaques }\end{array}$ & $\begin{array}{l}\text { Partially } \\
\text { protected }\end{array}$ & 9.6 & $\begin{array}{l}\text { Recreational } \\
\text { fishing: hook } \\
\text { and line }\end{array}$ & $\begin{array}{l}\text { Number of } \\
\text { people (nb/year) }\end{array}$ & 149 & data & medium & $\begin{array}{l}\text { http://parcsnaturals.gencat.cat/c } \\
\text { a/cap-creus/coneix- } \\
\text { nos/centre de documentacio/p } \\
\text { nat cc fons documental/biblio } \\
\text { teca digital/medi mari/ }\end{array}$ \\
\hline MPA 09 & $\begin{array}{l}\text { arc Natural } \\
\text { Cadaques }\end{array}$ & $\begin{array}{l}\text { Partially } \\
\text { protected }\end{array}$ & 9.6 & $\begin{array}{l}\text { Recreational } \\
\text { fishing: } \\
\text { spearfishing }\end{array}$ & $\begin{array}{l}\text { Number of } \\
\text { people (nb/year) }\end{array}$ & 23 & data & high & $\begin{array}{l}\text { http://parcsnaturals.gencat.cat/c } \\
\text { a/cap-creus/coneix- } \\
\text { nos/centre de documentacio/p } \\
\text { nat_cc fons_documental/biblio } \\
\text { teca_digital/medi_mari/ }\end{array}$ \\
\hline
\end{tabular}




\begin{tabular}{|c|c|c|c|c|c|c|c|c|c|}
\hline MPA 09 & $\begin{array}{l}\text { arc Natural } \\
\text { Cadaques }\end{array}$ & $\begin{array}{l}\text { Partially } \\
\text { protected }\end{array}$ & 9.6 & $\begin{array}{l}\text { Tourism: } \\
\text { bathing/trampl } \\
\text { ing }\end{array}$ & $\begin{array}{l}\text { Number of } \\
\text { people (nb/year) }\end{array}$ & 15750 & data & medium & https://www.idescat.cat/ \\
\hline MPA 09 & $\begin{array}{l}\text { arc Natural } \\
\text { Cadaques }\end{array}$ & $\begin{array}{l}\text { Partially } \\
\text { protected }\end{array}$ & 9.6 & $\begin{array}{l}\text { Tourism: } \\
\text { commercial } \\
\text { boating }\end{array}$ & $\begin{array}{l}\text { Number of } \\
\text { commercial } \\
\text { touristic boats } \\
\text { (nb/year) }\end{array}$ & 14 & data & high & $\begin{array}{l}\text { http://es.costabrava.org/a- } \\
\text { donde-ir/transportes/cruceros- } \\
\underline{\text { maritimos }}\end{array}$ \\
\hline MPA 09 & $\begin{array}{l}\text { arc Natural } \\
\text { Cadaques }\end{array}$ & $\begin{array}{l}\text { Partially } \\
\text { protected }\end{array}$ & 9.6 & $\begin{array}{l}\text { Tourism: } \\
\text { private } \\
\text { boating }\end{array}$ & $\begin{array}{l}\text { Number of } \\
\text { private boats } \\
\text { (nb/year) }\end{array}$ & $\begin{array}{r}12517 . \\
02128\end{array}$ & data & medium & http://ports.gencat.cat/es/ \\
\hline MPA 09 & $\begin{array}{l}\text { arc Natural } \\
\text { Cadaques }\end{array}$ & $\begin{array}{l}\text { Partially } \\
\text { protected }\end{array}$ & 9.6 & $\begin{array}{l}\text { Tourism: } \\
\text { scuba-diving }\end{array}$ & $\begin{array}{l}\text { Number of } \\
\text { dives (nb/year) }\end{array}$ & 7000 & data & medium & $\begin{array}{l}\text { http://nautica.gencat.cat/ca/bus } \\
\text { seig-esbarjo/centres immersio/ }\end{array}$ \\
\hline MPA 09 & $\begin{array}{l}\text { arc Natural } \\
\text { Cadaques }\end{array}$ & $\begin{array}{l}\text { Partially } \\
\text { protected }\end{array}$ & 9.6 & $\begin{array}{l}\text { Trawlers/purse } \\
\text {-seiners }\end{array}$ & $\begin{array}{l}\text { Number of } \\
\text { boats (nb/year) }\end{array}$ & 0 & data & high & MPA regulations \\
\hline MPA 09 & $\begin{array}{l}\text { Parc } \\
\text { Natural } \\
\text { Cap } \\
\text { Norfeu }\end{array}$ & $\begin{array}{l}\text { Partially } \\
\text { protected }\end{array}$ & 3.3 & $\begin{array}{l}\text { Artisanal } \\
\text { fishing }\end{array}$ & $\begin{array}{l}\text { Number of } \\
\text { boats (nb/year) }\end{array}$ & 12 & data & high & $\begin{array}{l}\mathrm{N}^{\mathrm{o}} \text { of boats actually fishing } \\
\text { here ( } \mathrm{N}^{\mathrm{o}} \text { of boats in the nearby } \\
\text { ports); } \\
\text { http://parcsnaturals.gencat.cat/c } \\
\text { a/cap-creus/coneix- } \\
\text { nos/normativa especifica/ }\end{array}$ \\
\hline MPA 09 & $\begin{array}{l}\text { Parc } \\
\text { Natural } \\
\text { Cap } \\
\text { Norfeu }\end{array}$ & $\begin{array}{l}\text { Partially } \\
\text { protected }\end{array}$ & 3.3 & $\begin{array}{l}\text { Recreational } \\
\text { fishing: hook } \\
\text { and line }\end{array}$ & $\begin{array}{l}\text { Number of } \\
\text { people (nb/year) }\end{array}$ & 180 & data & medium & $\begin{array}{l}\text { http://parcsnaturals.gencat.cat/c } \\
\text { a/cap-creus/coneix- } \\
\text { nos/centre de documentacio/p } \\
\text { nat cc fons documental } / \text { biblio } \\
\text { teca digital } / \text { medi mari/ }\end{array}$ \\
\hline MPA 09 & $\begin{array}{l}\text { Parc } \\
\text { Natural } \\
\text { Cap } \\
\text { Norfeu }\end{array}$ & $\begin{array}{l}\text { Partially } \\
\text { protected }\end{array}$ & 3.3 & $\begin{array}{l}\text { Recreational } \\
\text { fishing: } \\
\text { spearfishing }\end{array}$ & $\begin{array}{l}\text { Number of } \\
\text { people (nb/year) }\end{array}$ & 29 & data & high & $\begin{array}{l}\text { http://parcsnaturals.gencat.cat/c } \\
\text { a/cap-creus/coneix- } \\
\text { nos/centre de documentacio/p } \\
\text { nat cc fons documental/biblio } \\
\text { teca digital/medi mari/ }\end{array}$ \\
\hline MPA 09 & $\begin{array}{l}\text { Parc } \\
\text { Natural } \\
\text { Cap } \\
\text { Norfeu }\end{array}$ & $\begin{array}{l}\text { Partially } \\
\text { protected }\end{array}$ & 3.3 & $\begin{array}{l}\text { Tourism: } \\
\text { bathing/trampl } \\
\text { ing }\end{array}$ & $\begin{array}{l}\text { Number of } \\
\text { people (nb/year) }\end{array}$ & 18127 & data & medium & https://www.idescat.cat/ \\
\hline MPA 09 & $\begin{array}{l}\text { Parc } \\
\text { Natural } \\
\text { Cap } \\
\text { Norfeu }\end{array}$ & $\begin{array}{l}\text { Partially } \\
\text { protected }\end{array}$ & 3.3 & $\begin{array}{l}\text { Tourism: } \\
\text { commercial } \\
\text { boating }\end{array}$ & $\begin{array}{l}\text { Number of } \\
\text { commercial } \\
\text { touristic boats } \\
\text { (nb/year) }\end{array}$ & 14 & data & high & $\begin{array}{l}\text { http://es.costabrava.org/a- } \\
\text { donde-ir/transportes/cruceros- } \\
\text { maritimos }\end{array}$ \\
\hline
\end{tabular}




\begin{tabular}{|c|c|c|c|c|c|c|c|c|c|}
\hline MPA 09 & $\begin{array}{l}\text { Parc } \\
\text { Natural } \\
\text { Cap } \\
\text { Norfeu } \\
\end{array}$ & $\begin{array}{l}\text { Partially } \\
\text { protected }\end{array}$ & 3.3 & $\begin{array}{l}\text { Tourism: } \\
\text { private } \\
\text { boating }\end{array}$ & $\begin{array}{l}\text { Number of } \\
\text { private boats } \\
\text { (nb/year) }\end{array}$ & $\begin{array}{r}14406 . \\
38298\end{array}$ & data & medium & http://ports.gencat.cat/es/ \\
\hline MPA 09 & $\begin{array}{l}\text { Parc } \\
\text { Natural } \\
\text { Cap } \\
\text { Norfeu }\end{array}$ & $\begin{array}{l}\text { Partially } \\
\text { protected }\end{array}$ & 3.3 & $\begin{array}{l}\text { Tourism: } \\
\text { scuba-diving }\end{array}$ & $\begin{array}{l}\text { Number of } \\
\text { dives (nb/year) }\end{array}$ & 8400 & data & medium & $\begin{array}{l}\text { http://nautica.gencat.cat/ca/bus } \\
\text { seig-esbarjo/centres_immersio/ }\end{array}$ \\
\hline MPA 09 & $\begin{array}{l}\text { Parc } \\
\text { Natural } \\
\text { Cap } \\
\text { Norfeu }\end{array}$ & $\begin{array}{l}\text { Partially } \\
\text { protected }\end{array}$ & 3.3 & $\begin{array}{l}\text { Trawlers/purse } \\
\text {-seiners }\end{array}$ & $\begin{array}{l}\text { Number of } \\
\text { boats (nb/year) }\end{array}$ & 0 & data & high & MPA regulations \\
\hline MPA 09 & Outside & Outside & 76.52 & $\begin{array}{l}\text { Artisanal } \\
\text { fishing }\end{array}$ & $\begin{array}{l}\text { Number of } \\
\text { boats (nb/year) }\end{array}$ & 57 & data & high & $\begin{array}{l}\mathrm{N}^{\circ} \text { of boats in the nearby ports } \\
\text { (Roses, Port de la Selva \& } \\
\text { Llançà); } \\
\text { http://agricultura.gencat.cat/ca/ } \\
\text { ambits/pesca/dar_flota_pesquer } \\
\text { a/dar_estadistiques/dar_detall_ } \\
\text { flota_pesquera_per_ports/ }\end{array}$ \\
\hline MPA 09 & Outside & Outside & 76.52 & $\begin{array}{l}\text { Recreational } \\
\text { fishing: hook } \\
\text { and line }\end{array}$ & $\begin{array}{l}\text { Number of } \\
\text { people (nb/year) }\end{array}$ & 600 & $\begin{array}{l}\text { expert } \\
\text { opinion }\end{array}$ & low & Estimated \\
\hline MPA 09 & Outside & Outside & 76.52 & $\begin{array}{l}\text { Recreational } \\
\text { fishing: } \\
\text { spearfishing }\end{array}$ & $\begin{array}{l}\text { Number of } \\
\text { people (nb/year) }\end{array}$ & 60 & $\begin{array}{l}\text { expert } \\
\text { opinion }\end{array}$ & low & $\begin{array}{l}\text { Estimated (only rocy coasts } \\
\text { have been taken into account) }\end{array}$ \\
\hline MPA 09 & Outside & Outside & 76.52 & $\begin{array}{l}\text { Tourism: } \\
\text { bathing/trampl } \\
\text { ing }\end{array}$ & $\begin{array}{l}\text { Number of } \\
\text { people (nb/year) }\end{array}$ & 650000 & $\begin{array}{l}\text { expert } \\
\text { opinion }\end{array}$ & low & $\begin{array}{l}\text { Including sandy beaches; } \\
\text { https://www.idescat.cat/ }\end{array}$ \\
\hline MPA 09 & Outside & Outside & 76.52 & $\begin{array}{l}\text { Tourism: } \\
\text { commercial } \\
\text { boating }\end{array}$ & $\begin{array}{l}\text { Number of } \\
\text { commercial } \\
\text { touristic boats } \\
\text { (nb/year) }\end{array}$ & 14 & data & high & $\begin{array}{l}\text { http://es.costabrava.org/a- } \\
\text { donde-ir/transportes/cruceros- } \\
\underline{\text { maritimos }}\end{array}$ \\
\hline MPA 09 & Outside & Outside & 76.52 & $\begin{array}{l}\text { Tourism: } \\
\text { private } \\
\text { boating }\end{array}$ & $\begin{array}{l}\text { Number of } \\
\text { private boats } \\
\text { (nb/year) }\end{array}$ & 10000 & $\begin{array}{l}\text { expert } \\
\text { opinion }\end{array}$ & low & http://ports.gencat.cat/es/ \\
\hline MPA 09 & Outside & Outside & 76.52 & $\begin{array}{l}\text { Tourism: } \\
\text { scuba-diving }\end{array}$ & $\begin{array}{l}\text { Number of } \\
\text { dives (nb/year) }\end{array}$ & 150 & $\begin{array}{l}\text { expert } \\
\text { opinion }\end{array}$ & low & $\begin{array}{l}\text { http://nautica.gencat.cat/ca/bus } \\
\text { seig-esbarjo/centres immersio/ }\end{array}$ \\
\hline
\end{tabular}




\begin{tabular}{|c|c|c|c|c|c|c|c|c|c|}
\hline MPA 09 & Outside & Outside & 557.97 & $\begin{array}{l}\text { Trawlers/purse } \\
\text {-seiners }\end{array}$ & $\begin{array}{l}\text { Number of } \\
\text { boats (nb/year) }\end{array}$ & 44 & data & high & $\begin{array}{l}\mathrm{N}^{\circ} \text { of boats in the nearby ports } \\
\text { (Roses, Port de la Selva \& } \\
\text { Llançà); } \\
\text { http://agricultura.gencat.cat/ca/ } \\
\text { ambits/pesca/dar_flota_pesquer } \\
\text { a/dar_estadistiques/dar_detall_ } \\
\text { flota_pesquera_per_ports/ }\end{array}$ \\
\hline MPA 10 & $\begin{array}{l}\text { Reserva } \\
\text { Natural } \\
\text { Parcial de } \\
\text { les Illes } \\
\text { Medes }\end{array}$ & No-take & 1.003 & $\begin{array}{l}\text { Artisanal } \\
\text { fishing }\end{array}$ & $\begin{array}{l}\text { Number of } \\
\text { boats (nb/year) }\end{array}$ & 0 & data & high & MPA regulations \\
\hline MPA 10 & $\begin{array}{l}\text { Reserva } \\
\text { Natural } \\
\text { Parcial de } \\
\text { les Illes } \\
\text { Medes }\end{array}$ & No-take & 1.003 & $\begin{array}{l}\text { Recreational } \\
\text { fishing: hook } \\
\text { and line }\end{array}$ & $\begin{array}{l}\text { Number of } \\
\text { people (nb/year) }\end{array}$ & 0 & data & high & MPA regulations \\
\hline MPA 10 & $\begin{array}{l}\text { Reserva } \\
\text { Natural } \\
\text { Parcial de } \\
\text { les Illes } \\
\text { Medes }\end{array}$ & No-take & 1.003 & $\begin{array}{l}\text { Recreational } \\
\text { fishing: } \\
\text { spearfishing }\end{array}$ & $\begin{array}{l}\text { Number of } \\
\text { people (nb/year) }\end{array}$ & 0 & data & high & MPA regulations \\
\hline MPA 10 & $\begin{array}{l}\text { Reserva } \\
\text { Natural } \\
\text { Parcial de } \\
\text { les Illes } \\
\text { Medes }\end{array}$ & No-take & 1.003 & $\begin{array}{l}\text { Tourism: } \\
\text { bathing/trampl } \\
\text { ing }\end{array}$ & $\begin{array}{l}\text { Number of } \\
\text { people (nb/year) }\end{array}$ & 25000 & data & medium & $\begin{array}{l}\text { Estimated from } \\
\text { https://www.idescat.cat/ }\end{array}$ \\
\hline MPA 10 & $\begin{array}{l}\text { Reserva } \\
\text { Natural } \\
\text { Parcial de } \\
\text { les Illes } \\
\text { Medes } \\
\end{array}$ & No-take & 1.003 & $\begin{array}{l}\text { Tourism: } \\
\text { commercial } \\
\text { boating }\end{array}$ & $\begin{array}{l}\text { Number of } \\
\text { commercial } \\
\text { touristic boats } \\
\text { (nb/year) }\end{array}$ & 17 & data & high & $\begin{array}{l}\text { Official data }(2011) \text {; } \\
\text { http://es.costabrava.org/a- } \\
\text { donde-ir/transportes/cruceros- } \\
\text { maritimos }\end{array}$ \\
\hline MPA 10 & $\begin{array}{l}\text { Reserva } \\
\text { Natural } \\
\text { Parcial de } \\
\text { les Illes } \\
\text { Medes } \\
\end{array}$ & No-take & 1.003 & $\begin{array}{l}\text { Tourism: } \\
\text { private } \\
\text { boating }\end{array}$ & $\begin{array}{l}\text { Number of } \\
\text { private boats } \\
\text { (nb/year) }\end{array}$ & 17000 & $\begin{array}{l}\text { expert } \\
\text { opinion }\end{array}$ & low & $\begin{array}{l}\text { Estimated from } \\
\text { http://ports.gencat.cat/es/ }\end{array}$ \\
\hline
\end{tabular}




\begin{tabular}{|c|c|c|c|c|c|c|c|c|c|}
\hline MPA 10 & $\begin{array}{l}\text { Reserva } \\
\text { Natural } \\
\text { Parcial de } \\
\text { les Illes } \\
\text { Medes } \\
\end{array}$ & No-take & 1.003 & $\begin{array}{l}\text { Tourism: } \\
\text { scuba-diving }\end{array}$ & $\begin{array}{l}\text { Number of } \\
\text { dives (nb/year) }\end{array}$ & 67000 & data & medium & $\begin{array}{l}\text { Official data (2011); } \\
\text { http://parcsnaturals.gencat.cat/c } \\
\text { a/illes-medes/coneixeu- } \\
\text { nos/normativa_especifica/ }\end{array}$ \\
\hline MPA 10 & $\begin{array}{l}\text { Reserva } \\
\text { Natural } \\
\text { Parcial de } \\
\text { les Illes } \\
\text { Medes }\end{array}$ & No-take & 1.003 & $\begin{array}{l}\text { Trawlers/purse } \\
\text {-seiners }\end{array}$ & $\begin{array}{l}\text { Number of } \\
\text { boats (nb/year) }\end{array}$ & 0 & data & high & MPA regulations \\
\hline MPA 10 & $\begin{array}{l}\text { Zona } \\
\text { Perifirica } \\
\text { de la RNP } \\
\text { marina }\end{array}$ & $\begin{array}{l}\text { Partially } \\
\text { protected }\end{array}$ & 4.79 & $\begin{array}{l}\text { Artisanal } \\
\text { fishing }\end{array}$ & $\begin{array}{l}\text { Number of } \\
\text { boats (nb/year) }\end{array}$ & 15 & data & high & $\begin{array}{l}\text { Official data } \\
\text { http://parcsnaturals.gencat.cat/c } \\
\text { a/illes-medes/coneixeu- } \\
\text { nos/normativa especifica/ }\end{array}$ \\
\hline MPA 10 & $\begin{array}{l}\text { Zona } \\
\text { Perifirica } \\
\text { de la RNP } \\
\text { marina }\end{array}$ & $\begin{array}{l}\text { Partially } \\
\text { protected }\end{array}$ & 4.79 & $\begin{array}{l}\text { Recreational } \\
\text { fishing: hook } \\
\text { and line }\end{array}$ & $\begin{array}{l}\text { Number of } \\
\text { people (nb/year) }\end{array}$ & 950 & data & medium & $\begin{array}{l}\text { Font T., Lloret J., Piante C. } \\
\text { 2012. Recreational fishing } \\
\text { within Marine Protected Areas } \\
\text { in the Mediterranean. MedPAN } \\
\text { North Project. WWFFrance. }\end{array}$ \\
\hline MPA 10 & $\begin{array}{l}\text { Zona } \\
\text { Perifirica } \\
\text { de la RNP } \\
\text { marina }\end{array}$ & $\begin{array}{l}\text { Partially } \\
\text { protected }\end{array}$ & 4.79 & $\begin{array}{l}\text { Recreational } \\
\text { fishing: } \\
\text { spearfishing }\end{array}$ & $\begin{array}{l}\text { Number of } \\
\text { people (nb/year) }\end{array}$ & 0 & data & medium & $\begin{array}{l}\text { Font T., Lloret J., Piante C. } \\
\text { 2012. Recreational fishing } \\
\text { within Marine Protected Areas } \\
\text { in the Mediterranean. MedPAN } \\
\text { North Project. WWFFrance. }\end{array}$ \\
\hline MPA 10 & $\begin{array}{l}\text { Zona } \\
\text { Perifirica } \\
\text { de la RNP } \\
\text { marina } \\
\end{array}$ & $\begin{array}{l}\text { Partially } \\
\text { protected }\end{array}$ & 4.79 & $\begin{array}{l}\text { Tourism: } \\
\text { bathing/trampl } \\
\text { ing }\end{array}$ & $\begin{array}{l}\text { Number of } \\
\text { people (nb/year) }\end{array}$ & 1000 & $\begin{array}{l}\text { expert } \\
\text { opinion }\end{array}$ & low & $\begin{array}{l}\text { Estimated from } \\
\text { https://www.idescat.cat/ }\end{array}$ \\
\hline MPA 10 & $\begin{array}{l}\text { Zona } \\
\text { Perifirica } \\
\text { de la RNP } \\
\text { marina } \\
\end{array}$ & $\begin{array}{l}\text { Partially } \\
\text { protected }\end{array}$ & 4.79 & $\begin{array}{l}\text { Tourism: } \\
\text { commercial } \\
\text { boating }\end{array}$ & $\begin{array}{l}\text { Number of } \\
\text { commercial } \\
\text { touristic boats } \\
\text { (nb/year) }\end{array}$ & 17 & data & high & $\begin{array}{l}\text { http://es.costabrava.org/a- } \\
\text { donde-ir/transportes/cruceros- } \\
\underline{\text { maritimos }}\end{array}$ \\
\hline MPA 10 & $\begin{array}{l}\text { Zona } \\
\text { Perifirica } \\
\text { de la RNP } \\
\text { marina }\end{array}$ & $\begin{array}{l}\text { Partially } \\
\text { protected }\end{array}$ & 4.79 & $\begin{array}{l}\text { Tourism: } \\
\text { private } \\
\text { boating }\end{array}$ & $\begin{array}{l}\text { Number of } \\
\text { private boats } \\
\text { (nb/year) }\end{array}$ & 500 & $\begin{array}{l}\text { expert } \\
\text { opinion }\end{array}$ & medium & $\begin{array}{l}\text { Estimated from } \\
\text { http://ports.gencat.cat/es/ }\end{array}$ \\
\hline
\end{tabular}




\begin{tabular}{|c|c|c|c|c|c|c|c|c|c|}
\hline MPA 10 & $\begin{array}{l}\text { Zona } \\
\text { Perifirica } \\
\text { de la RNP } \\
\text { marina }\end{array}$ & $\begin{array}{l}\text { Partially } \\
\text { protected }\end{array}$ & 4.79 & $\begin{array}{l}\text { Tourism: } \\
\text { scuba-diving }\end{array}$ & $\begin{array}{l}\text { Number of } \\
\text { dives (nb/year) }\end{array}$ & 75 & $\begin{array}{l}\text { expert } \\
\text { opinion }\end{array}$ & low & $\begin{array}{l}\text { Estimated from } \\
\text { http://nautica.gencat.cat/ca/bus } \\
\text { seig-esbarjo/centres_immersio/ }\end{array}$ \\
\hline MPA 10 & $\begin{array}{l}\text { Zona } \\
\text { Perifirica } \\
\text { de la RNP } \\
\text { marina }\end{array}$ & $\begin{array}{l}\text { Partially } \\
\text { protected }\end{array}$ & 4.79 & $\begin{array}{l}\text { Trawlers/purse } \\
\text {-seiners }\end{array}$ & $\begin{array}{l}\text { Number of } \\
\text { boats (nb/year) }\end{array}$ & 0 & data & high & $\begin{array}{l}\text { http://agricultura.gencat.cat/ca/ } \\
\text { ambits/pesca/dar_flota_pesquer } \\
\text { a/dar_estadistiques/dar_detall } \\
\text { flota pesquera per ports/ }\end{array}$ \\
\hline MPA 10 & $\begin{array}{l}\text { Parc } \\
\text { Natural } \\
\text { Mari }\end{array}$ & $\begin{array}{l}\text { Partially } \\
\text { protected }\end{array}$ & 9.4 & $\begin{array}{l}\text { Artisanal } \\
\text { fishing }\end{array}$ & $\begin{array}{l}\text { Number of } \\
\text { boats (nb/year) }\end{array}$ & 35 & data & high & estimated from Secanell (2011) \\
\hline MPA 10 & $\begin{array}{l}\text { Parc } \\
\text { Natural } \\
\text { Mari }\end{array}$ & $\begin{array}{l}\text { Partially } \\
\text { protected }\end{array}$ & 9.4 & $\begin{array}{l}\text { Recreational } \\
\text { fishing: hook } \\
\text { and line }\end{array}$ & $\begin{array}{l}\text { Number of } \\
\text { people (nb/year) }\end{array}$ & 950 & data & medium & Font et al. (2012) \\
\hline MPA 10 & $\begin{array}{l}\text { Parc } \\
\text { Natural } \\
\text { Mari }\end{array}$ & $\begin{array}{l}\text { Partially } \\
\text { protected }\end{array}$ & 9.4 & $\begin{array}{l}\text { Recreational } \\
\text { fishing: } \\
\text { spearfishing }\end{array}$ & $\begin{array}{l}\text { Number of } \\
\text { people (nb/year) }\end{array}$ & 95 & data & medium & Font et al. (2012) \\
\hline MPA 10 & $\begin{array}{l}\text { Parc } \\
\text { Natural } \\
\text { Mari }\end{array}$ & $\begin{array}{l}\text { Partially } \\
\text { protected }\end{array}$ & 9.4 & $\begin{array}{l}\text { Tourism: } \\
\text { bathing/trampl } \\
\text { ing }\end{array}$ & $\begin{array}{l}\text { Number of } \\
\text { people (nb/year) }\end{array}$ & 40000 & $\begin{array}{l}\text { expert } \\
\text { opinion }\end{array}$ & low & https://www.idescat.cat/ \\
\hline MPA 10 & $\begin{array}{l}\text { Parc } \\
\text { Natural } \\
\text { Mari }\end{array}$ & $\begin{array}{l}\text { Partially } \\
\text { protected }\end{array}$ & 9.4 & $\begin{array}{l}\text { Tourism: } \\
\text { commercial } \\
\text { boating }\end{array}$ & $\begin{array}{l}\text { Number of } \\
\text { commercial } \\
\text { touristic boats } \\
\text { (nb/year) }\end{array}$ & 17 & data & high & $\begin{array}{l}\text { http://es.costabrava.org/a- } \\
\underline{\text { donde-ir/transportes/cruceros- }} \\
\underline{\text { maritimos }}\end{array}$ \\
\hline MPA 10 & $\begin{array}{l}\text { Parc } \\
\text { Natural } \\
\text { Mari } \\
\end{array}$ & $\begin{array}{l}\text { Partially } \\
\text { protected }\end{array}$ & 9.4 & $\begin{array}{l}\text { Tourism: } \\
\text { private } \\
\text { boating }\end{array}$ & $\begin{array}{l}\text { Number of } \\
\text { private boats } \\
\text { (nb/year) }\end{array}$ & 20000 & $\begin{array}{l}\text { expert } \\
\text { opinion }\end{array}$ & low & http://ports.gencat.cat/es/ \\
\hline MPA 10 & $\begin{array}{l}\text { Parc } \\
\text { Natural } \\
\text { Mari }\end{array}$ & $\begin{array}{l}\text { Partially } \\
\text { protected }\end{array}$ & 9.4 & $\begin{array}{l}\text { Tourism: } \\
\text { scuba-diving }\end{array}$ & $\begin{array}{l}\text { Number of } \\
\text { dives (nb/year) }\end{array}$ & 12700 & data & high & $\begin{array}{l}\underline{\text { http://nautica.gencat.cat/ca/bus }} \\
\text { seig-esbarjo/centres immersio/ }\end{array}$ \\
\hline MPA 10 & $\begin{array}{l}\text { Parc } \\
\text { Natural } \\
\text { Mari }\end{array}$ & $\begin{array}{l}\text { Partially } \\
\text { protected }\end{array}$ & 9.4 & $\begin{array}{l}\text { Trawlers/purse } \\
\text {-seiners }\end{array}$ & $\begin{array}{l}\text { Number of } \\
\text { boats (nb/year) }\end{array}$ & 0 & data & high & $\begin{array}{l}\text { http://agricultura.gencat.cat/ca/ } \\
\text { ambits/pesca/dar_flota_pesquer } \\
\text { a/dar_estadistiques/dar_detall } \\
\text { flota_pesquera per ports/ }\end{array}$ \\
\hline MPA 10 & Outside & Outside & 94.35 & $\begin{array}{l}\text { Artisanal } \\
\text { fishing }\end{array}$ & $\begin{array}{l}\text { Number of } \\
\text { boats (nb/year) }\end{array}$ & 36 & data & high & $\begin{array}{l}\text { http://agricultura.gencat.cat/ca/ } \\
\text { ambits/pesca/dar flota pesquer } \\
\text { a/dar estadistiques/dar detall } \\
\text { flota pesquera per ports/ }\end{array}$ \\
\hline
\end{tabular}




\begin{tabular}{|c|c|c|c|c|c|c|c|c|c|}
\hline MPA 10 & Outside & Outside & 94.35 & $\begin{array}{l}\text { Recreational } \\
\text { fishing: hook } \\
\text { and line }\end{array}$ & $\begin{array}{l}\text { Number of } \\
\text { people (nb/year) }\end{array}$ & 1000 & $\begin{array}{l}\text { expert } \\
\text { opinion }\end{array}$ & low & Font et al. (2012) \\
\hline MPA 10 & Outside & Outside & 94.35 & $\begin{array}{l}\text { Recreational } \\
\text { fishing: } \\
\text { spearfishing }\end{array}$ & $\begin{array}{l}\text { Number of } \\
\text { people (nb/year) }\end{array}$ & 50 & $\begin{array}{l}\text { expert } \\
\text { opinion }\end{array}$ & low & Font et al. (2012) \\
\hline MPA 10 & Outside & Outside & 94.35 & $\begin{array}{l}\text { Tourism: } \\
\text { bathing/trampl } \\
\text { ing }\end{array}$ & $\begin{array}{l}\text { Number of } \\
\text { people (nb/year) }\end{array}$ & 600000 & $\begin{array}{l}\text { expert } \\
\text { opinion }\end{array}$ & low & http://ports.gencat.cat/es/ \\
\hline MPA 10 & Outside & Outside & 94.35 & $\begin{array}{l}\text { Tourism: } \\
\text { commercial } \\
\text { boating }\end{array}$ & $\begin{array}{l}\text { Number of } \\
\text { commercial } \\
\text { touristic boats } \\
\text { (nb/year) }\end{array}$ & 17 & data & high & $\begin{array}{l}\text { http://es.costabrava.org/a- } \\
\text { donde-ir/transportes/cruceros- } \\
\underline{\text { maritimos }}\end{array}$ \\
\hline MPA 10 & Outside & Outside & 94.35 & $\begin{array}{l}\text { Tourism: } \\
\text { private } \\
\text { boating }\end{array}$ & $\begin{array}{l}\text { Number of } \\
\text { private boats } \\
\text { (nb/year) }\end{array}$ & 500 & $\begin{array}{l}\text { expert } \\
\text { opinion }\end{array}$ & low & http://ports.gencat.cat/es/ \\
\hline MPA 10 & Outside & Outside & 94.35 & $\begin{array}{l}\text { Tourism: } \\
\text { scuba-diving }\end{array}$ & $\begin{array}{l}\text { Number of } \\
\text { dives (nb/year) }\end{array}$ & 200 & $\begin{array}{l}\text { expert } \\
\text { opinion }\end{array}$ & low & $\begin{array}{l}\text { http://nautica.gencat.cat/ca/bus } \\
\text { seig-esbarjo/centres immersio/ }\end{array}$ \\
\hline MPA 10 & Outside & Outside & 348.87 & $\begin{array}{l}\text { Trawlers/purse } \\
\text {-seiners }\end{array}$ & $\begin{array}{l}\text { Number of } \\
\text { boats (nb/year) }\end{array}$ & 44 & data & high & $\begin{array}{l}\text { http://agricultura.gencat.cat/ca/ } \\
\text { ambits/pesca/dar_flota_pesquer } \\
\text { a/dar_estadistiques/dar_detall } \\
\text { flota_pesquera per_ports/ }\end{array}$ \\
\hline MPA 11 & $\begin{array}{l}\text { Reserva } \\
\text { marina }\end{array}$ & No-entry & 2.12 & $\begin{array}{l}\text { Artisanal } \\
\text { fishing }\end{array}$ & $\begin{array}{l}\text { Number of } \\
\text { boats (nb/year) }\end{array}$ & 0 & data & high & $\begin{array}{l}\text { http://www.caib.es/sites/espais } \\
\text { naturalsprotegits/f/127403 }\end{array}$ \\
\hline MPA 11 & $\begin{array}{l}\text { Reserva } \\
\text { marina }\end{array}$ & No-entry & 2.12 & $\begin{array}{l}\text { Recreational } \\
\text { fishing: hook } \\
\text { and line }\end{array}$ & $\begin{array}{l}\text { Number of } \\
\text { people (nb/year) }\end{array}$ & 0 & data & high & $\begin{array}{l}\text { http://www.caib.es/sites/espais } \\
\text { naturalsprotegits/f/127403 }\end{array}$ \\
\hline MPA 11 & $\begin{array}{l}\text { Reserva } \\
\text { marina }\end{array}$ & No-entry & 2.12 & $\begin{array}{l}\text { Recreational } \\
\text { fishing: } \\
\text { spearfishing }\end{array}$ & $\begin{array}{l}\text { Number of } \\
\text { people (nb/year) }\end{array}$ & 0 & data & high & $\begin{array}{l}\text { http://www.caib.es/sites/espais } \\
\text { naturalsprotegits/f/127403 }\end{array}$ \\
\hline MPA 11 & $\begin{array}{l}\text { Reserva } \\
\text { marina }\end{array}$ & No-entry & 2.12 & $\begin{array}{l}\text { Tourism: } \\
\text { bathing/trampl } \\
\text { ing }\end{array}$ & $\begin{array}{l}\text { Number of } \\
\text { people (nb/year) }\end{array}$ & 0 & data & high & $\begin{array}{l}\text { http://www.caib.es/sites/espais } \\
\text { naturalsprotegits/f/127403 }\end{array}$ \\
\hline MPA 11 & $\begin{array}{l}\text { Reserva } \\
\text { marina }\end{array}$ & No-entry & 2.12 & $\begin{array}{l}\text { Tourism: } \\
\text { commercial } \\
\text { boating }\end{array}$ & $\begin{array}{l}\text { Number of } \\
\text { commercial } \\
\text { touristic boats } \\
\text { (nb/year) }\end{array}$ & 0 & data & high & $\begin{array}{l}\text { http://www.caib.es/sites/espais } \\
\text { naturalsprotegits/f/127403 }\end{array}$ \\
\hline
\end{tabular}




\begin{tabular}{|c|c|c|c|c|c|c|c|c|c|}
\hline MPA 11 & $\begin{array}{l}\text { Reserva } \\
\text { marina }\end{array}$ & No-entry & 2.12 & $\begin{array}{l}\text { Tourism: } \\
\text { private } \\
\text { boating }\end{array}$ & $\begin{array}{l}\text { Number of } \\
\text { private boats } \\
\text { (nb/year) }\end{array}$ & 0 & data & high & $\begin{array}{l}\text { http://www.caib.es/sites/espais } \\
\text { naturalsprotegits/f/127403 }\end{array}$ \\
\hline MPA 11 & $\begin{array}{l}\text { Reserva } \\
\text { marina }\end{array}$ & No-entry & 2.12 & $\begin{array}{l}\text { Tourism: } \\
\text { scuba-diving }\end{array}$ & $\begin{array}{l}\text { Number of } \\
\text { dives (nb/year) }\end{array}$ & 0 & data & high & $\begin{array}{l}\text { http://www.caib.es/sites/espais } \\
\text { naturalsprotegits/f/127403 }\end{array}$ \\
\hline MPA 11 & $\begin{array}{l}\text { Reserva } \\
\text { marina }\end{array}$ & No-entry & 2.12 & $\begin{array}{l}\text { Trawlers/purse } \\
\text {-seiners }\end{array}$ & $\begin{array}{l}\text { Number of } \\
\text { boats (nb/year) }\end{array}$ & 0 & data & high & $\begin{array}{l}\text { http://www.caib.es/sites/espais } \\
\text { naturalsprotegits/f/127403 }\end{array}$ \\
\hline MPA 11 & $\begin{array}{l}\text { Uso } \\
\text { especial }\end{array}$ & No-take & 0.71 & $\begin{array}{l}\text { Artisanal } \\
\text { fishing }\end{array}$ & $\begin{array}{l}\text { Number of } \\
\text { boats (nb/year) }\end{array}$ & 0 & data & high & $\begin{array}{l}\text { http://www.caib.es/sites/espais } \\
\text { naturalsprotegits/f/127403 }\end{array}$ \\
\hline MPA 11 & $\begin{array}{l}\text { Uso } \\
\text { especial }\end{array}$ & No-take & 0.71 & $\begin{array}{l}\text { Recreational } \\
\text { fishing: hook } \\
\text { and line }\end{array}$ & $\begin{array}{l}\text { Number of } \\
\text { people (nb/year) }\end{array}$ & 0 & data & high & $\begin{array}{l}\text { http://www.caib.es/sites/espais } \\
\text { naturalsprotegits/f/127403 }\end{array}$ \\
\hline MPA 11 & $\begin{array}{l}\text { Uso } \\
\text { especial }\end{array}$ & No-take & 0.71 & $\begin{array}{l}\text { Recreational } \\
\text { fishing: } \\
\text { spearfishing }\end{array}$ & $\begin{array}{l}\text { Number of } \\
\text { people (nb/year) }\end{array}$ & 0 & data & high & $\begin{array}{l}\text { http://www.caib.es/sites/espais } \\
\text { naturalsprotegits/f/127403 }\end{array}$ \\
\hline MPA 11 & $\begin{array}{l}\text { Uso } \\
\text { especial }\end{array}$ & No-take & 0.71 & $\begin{array}{l}\text { Tourism: } \\
\text { bathing/trampl } \\
\text { ing }\end{array}$ & $\begin{array}{l}\text { Number of } \\
\text { people (nb/year) }\end{array}$ & 59319 & data & high & $\begin{array}{l}\text { Sum of: } 21272 \\
\text { bathing/trampling from } \\
\text { commercial boats; and } 38047 \\
\text { bathing/trampling from private } \\
\text { boats }\end{array}$ \\
\hline MPA 11 & $\begin{array}{l}\text { Uso } \\
\text { especial }\end{array}$ & No-take & 0.71 & $\begin{array}{l}\text { Tourism: } \\
\text { commercial } \\
\text { boating }\end{array}$ & $\begin{array}{l}\text { Number of } \\
\text { commercial } \\
\text { touristic boats } \\
\text { (nb/year) }\end{array}$ & 497 & data & high & $\begin{array}{l}\text { http://www.caib.es/sites/espais } \\
\text { naturalsprotegits/f/127403 }\end{array}$ \\
\hline MPA 11 & $\begin{array}{l}\text { Uso } \\
\text { especial }\end{array}$ & No-take & 0.71 & $\begin{array}{l}\text { Tourism: } \\
\text { private } \\
\text { boating }\end{array}$ & $\begin{array}{l}\text { Number of } \\
\text { private boats } \\
\text { (nb/year) }\end{array}$ & 8095 & data & high & $\begin{array}{l}\text { http://www.caib.es/sites/espais } \\
\text { naturalsprotegits/f/127403 }\end{array}$ \\
\hline MPA 11 & $\begin{array}{l}\text { Uso } \\
\text { especial }\end{array}$ & No-take & 0.71 & $\begin{array}{l}\text { Tourism: } \\
\text { scuba-diving }\end{array}$ & $\begin{array}{l}\text { Number of } \\
\text { dives (nb/year) }\end{array}$ & 0 & data & high & $\begin{array}{l}\text { http://www.caib.es/sites/espais } \\
\text { naturalsprotegits/f/127403 }\end{array}$ \\
\hline MPA 11 & $\begin{array}{l}\text { Uso } \\
\text { especial }\end{array}$ & No-take & 0.71 & $\begin{array}{l}\text { Trawlers/purse } \\
\text {-seiners }\end{array}$ & $\begin{array}{l}\text { Number of } \\
\text { boats (nb/year) }\end{array}$ & 0 & data & high & $\begin{array}{l}\text { http://www.caib.es/sites/espais } \\
\text { naturalsprotegits/f/127403 }\end{array}$ \\
\hline MPA 11 & $\begin{array}{l}\text { Uso } \\
\text { moderado }\end{array}$ & $\begin{array}{l}\text { Partially } \\
\text { protected }\end{array}$ & 77.98 & $\begin{array}{l}\text { Artisanal } \\
\text { fishing }\end{array}$ & $\begin{array}{l}\text { Number of } \\
\text { boats (nb/year) }\end{array}$ & 47 & data & high & $\begin{array}{l}\text { License for } 47 \text { boats, data on } \\
\text { how many days have been } \\
\text { working are available from the } \\
\text { managers of the MPA, but are } \\
\text { not processed }\end{array}$ \\
\hline
\end{tabular}




\begin{tabular}{|c|c|c|c|c|c|c|c|c|c|}
\hline MPA 11 & $\begin{array}{l}\text { Uso } \\
\text { moderado }\end{array}$ & $\begin{array}{l}\text { Partially } \\
\text { protected }\end{array}$ & 77.98 & $\begin{array}{l}\text { Recreational } \\
\text { fishing: hook } \\
\text { and line }\end{array}$ & $\begin{array}{l}\text { Number of } \\
\text { people (nb/year) }\end{array}$ & 0 & data & high & $\begin{array}{l}\text { http://www.caib.es/sites/espais } \\
\text { naturalsprotegits/f/127403 }\end{array}$ \\
\hline MPA 11 & $\begin{array}{l}\text { Uso } \\
\text { moderado }\end{array}$ & $\begin{array}{l}\text { Partially } \\
\text { protected }\end{array}$ & 77.98 & $\begin{array}{l}\text { Recreational } \\
\text { fishing: } \\
\text { spearfishing }\end{array}$ & $\begin{array}{l}\text { Number of } \\
\text { people (nb/year) }\end{array}$ & 0 & data & high & $\begin{array}{l}\text { http://www.caib.es/sites/espais } \\
\text { naturalsprotegits/f/127403 }\end{array}$ \\
\hline MPA 11 & $\begin{array}{l}\text { Uso } \\
\text { moderado }\end{array}$ & $\begin{array}{l}\text { Partially } \\
\text { protected }\end{array}$ & 77.98 & $\begin{array}{l}\text { Tourism: } \\
\text { bathing/trampl } \\
\text { ing }\end{array}$ & $\begin{array}{l}\text { Number of } \\
\text { people (nb/year) }\end{array}$ & 14830 & $\begin{array}{l}\text { expert } \\
\text { opinion }\end{array}$ & low & $\begin{array}{l}\text { http://www.caib.es/sites/espais } \\
\text { naturalsprotegits/f/127403 }\end{array}$ \\
\hline MPA 11 & $\begin{array}{l}\text { Uso } \\
\text { moderado }\end{array}$ & $\begin{array}{l}\text { Partially } \\
\text { protected }\end{array}$ & 77.98 & $\begin{array}{l}\text { Tourism: } \\
\text { commercial } \\
\text { boating }\end{array}$ & $\begin{array}{l}\text { Number of } \\
\text { commercial } \\
\text { touristic boats } \\
\text { (nb/year) }\end{array}$ & 248 & $\begin{array}{l}\text { expert } \\
\text { opinion }\end{array}$ & low & $\begin{array}{l}\text { http://www.caib.es/sites/espais } \\
\text { naturalsprotegits/f/127403 }\end{array}$ \\
\hline MPA 11 & $\begin{array}{l}\text { Uso } \\
\text { moderado }\end{array}$ & $\begin{array}{l}\text { Partially } \\
\text { protected }\end{array}$ & 77.98 & $\begin{array}{l}\text { Tourism: } \\
\text { private } \\
\text { boating }\end{array}$ & $\begin{array}{l}\text { Number of } \\
\text { private boats } \\
\text { (nb/year) }\end{array}$ & 4000 & $\begin{array}{l}\text { expert } \\
\text { opinion }\end{array}$ & low & $\begin{array}{l}\text { http://www.caib.es/sites/espais } \\
\text { naturalsprotegits/f/127403 }\end{array}$ \\
\hline MPA 11 & $\begin{array}{l}\text { Uso } \\
\text { moderado }\end{array}$ & $\begin{array}{l}\text { Partially } \\
\text { protected }\end{array}$ & 77.98 & $\begin{array}{l}\text { Tourism: } \\
\text { scuba-diving }\end{array}$ & $\begin{array}{l}\text { Number of } \\
\text { dives (nb/year) }\end{array}$ & 0 & data & high & $\begin{array}{l}\text { http://www.caib.es/sites/espais } \\
\text { naturalsprotegits/f/127403 }\end{array}$ \\
\hline MPA 11 & $\begin{array}{l}\text { Uso } \\
\text { moderado }\end{array}$ & $\begin{array}{l}\text { Partially } \\
\text { protected }\end{array}$ & 77.98 & $\begin{array}{l}\text { Trawlers/purse } \\
\text {-seiners }\end{array}$ & $\begin{array}{l}\text { Number of } \\
\text { boats (nb/year) }\end{array}$ & 1 & data & high & $\begin{array}{l}\text { License for } 1 \text { boat with a } \\
\text { maximum of } 20 \text { working days } \\
\text { per year }\end{array}$ \\
\hline MPA 11 & $\begin{array}{l}\text { Uso } \\
\text { restringido }\end{array}$ & No-take & 0.68 & $\begin{array}{l}\text { Artisanal } \\
\text { fishing }\end{array}$ & $\begin{array}{l}\text { Number of } \\
\text { boats (nb/year) }\end{array}$ & 0 & data & high & $\begin{array}{l}\text { http://www.caib.es/sites/espais } \\
\text { naturalsprotegits/f/127403 }\end{array}$ \\
\hline MPA 11 & $\begin{array}{l}\text { Uso } \\
\text { restringido }\end{array}$ & No-take & 0.68 & $\begin{array}{l}\text { Recreational } \\
\text { fishing: hook } \\
\text { and line }\end{array}$ & $\begin{array}{l}\text { Number of } \\
\text { people (nb/year) }\end{array}$ & 0 & data & high & $\begin{array}{l}\text { http://www.caib.es/sites/espais } \\
\text { naturalsprotegits/f/127403 }\end{array}$ \\
\hline MPA 11 & $\begin{array}{l}\text { Uso } \\
\text { restringido }\end{array}$ & No-take & 0.68 & $\begin{array}{l}\text { Recreational } \\
\text { fishing: } \\
\text { spearfishing }\end{array}$ & $\begin{array}{l}\text { Number of } \\
\text { people (nb/year) }\end{array}$ & 0 & data & high & $\begin{array}{l}\text { http://www.caib.es/sites/espais } \\
\text { naturalsprotegits/f/127403 }\end{array}$ \\
\hline MPA 11 & $\begin{array}{l}\text { Uso } \\
\text { restringido }\end{array}$ & No-take & 0.68 & $\begin{array}{l}\text { Tourism: } \\
\text { bathing/trampl } \\
\text { ing }\end{array}$ & $\begin{array}{l}\text { Number of } \\
\text { people (nb/year) }\end{array}$ & 4794 & $\begin{array}{l}\text { expert } \\
\text { opinion }\end{array}$ & low & $\begin{array}{l}\text { http://www.caib.es/sites/espais } \\
\text { naturalsprotegits/f/127403 }\end{array}$ \\
\hline MPA 11 & $\begin{array}{l}\text { Uso } \\
\text { restringido }\end{array}$ & No-take & 0.68 & $\begin{array}{l}\text { Tourism: } \\
\text { commercial } \\
\text { boating }\end{array}$ & $\begin{array}{l}\text { Number of } \\
\text { commercial } \\
\text { touristic boats } \\
\text { (nb/year) }\end{array}$ & 50 & $\begin{array}{l}\text { expert } \\
\text { opinion }\end{array}$ & low & $\begin{array}{l}\text { http://www.caib.es/sites/espais } \\
\text { naturalsprotegits/f/127403 }\end{array}$ \\
\hline
\end{tabular}




\begin{tabular}{|c|c|c|c|c|c|c|c|c|c|}
\hline MPA 11 & $\begin{array}{l}\text { Uso } \\
\text { restringido }\end{array}$ & No-take & 0.68 & $\begin{array}{l}\text { Tourism: } \\
\text { private } \\
\text { boating }\end{array}$ & $\begin{array}{l}\text { Number of } \\
\text { private boats } \\
\text { (nb/year) }\end{array}$ & 1020 & $\begin{array}{l}\text { expert } \\
\text { opinion }\end{array}$ & low & $\begin{array}{l}\text { http://www.caib.es/sites/espais } \\
\text { naturalsprotegits/f/127403 }\end{array}$ \\
\hline MPA 11 & $\begin{array}{l}\text { Uso } \\
\text { restringido }\end{array}$ & No-take & 0.68 & $\begin{array}{l}\text { Tourism: } \\
\text { scuba-diving }\end{array}$ & $\begin{array}{l}\text { Number of } \\
\text { dives (nb/year) }\end{array}$ & 3000 & data & high & $\begin{array}{l}\text { http://www.caib.es/sites/espais } \\
\text { naturalsprotegits/f/127403 }\end{array}$ \\
\hline MPA 11 & $\begin{array}{l}\text { Uso } \\
\text { restringido }\end{array}$ & No-take & 0.68 & $\begin{array}{l}\text { Trawlers/purse } \\
\text {-seiners }\end{array}$ & $\begin{array}{l}\text { Number of } \\
\text { boats (nb/year) }\end{array}$ & 0 & data & high & $\begin{array}{l}\text { http://www.caib.es/sites/espais } \\
\text { naturalsprotegits/f/127403 }\end{array}$ \\
\hline MPA 11 & $\begin{array}{l}\text { Uso } \\
\text { restringido } \\
\text { pesquero }\end{array}$ & $\begin{array}{l}\text { Partially } \\
\text { protected }\end{array}$ & 5.62 & $\begin{array}{l}\text { Artisanal } \\
\text { fishing }\end{array}$ & $\begin{array}{l}\text { Number of } \\
\text { boats (nb/year) }\end{array}$ & 25 & $\begin{array}{l}\text { expert } \\
\text { opinion }\end{array}$ & low & $\begin{array}{l}\text { http://www.caib.es/sites/espais } \\
\text { naturalsprotegits/f/127403 }\end{array}$ \\
\hline MPA 11 & $\begin{array}{l}\text { Uso } \\
\text { restringido } \\
\text { pesquero }\end{array}$ & $\begin{array}{l}\text { Partially } \\
\text { protected }\end{array}$ & 5.62 & $\begin{array}{l}\text { Recreational } \\
\text { fishing: hook } \\
\text { and line }\end{array}$ & $\begin{array}{l}\text { Number of } \\
\text { people (nb/year) }\end{array}$ & 0 & data & high & $\begin{array}{l}\text { http://www.caib.es/sites/espais } \\
\text { naturalsprotegits/f/127403 }\end{array}$ \\
\hline MPA 11 & $\begin{array}{l}\text { Uso } \\
\text { restringido } \\
\text { pesquero }\end{array}$ & $\begin{array}{l}\text { Partially } \\
\text { protected }\end{array}$ & 5.62 & $\begin{array}{l}\text { Recreational } \\
\text { fishing: } \\
\text { spearfishing }\end{array}$ & $\begin{array}{l}\text { Number of } \\
\text { people (nb/year) }\end{array}$ & 0 & data & high & $\begin{array}{l}\text { http://www.caib.es/sites/espais } \\
\text { naturalsprotegits/f/127403 }\end{array}$ \\
\hline MPA 11 & $\begin{array}{l}\text { Uso } \\
\text { restringido } \\
\text { pesquero }\end{array}$ & $\begin{array}{l}\text { Partially } \\
\text { protected }\end{array}$ & 5.62 & $\begin{array}{l}\text { Tourism: } \\
\text { bathing/trampl } \\
\text { ing }\end{array}$ & $\begin{array}{l}\text { Number of } \\
\text { people (nb/year) }\end{array}$ & 0 & data & high & $\begin{array}{l}\text { http://www.caib.es/sites/espais } \\
\text { naturalsprotegits/f/127403 }\end{array}$ \\
\hline MPA 11 & $\begin{array}{l}\text { Uso } \\
\text { restringido } \\
\text { pesquero }\end{array}$ & $\begin{array}{l}\text { Partially } \\
\text { protected }\end{array}$ & 5.62 & $\begin{array}{l}\text { Tourism: } \\
\text { commercial } \\
\text { boating }\end{array}$ & $\begin{array}{l}\text { Number of } \\
\text { commercial } \\
\text { touristic boats } \\
\text { (nb/year) }\end{array}$ & 0 & data & high & $\begin{array}{l}\text { http://www.caib.es/sites/espais } \\
\text { naturalsprotegits/f/127403 }\end{array}$ \\
\hline MPA 11 & $\begin{array}{l}\text { Uso } \\
\text { restringido } \\
\text { pesquero }\end{array}$ & $\begin{array}{l}\text { Partially } \\
\text { protected }\end{array}$ & 5.62 & $\begin{array}{l}\text { Tourism: } \\
\text { private } \\
\text { boating }\end{array}$ & $\begin{array}{l}\text { Number of } \\
\text { private boats } \\
\text { (nb/year) }\end{array}$ & 0 & data & high & $\begin{array}{l}\text { http://www.caib.es/sites/espais } \\
\text { naturalsprotegits/f/127403 }\end{array}$ \\
\hline MPA 11 & $\begin{array}{l}\text { Uso } \\
\text { restringido } \\
\text { pesquero }\end{array}$ & $\begin{array}{l}\text { Partially } \\
\text { protected }\end{array}$ & 5.62 & $\begin{array}{l}\text { Tourism: } \\
\text { scuba-diving }\end{array}$ & $\begin{array}{l}\text { Number of } \\
\text { dives (nb/year) }\end{array}$ & 0 & data & high & $\begin{array}{l}\text { http://www.caib.es/sites/espais } \\
\text { naturalsprotegits/f/127403 }\end{array}$ \\
\hline MPA 11 & $\begin{array}{l}\text { Uso } \\
\text { restringido } \\
\text { pesquero }\end{array}$ & $\begin{array}{l}\text { Partially } \\
\text { protected }\end{array}$ & 5.62 & $\begin{array}{l}\text { Trawlers/purse } \\
\text {-seiners }\end{array}$ & $\begin{array}{l}\text { Number of } \\
\text { boats (nb/year) }\end{array}$ & 0 & data & high & $\begin{array}{l}\text { http://www.caib.es/sites/espais } \\
\text { naturalsprotegits/f/127403 }\end{array}$ \\
\hline MPA 11 & Fuera & Outside & 64.91 & $\begin{array}{l}\text { Artisanal } \\
\text { fishing }\end{array}$ & $\begin{array}{l}\text { Number of } \\
\text { boats (nb/year) }\end{array}$ & 6 & data & high & $\begin{array}{l}\text { http://www.caib.es/sites/espais } \\
\text { naturalsprotegits/f/127403 }\end{array}$ \\
\hline MPA 11 & Fuera & Outside & 64.91 & $\begin{array}{l}\text { Recreational } \\
\text { fishing: hook } \\
\text { and line }\end{array}$ & $\begin{array}{l}\text { Number of } \\
\text { people (nb/year) }\end{array}$ & 555 & $\begin{array}{l}\text { expert } \\
\text { opinion }\end{array}$ & low & $\begin{array}{l}\text { Estimation from data of a study } \\
\text { on recreational fishing } \\
\text { (Morales-Nin et al. 2005) }\end{array}$ \\
\hline
\end{tabular}




\begin{tabular}{|c|c|c|c|c|c|c|c|c|c|}
\hline MPA 11 & Fuera & Outside & 64.91 & $\begin{array}{l}\text { Recreational } \\
\text { fishing: } \\
\text { spearfishing }\end{array}$ & $\begin{array}{l}\text { Number of } \\
\text { people (nb/year) }\end{array}$ & 277 & $\begin{array}{l}\text { expert } \\
\text { opinion }\end{array}$ & low & $\begin{array}{l}\text { Estimation from data of a study } \\
\text { on recreational fishing } \\
\text { (Morales-Nin et al. 2005) }\end{array}$ \\
\hline MPA 11 & Fuera & Outside & 64.91 & $\begin{array}{l}\text { Tourism: } \\
\text { bathing/trampl } \\
\text { ing }\end{array}$ & $\begin{array}{l}\text { Number of } \\
\text { people (nb/year) }\end{array}$ & 96122 & $\begin{array}{l}\text { expert } \\
\text { opinion }\end{array}$ & low & $\begin{array}{l}\text { Data from VMS, a total of } 7 \\
\text { boats }\end{array}$ \\
\hline MPA 11 & Fuera & Outside & 64.91 & $\begin{array}{l}\text { Tourism: } \\
\text { commercial } \\
\text { boating }\end{array}$ & $\begin{array}{l}\text { Number of } \\
\text { commercial } \\
\text { touristic boats } \\
\text { (nb/year) }\end{array}$ & 150 & $\begin{array}{l}\text { expert } \\
\text { opinion }\end{array}$ & low & $\begin{array}{l}\text { http://www.caib.es/sites/espais } \\
\text { naturalsprotegits/f/127403 }\end{array}$ \\
\hline MPA 11 & Fuera & Outside & 64.91 & $\begin{array}{l}\text { Tourism: } \\
\text { private } \\
\text { boating }\end{array}$ & $\begin{array}{l}\text { Number of } \\
\text { private boats } \\
\text { (nb/year) }\end{array}$ & 12050 & $\begin{array}{l}\text { expert } \\
\text { opinion }\end{array}$ & low & $\begin{array}{l}\text { Data from VMS, a total of } 7 \\
\text { boats }\end{array}$ \\
\hline MPA 11 & Fuera & Outside & 64.91 & $\begin{array}{l}\text { Tourism: } \\
\text { scuba-diving }\end{array}$ & $\begin{array}{l}\text { Number of } \\
\text { dives (nb/year) }\end{array}$ & 25 & $\begin{array}{l}\text { expert } \\
\text { opinion }\end{array}$ & low & $\begin{array}{l}\text { Data from VMS, a total of } 6 \\
\text { boats }\end{array}$ \\
\hline MPA 11 & Fuera & Outside & 800.32 & $\begin{array}{l}\text { Trawlers/purse } \\
\text {-seiners }\end{array}$ & $\begin{array}{l}\text { Number of } \\
\text { boats (nb/year) }\end{array}$ & 7 & data & high & $\begin{array}{l}\text { http://www.caib.es/sites/espais } \\
\text { naturalsprotegits/f/127403 }\end{array}$ \\
\hline MPA 12 & Zona A & No-take & 0.782 & $\begin{array}{l}\text { Artisanal } \\
\text { fishing }\end{array}$ & $\begin{array}{l}\text { Number of } \\
\text { boats (nb/year) }\end{array}$ & 0 & $\begin{array}{l}\text { expert } \\
\text { opinion }\end{array}$ & medium & MPA Consortium \\
\hline MPA 12 & Zona A & No-take & 0.782 & $\begin{array}{l}\text { Recreational } \\
\text { fishing: hook } \\
\text { and line }\end{array}$ & $\begin{array}{l}\text { Number of } \\
\text { people (nb/year) }\end{array}$ & 0 & $\begin{array}{l}\text { expert } \\
\text { opinion }\end{array}$ & medium & MPA Consortium \\
\hline MPA 12 & Zona A & No-take & 0.782 & $\begin{array}{l}\text { Recreational } \\
\text { fishing: } \\
\text { spearfishing }\end{array}$ & $\begin{array}{l}\text { Number of } \\
\text { people (nb/year) }\end{array}$ & 0 & $\begin{array}{l}\text { expert } \\
\text { opinion }\end{array}$ & medium & MPA Consortium \\
\hline MPA 12 & Zona $\mathrm{A}$ & No-take & 0.782 & $\begin{array}{l}\text { Tourism: } \\
\text { bathing/trampl } \\
\text { ing }\end{array}$ & $\begin{array}{l}\text { Number of } \\
\text { people (nb/year) }\end{array}$ & 0 & data & medium & MPA Consortium \\
\hline MPA 12 & Zona A & No-take & 0.782 & $\begin{array}{l}\text { Tourism: } \\
\text { commercial } \\
\text { boating }\end{array}$ & $\begin{array}{l}\text { Number of } \\
\text { commercial } \\
\text { touristic boats } \\
\text { (nb/year) }\end{array}$ & 0 & $\begin{array}{l}\text { expert } \\
\text { opinion }\end{array}$ & high & MPA Consortium \\
\hline MPA 12 & Zona A & No-take & 0.782 & $\begin{array}{l}\text { Tourism: } \\
\text { private } \\
\text { boating }\end{array}$ & $\begin{array}{l}\text { Number of } \\
\text { private boats } \\
\text { (nb/year) }\end{array}$ & 50 & $\begin{array}{l}\text { expert } \\
\text { opinion }\end{array}$ & medium & MPA Consortium \\
\hline MPA 12 & Zona A & No-take & 0.782 & $\begin{array}{l}\text { Tourism: } \\
\text { scuba-diving }\end{array}$ & $\begin{array}{l}\text { Number of } \\
\text { dives (nb/year) }\end{array}$ & 0 & data & high & MPA Consortium \\
\hline
\end{tabular}




\begin{tabular}{|c|c|c|c|c|c|c|c|c|c|}
\hline MPA 12 & Zona A & No-take & 0.782 & $\begin{array}{l}\text { Trawlers/purse } \\
\text {-seiners }\end{array}$ & $\begin{array}{l}\text { Number of } \\
\text { boats (nb/year) }\end{array}$ & 0 & data & high & MPA Consortium \\
\hline MPA 12 & Zona A & No-take & 1.213 & $\begin{array}{l}\text { Artisanal } \\
\text { fishing }\end{array}$ & $\begin{array}{l}\text { Number of } \\
\text { boats (nb/year) }\end{array}$ & 0 & $\begin{array}{l}\text { expert } \\
\text { opinion }\end{array}$ & medium & MPA Consortium \\
\hline MPA 12 & Zona A & No-take & 1.213 & $\begin{array}{l}\text { Recreational } \\
\text { fishing: hook } \\
\text { and line }\end{array}$ & $\begin{array}{l}\text { Number of } \\
\text { people (nb/year) }\end{array}$ & 0 & $\begin{array}{l}\text { expert } \\
\text { opinion }\end{array}$ & medium & MPA Consortium \\
\hline MPA 12 & Zona A & No-take & 1.213 & $\begin{array}{l}\text { Recreational } \\
\text { fishing: } \\
\text { spearfishing }\end{array}$ & $\begin{array}{l}\text { Number of } \\
\text { people (nb/year) }\end{array}$ & 0 & $\begin{array}{l}\text { expert } \\
\text { opinion }\end{array}$ & medium & MPA Consortium \\
\hline MPA 12 & Zona $\mathrm{A}$ & No-take & 1.213 & $\begin{array}{l}\text { Tourism: } \\
\text { bathing/trampl } \\
\text { ing }\end{array}$ & $\begin{array}{l}\text { Number of } \\
\text { people (nb/year) }\end{array}$ & 5500 & $\begin{array}{l}\text { expert } \\
\text { opinion }\end{array}$ & medium & $\begin{array}{l}\text { Estimated on the basis of beach } \\
\text { extension and the total number } \\
\text { of tourists within the } \mathrm{C} \text { zone }\end{array}$ \\
\hline MPA 12 & Zona A & No-take & 1.213 & $\begin{array}{l}\text { Tourism: } \\
\text { commercial } \\
\text { boating }\end{array}$ & $\begin{array}{l}\text { Number of } \\
\text { commercial } \\
\text { touristic boats } \\
\text { (nb/year) }\end{array}$ & 0 & data & high & MPA Consortium \\
\hline MPA 12 & Zona $\mathrm{A}$ & No-take & 1.213 & $\begin{array}{l}\text { Tourism: } \\
\text { private } \\
\text { boating }\end{array}$ & $\begin{array}{l}\text { Number of } \\
\text { private boats } \\
\text { (nb/year) }\end{array}$ & 50 & $\begin{array}{l}\text { expert } \\
\text { opinion }\end{array}$ & medium & MPA Consortium \\
\hline MPA 12 & Zona A & No-take & 1.213 & $\begin{array}{l}\text { Tourism: } \\
\text { scuba-diving }\end{array}$ & $\begin{array}{l}\text { Number of } \\
\text { dives (nb/year) }\end{array}$ & 0 & data & high & MPA Consortium \\
\hline MPA 12 & Zona A & No-take & 1.213 & $\begin{array}{l}\text { Trawlers/purse } \\
\text {-seiners }\end{array}$ & $\begin{array}{l}\text { Number of } \\
\text { boats (nb/year) }\end{array}$ & 0 & data & high & MPA Consortium \\
\hline MPA 12 & Zona B & $\begin{array}{l}\text { Partially } \\
\text { protected }\end{array}$ & 12.302 & $\begin{array}{l}\text { Artisanal } \\
\text { fishing }\end{array}$ & $\begin{array}{l}\text { Number of } \\
\text { boats (nb/year) }\end{array}$ & 107 & data & high & MPA Consortium \\
\hline MPA 12 & Zona B & $\begin{array}{l}\text { Partially } \\
\text { protected }\end{array}$ & 12.302 & $\begin{array}{l}\text { Recreational } \\
\text { fishing: hook } \\
\text { and line }\end{array}$ & $\begin{array}{l}\text { Number of } \\
\text { people (nb/year) }\end{array}$ & 0 & data & high & MPA Consortium \\
\hline MPA 12 & Zona B & $\begin{array}{l}\text { Partially } \\
\text { protected }\end{array}$ & 12.302 & $\begin{array}{l}\text { Recreational } \\
\text { fishing: } \\
\text { spearfishing }\end{array}$ & $\begin{array}{l}\text { Number of } \\
\text { people (nb/year) }\end{array}$ & 0 & data & high & MPA Consortium \\
\hline MPA 12 & Zona B & $\begin{array}{l}\text { Partially } \\
\text { protected }\end{array}$ & 12.302 & $\begin{array}{l}\text { Tourism: } \\
\text { bathing/trampl } \\
\text { ing }\end{array}$ & $\begin{array}{l}\text { Number of } \\
\text { people (nb/year) }\end{array}$ & 0 & $\begin{array}{l}\text { expert } \\
\text { opinion }\end{array}$ & medium & MPA Consortium \\
\hline MPA 12 & Zona B & $\begin{array}{l}\text { Partially } \\
\text { protected }\end{array}$ & 12.302 & $\begin{array}{l}\text { Tourism: } \\
\text { commercial } \\
\text { boating }\end{array}$ & $\begin{array}{l}\text { Number of } \\
\text { commercial }\end{array}$ & 10 & data & medium & MPA Consortium \\
\hline
\end{tabular}




\begin{tabular}{|c|c|c|c|c|c|c|c|c|c|}
\hline & & & & & $\begin{array}{l}\text { touristic boats } \\
\text { (nb/year) }\end{array}$ & & & & \\
\hline MPA 12 & Zona B & $\begin{array}{l}\text { Partially } \\
\text { protected }\end{array}$ & 12.302 & $\begin{array}{l}\text { Tourism: } \\
\text { private } \\
\text { boating }\end{array}$ & $\begin{array}{l}\text { Number of } \\
\text { private boats } \\
\text { (nb/year) }\end{array}$ & 3000 & $\begin{array}{l}\text { expert } \\
\text { opinion }\end{array}$ & low & MPA Consortium \\
\hline MPA 12 & Zona B & $\begin{array}{l}\text { Partially } \\
\text { protected }\end{array}$ & 12.302 & $\begin{array}{l}\text { Tourism: } \\
\text { scuba-diving }\end{array}$ & $\begin{array}{l}\text { Number of } \\
\text { dives (nb/year) }\end{array}$ & 0 & data & medium & MPA Consortium \\
\hline MPA 12 & Zona B & $\begin{array}{l}\text { Partially } \\
\text { protected }\end{array}$ & 12.302 & $\begin{array}{l}\text { Trawlers/purse } \\
\text {-seiners }\end{array}$ & $\begin{array}{l}\text { Number of } \\
\text { boats (nb/year) }\end{array}$ & 0 & data & high & MPA Consortium \\
\hline MPA 12 & Zona B & $\begin{array}{l}\text { Partially } \\
\text { protected }\end{array}$ & 17.904 & $\begin{array}{l}\text { Artisanal } \\
\text { fishing }\end{array}$ & $\begin{array}{l}\text { Number of } \\
\text { boats (nb/year) }\end{array}$ & 107 & data & high & MPA Consortium \\
\hline MPA 12 & Zona B & $\begin{array}{l}\text { Partially } \\
\text { protected }\end{array}$ & 17.904 & $\begin{array}{l}\text { Recreational } \\
\text { fishing: hook } \\
\text { and line }\end{array}$ & $\begin{array}{l}\text { Number of } \\
\text { people (nb/year) }\end{array}$ & 0 & data & high & MPA Consortium \\
\hline MPA 12 & Zona B & $\begin{array}{l}\text { Partially } \\
\text { protected }\end{array}$ & 17.904 & $\begin{array}{l}\text { Recreational } \\
\text { fishing: } \\
\text { spearfishing }\end{array}$ & $\begin{array}{l}\text { Number of } \\
\text { people (nb/year) }\end{array}$ & 0 & data & high & MPA Consortium \\
\hline MPA 12 & Zona B & $\begin{array}{l}\text { Partially } \\
\text { protected }\end{array}$ & 17.904 & $\begin{array}{l}\text { Tourism: } \\
\text { bathing/trampl } \\
\text { ing }\end{array}$ & $\begin{array}{l}\text { Number of } \\
\text { people (nb/year) }\end{array}$ & 0 & $\begin{array}{l}\text { expert } \\
\text { opinion }\end{array}$ & medium & MPA Consortium \\
\hline MPA 12 & Zona B & $\begin{array}{l}\text { Partially } \\
\text { protected }\end{array}$ & 17.904 & $\begin{array}{l}\text { Tourism: } \\
\text { commercial } \\
\text { boating }\end{array}$ & $\begin{array}{l}\text { Number of } \\
\text { commercial } \\
\text { touristic boats } \\
\text { (nb/year) }\end{array}$ & 10 & data & medium & MPA Consortium \\
\hline MPA 12 & Zona B & $\begin{array}{l}\text { Partially } \\
\text { protected }\end{array}$ & 17.904 & $\begin{array}{l}\text { Tourism: } \\
\text { private } \\
\text { boating }\end{array}$ & $\begin{array}{l}\text { Number of } \\
\text { private boats } \\
\text { (nb/year) }\end{array}$ & 0 & $\begin{array}{l}\text { expert } \\
\text { opinion }\end{array}$ & low & MPA Consortium \\
\hline MPA 12 & Zona B & $\begin{array}{l}\text { Partially } \\
\text { protected }\end{array}$ & 17.904 & $\begin{array}{l}\text { Tourism: } \\
\text { scuba-diving }\end{array}$ & $\begin{array}{l}\text { Number of } \\
\text { dives (nb/year) }\end{array}$ & 0 & data & medium & MPA Consortium \\
\hline MPA 12 & Zona B & $\begin{array}{l}\text { Partially } \\
\text { protected }\end{array}$ & 17.904 & $\begin{array}{l}\text { Trawlers/purse } \\
\text {-seiners }\end{array}$ & $\begin{array}{l}\text { Number of } \\
\text { boats (nb/year) }\end{array}$ & 0 & data & high & MPA Consortium \\
\hline MPA 12 & Zona $\mathrm{C}$ & $\begin{array}{l}\text { Partially } \\
\text { protected }\end{array}$ & 132.666 & $\begin{array}{l}\text { Artisanal } \\
\text { fishing }\end{array}$ & $\begin{array}{l}\text { Number of } \\
\text { boats (nb/year) }\end{array}$ & 107 & data & high & MPA Consortium \\
\hline MPA 12 & Zona $\mathrm{C}$ & $\begin{array}{l}\text { Partially } \\
\text { protected }\end{array}$ & 132.666 & $\begin{array}{l}\text { Recreational } \\
\text { fishing: hook } \\
\text { and line }\end{array}$ & $\begin{array}{l}\text { Number of } \\
\text { people (nb/year) }\end{array}$ & 1150 & data & high & MPA Consortium \\
\hline
\end{tabular}




\begin{tabular}{|c|c|c|c|c|c|c|c|c|c|}
\hline MPA 12 & Zona $\mathrm{C}$ & $\begin{array}{l}\text { Partially } \\
\text { protected }\end{array}$ & 132.666 & $\begin{array}{l}\text { Recreational } \\
\text { fishing: } \\
\text { spearfishing }\end{array}$ & $\begin{array}{l}\text { Number of } \\
\text { people (nb/year) }\end{array}$ & 500 & data & high & MPA Consortium \\
\hline MPA 12 & Zona $\mathrm{C}$ & $\begin{array}{l}\text { Partially } \\
\text { protected }\end{array}$ & 132.666 & $\begin{array}{l}\text { Tourism: } \\
\text { bathing/trampl } \\
\text { ing }\end{array}$ & $\begin{array}{l}\text { Number of } \\
\text { people (nb/year) }\end{array}$ & $\begin{array}{r}150000 \\
0\end{array}$ & $\begin{array}{l}\text { expert } \\
\text { opinion }\end{array}$ & medium & $\begin{array}{l}\text { Estimated on the basis of nb of } \\
\text { presence recorded by Touristic } \\
\text { agency of Apulia }\end{array}$ \\
\hline MPA 12 & Zona $\mathrm{C}$ & $\begin{array}{l}\text { Partially } \\
\text { protected }\end{array}$ & 132.666 & $\begin{array}{l}\text { Tourism: } \\
\text { commercial } \\
\text { boating }\end{array}$ & $\begin{array}{l}\text { Number of } \\
\text { commercial } \\
\text { touristic boats } \\
\text { (nb/year) }\end{array}$ & 10 & data & low & MPA Consortium \\
\hline MPA 12 & Zona $\mathrm{C}$ & $\begin{array}{l}\text { Partially } \\
\text { protected }\end{array}$ & 132.666 & $\begin{array}{l}\text { Tourism: } \\
\text { private } \\
\text { boating }\end{array}$ & $\begin{array}{l}\text { Number of } \\
\text { private boats } \\
\text { (nb/year) }\end{array}$ & 3000 & $\begin{array}{l}\text { expert } \\
\text { opinion }\end{array}$ & low & MPA Consortium \\
\hline MPA 12 & Zona $\mathrm{C}$ & $\begin{array}{l}\text { Partially } \\
\text { protected }\end{array}$ & 132.666 & $\begin{array}{l}\text { Tourism: } \\
\text { scuba-diving }\end{array}$ & $\begin{array}{l}\text { Number of } \\
\text { dives (nb/year) }\end{array}$ & 2000 & data & low & MPA Consortium \\
\hline MPA 12 & Zona $\mathrm{C}$ & $\begin{array}{l}\text { Partially } \\
\text { protected }\end{array}$ & 132.666 & $\begin{array}{l}\text { Trawlers/purse } \\
\text {-seiners }\end{array}$ & $\begin{array}{l}\text { Number of } \\
\text { boats (nb/year) }\end{array}$ & 0 & data & high & MPA Consortium \\
\hline MPA 12 & Outside & Outside & 307.91 & $\begin{array}{l}\text { Artisanal } \\
\text { fishing }\end{array}$ & $\begin{array}{l}\text { Number of } \\
\text { boats (nb/year) }\end{array}$ & 107 & $\begin{array}{l}\text { expert } \\
\text { opinion }\end{array}$ & low & Assumed the same of C zone \\
\hline MPA 12 & Outside & Outside & 307.91 & $\begin{array}{l}\text { Recreational } \\
\text { fishing: hook } \\
\text { and line }\end{array}$ & $\begin{array}{l}\text { Number of } \\
\text { people (nb/year) }\end{array}$ & 1150 & $\begin{array}{l}\text { expert } \\
\text { opinion }\end{array}$ & low & Assumed the same of C zone \\
\hline MPA 12 & Outside & Outside & 307.91 & $\begin{array}{l}\text { Recreational } \\
\text { fishing: } \\
\text { spearfishing }\end{array}$ & $\begin{array}{l}\text { Number of } \\
\text { people (nb/year) }\end{array}$ & 1000 & $\begin{array}{l}\text { expert } \\
\text { opinion }\end{array}$ & low & Assumed the same of C zone \\
\hline MPA 12 & Outside & Outside & 307.91 & $\begin{array}{l}\text { Tourism: } \\
\text { bathing/trampl } \\
\text { ing }\end{array}$ & $\begin{array}{l}\text { Number of } \\
\text { people (nb/year) }\end{array}$ & $\begin{array}{r}150000 \\
0\end{array}$ & $\begin{array}{l}\text { expert } \\
\text { opinion }\end{array}$ & medium & Assumed the same of C zone \\
\hline MPA 12 & Outside & Outside & 307.91 & $\begin{array}{l}\text { Tourism: } \\
\text { commercial } \\
\text { boating }\end{array}$ & $\begin{array}{l}\text { Number of } \\
\text { commercial } \\
\text { touristic boats } \\
\text { (nb/year) }\end{array}$ & 10 & $\begin{array}{l}\text { expert } \\
\text { opinion }\end{array}$ & low & Assumed the same of C zone \\
\hline MPA 12 & Outside & Outside & 307.91 & $\begin{array}{l}\text { Tourism: } \\
\text { private } \\
\text { boating }\end{array}$ & $\begin{array}{l}\text { Number of } \\
\text { private boats } \\
\text { (nb/year) }\end{array}$ & 3000 & $\begin{array}{l}\text { expert } \\
\text { opinion }\end{array}$ & low & Assumed the same of C zone \\
\hline MPA 12 & Outside & Outside & 307.91 & $\begin{array}{l}\text { Tourism: } \\
\text { scuba-diving }\end{array}$ & $\begin{array}{l}\text { Number of } \\
\text { dives (nb/year) }\end{array}$ & 2000 & $\begin{array}{l}\text { expert } \\
\text { opinion }\end{array}$ & low & Assumed the same of C zone \\
\hline
\end{tabular}




\begin{tabular}{|c|c|c|c|c|c|c|c|c|c|}
\hline MPA 12 & Outside & Outside & 407.17 & $\begin{array}{l}\text { Trawlers/purse } \\
\text {-seiners }\end{array}$ & $\begin{array}{l}\text { Number of } \\
\text { boats (nb/year) }\end{array}$ & 0 & $\begin{array}{l}\text { expert } \\
\text { opinion }\end{array}$ & low & Assumed the same of C zone \\
\hline MPA 13 & Inside & $\begin{array}{l}\text { Partially } \\
\text { protected }\end{array}$ & 8.487 & $\begin{array}{l}\text { Artisanal } \\
\text { fishing }\end{array}$ & $\begin{array}{l}\text { Number of } \\
\text { boats (nb/year) }\end{array}$ & 48 & data & medium & $\begin{array}{l}\text { Registry of fishing vessels held } \\
\text { by Ministry }\end{array}$ \\
\hline MPA 13 & Inside & $\begin{array}{l}\text { Partially } \\
\text { protected }\end{array}$ & 8.487 & $\begin{array}{l}\text { Recreational } \\
\text { fishing: hook } \\
\text { and line }\end{array}$ & $\begin{array}{l}\text { Number of } \\
\text { people (nb/year) }\end{array}$ & 50 & $\begin{array}{l}\text { expert } \\
\text { opinion }\end{array}$ & low & Estimated \\
\hline MPA 13 & Inside & $\begin{array}{l}\text { Partially } \\
\text { protected }\end{array}$ & 8.487 & $\begin{array}{l}\text { Recreational } \\
\text { fishing: } \\
\text { spearfishing }\end{array}$ & $\begin{array}{l}\text { Number of } \\
\text { people (nb/year) }\end{array}$ & 2873 & data & low & $\begin{array}{l}\text { Registry of speargun licences } \\
\text { held by Malta Police Force }\end{array}$ \\
\hline MPA 13 & Inside & $\begin{array}{l}\text { Partially } \\
\text { protected }\end{array}$ & 8.487 & $\begin{array}{l}\text { Tourism: } \\
\text { bathing/trampl } \\
\text { ing }\end{array}$ & $\begin{array}{l}\text { Number of } \\
\text { people (nb/year) }\end{array}$ & 30000 & data & low & $\begin{array}{l}\text { Estimated based on logs kept } \\
\text { by Malta Tourism Authority } \\
\text { beach supervisors }\end{array}$ \\
\hline MPA 13 & Inside & $\begin{array}{l}\text { Partially } \\
\text { protected }\end{array}$ & 8.487 & $\begin{array}{l}\text { Tourism: } \\
\text { commercial } \\
\text { boating }\end{array}$ & $\begin{array}{l}\text { Number of } \\
\text { commercial } \\
\text { touristic boats } \\
\text { (nb/year) }\end{array}$ & 25 & $\begin{array}{l}\text { expert } \\
\text { opinion }\end{array}$ & low & Estimated \\
\hline MPA 13 & Inside & $\begin{array}{l}\text { Partially } \\
\text { protected }\end{array}$ & 8.487 & $\begin{array}{l}\text { Tourism: } \\
\text { private } \\
\text { boating }\end{array}$ & $\begin{array}{l}\text { Number of } \\
\text { private boats } \\
\text { (nb/year) }\end{array}$ & 100 & data & low & $\begin{array}{l}\text { Estimated based on satellite } \\
\text { imagry obtained from Google } \\
\text { Earth }\end{array}$ \\
\hline MPA 13 & Inside & $\begin{array}{l}\text { Partially } \\
\text { protected }\end{array}$ & 8.487 & $\begin{array}{l}\text { Tourism: } \\
\text { scuba-diving }\end{array}$ & $\begin{array}{l}\text { Number of } \\
\text { dives (nb/year) }\end{array}$ & 100 & $\begin{array}{l}\text { expert } \\
\text { opinion }\end{array}$ & low & Estimated \\
\hline MPA 13 & Inside & $\begin{array}{l}\text { Partially } \\
\text { protected }\end{array}$ & 8.487 & $\begin{array}{l}\text { Trawlers/purse } \\
\text {-seiners }\end{array}$ & $\begin{array}{l}\text { Number of } \\
\text { boats (nb/year) }\end{array}$ & 0 & data & high & $\begin{array}{l}\text { Registry of fishing vessels held } \\
\text { by Ministry }\end{array}$ \\
\hline MPA 13 & Outside & Outside & 115.8 & $\begin{array}{l}\text { Artisanal } \\
\text { fishing }\end{array}$ & $\begin{array}{l}\text { Number of } \\
\text { boats (nb/year) }\end{array}$ & 388 & data & medium & $\begin{array}{l}\text { Registry of fishing vessels held } \\
\text { by Ministry }\end{array}$ \\
\hline MPA 13 & Outside & Outside & 115.8 & $\begin{array}{l}\text { Recreational } \\
\text { fishing: hook } \\
\text { and line }\end{array}$ & $\begin{array}{l}\text { Number of } \\
\text { people (nb/year) }\end{array}$ & 1000 & $\begin{array}{l}\text { expert } \\
\text { opinion }\end{array}$ & low & Estimated \\
\hline MPA 13 & Outside & Outside & 115.8 & $\begin{array}{l}\text { Recreational } \\
\text { fishing: } \\
\text { spearfishing }\end{array}$ & $\begin{array}{l}\text { Number of } \\
\text { people (nb/year) }\end{array}$ & 2873 & data & low & $\begin{array}{l}\text { Registry of speargun licences } \\
\text { held by Malta Police Force }\end{array}$ \\
\hline MPA 13 & Outside & Outside & 115.8 & $\begin{array}{l}\text { Tourism: } \\
\text { bathing/trampl } \\
\text { ing }\end{array}$ & $\begin{array}{l}\text { Number of } \\
\text { people (nb/year) }\end{array}$ & 125000 & data & low & $\begin{array}{l}\text { Estimated based on logs kept } \\
\text { by Malta Tourism Authority } \\
\text { beach supervisors }\end{array}$ \\
\hline MPA 13 & Outside & Outside & 115.8 & $\begin{array}{l}\text { Tourism: } \\
\text { commercial } \\
\text { boating }\end{array}$ & $\begin{array}{l}\text { Number of } \\
\text { commercial }\end{array}$ & 150 & $\begin{array}{l}\text { expert } \\
\text { opinion }\end{array}$ & low & Estimated \\
\hline
\end{tabular}




\begin{tabular}{|c|c|c|c|c|c|c|c|c|c|}
\hline & & & & & $\begin{array}{l}\text { touristic boats } \\
\text { (nb/year) }\end{array}$ & & & & \\
\hline MPA 13 & Outside & Outside & 115.8 & $\begin{array}{l}\text { Tourism: } \\
\text { private } \\
\text { boating }\end{array}$ & $\begin{array}{l}\text { Number of } \\
\text { private boats } \\
\text { (nb/year) }\end{array}$ & 1000 & data & low & $\begin{array}{l}\text { Estimated based on satellite } \\
\text { imagry obtained from Google } \\
\text { Earth }\end{array}$ \\
\hline MPA 13 & Outside & Outside & 115.8 & $\begin{array}{l}\text { Tourism: } \\
\text { scuba-diving }\end{array}$ & $\begin{array}{l}\text { Number of } \\
\text { dives (nb/year) }\end{array}$ & 20000 & $\begin{array}{l}\text { expert } \\
\text { opinion }\end{array}$ & low & Estimated \\
\hline MPA 13 & Outside & Outside & 308.29 & $\begin{array}{l}\text { Trawlers/purse } \\
\text {-seiners }\end{array}$ & $\begin{array}{l}\text { Number of } \\
\text { boats (nb/year) }\end{array}$ & 49 & data & high & $\begin{array}{l}\text { Registry of fishing vessels held } \\
\text { by Ministry }\end{array}$ \\
\hline MPA 14 & Zona A & No-take & 1.386 & $\begin{array}{l}\text { Artisanal } \\
\text { fishing }\end{array}$ & $\begin{array}{l}\text { Number of } \\
\text { boats (nb/year) }\end{array}$ & 0 & data & high & MPA regulations \\
\hline MPA 14 & Zona A & No-take & 1.386 & $\begin{array}{l}\text { Recreational } \\
\text { fishing: hook } \\
\text { and line }\end{array}$ & $\begin{array}{l}\text { Number of } \\
\text { people (nb/year) }\end{array}$ & 0 & data & high & MPA regulations \\
\hline MPA 14 & Zona A & No-take & 1.386 & $\begin{array}{l}\text { Recreational } \\
\text { fishing: } \\
\text { spearfishing }\end{array}$ & $\begin{array}{l}\text { Number of } \\
\text { people (nb/year) }\end{array}$ & 0 & data & high & MPA regulations \\
\hline MPA 14 & Zona A & No-take & 1.386 & $\begin{array}{l}\text { Tourism: } \\
\text { bathing/trampl } \\
\text { ing }\end{array}$ & $\begin{array}{l}\text { Number of } \\
\text { people (nb/year) }\end{array}$ & 473.5 & data & high & $\begin{array}{l}\text { Curtesy of Torre Guaceto } \\
\text { Management Consortium - Just } \\
\text { snorkeling linked to } \\
\text { environmental education } \\
\text { activities (nb of visitors) }\end{array}$ \\
\hline MPA 14 & Zona A & No-take & 1.386 & $\begin{array}{l}\text { Tourism: } \\
\text { commercial } \\
\text { boating }\end{array}$ & $\begin{array}{l}\text { Number of } \\
\text { commercial } \\
\text { touristic boats } \\
\text { (nb/year) }\end{array}$ & 0 & data & high & MPA regulations \\
\hline MPA 14 & Zona A & No-take & 1.386 & $\begin{array}{l}\text { Tourism: } \\
\text { private } \\
\text { boating }\end{array}$ & $\begin{array}{l}\text { Number of } \\
\text { private boats } \\
\text { (nb/year) }\end{array}$ & 0 & data & high & MPA regulations \\
\hline MPA 14 & Zona A & No-take & 1.386 & $\begin{array}{l}\text { Tourism: } \\
\text { scuba-diving }\end{array}$ & $\begin{array}{l}\text { Number of } \\
\text { dives (nb/year) }\end{array}$ & 0 & data & high & MPA regulations \\
\hline MPA 14 & Zona A & No-take & 1.386 & $\begin{array}{l}\text { Trawlers/purse } \\
\text {-seiners }\end{array}$ & $\begin{array}{l}\text { Number of } \\
\text { boats (nb/year) }\end{array}$ & 0 & data & high & MPA regulations \\
\hline MPA 14 & Zona A & No-entry & 0.46 & $\begin{array}{l}\text { Artisanal } \\
\text { fishing }\end{array}$ & $\begin{array}{l}\text { Number of } \\
\text { boats (nb/year) }\end{array}$ & 0 & data & high & MPA regulations \\
\hline MPA 14 & Zona A & No-entry & 0.46 & $\begin{array}{l}\text { Recreational } \\
\text { fishing: hook } \\
\text { and line }\end{array}$ & $\begin{array}{l}\text { Number of } \\
\text { people (nb/year) }\end{array}$ & 0 & data & high & MPA regulations \\
\hline
\end{tabular}




\begin{tabular}{|c|c|c|c|c|c|c|c|c|c|}
\hline MPA 14 & Zona A & No-entry & 0.46 & $\begin{array}{l}\text { Recreational } \\
\text { fishing: } \\
\text { spearfishing }\end{array}$ & $\begin{array}{l}\text { Number of } \\
\text { people (nb/year) }\end{array}$ & 0 & data & high & MPA regulations \\
\hline MPA 14 & Zona A & No-entry & 0.46 & $\begin{array}{l}\text { Tourism: } \\
\text { bathing/trampl } \\
\text { ing }\end{array}$ & $\begin{array}{l}\text { Number of } \\
\text { people (nb/year) }\end{array}$ & 0 & data & high & MPA regulations \\
\hline MPA 14 & Zona A & No-entry & 0.46 & $\begin{array}{l}\text { Tourism: } \\
\text { commercial } \\
\text { boating }\end{array}$ & $\begin{array}{l}\text { Number of } \\
\text { commercial } \\
\text { touristic boats } \\
\text { (nb/year) }\end{array}$ & 0 & data & high & MPA regulations \\
\hline MPA 14 & Zona A & No-entry & 0.46 & $\begin{array}{l}\text { Tourism: } \\
\text { private } \\
\text { boating }\end{array}$ & $\begin{array}{l}\text { Number of } \\
\text { private boats } \\
\text { (nb/year) }\end{array}$ & 0 & data & high & MPA regulations \\
\hline MPA 14 & Zona A & No-entry & 0.46 & $\begin{array}{l}\text { Tourism: } \\
\text { scuba-diving }\end{array}$ & $\begin{array}{l}\text { Number of } \\
\text { dives (nb/year) }\end{array}$ & 0 & data & high & MPA regulations \\
\hline MPA 14 & Zona A & No-entry & 0.46 & $\begin{array}{l}\text { Trawlers/purse } \\
\text {-seiners }\end{array}$ & $\begin{array}{l}\text { Number of } \\
\text { boats (nb/year) }\end{array}$ & 0 & data & high & MPA regulations \\
\hline MPA 14 & Zona B & $\begin{array}{l}\text { Partially } \\
\text { protected }\end{array}$ & 1.63 & $\begin{array}{l}\text { Artisanal } \\
\text { fishing }\end{array}$ & $\begin{array}{l}\text { Number of } \\
\text { boats (nb/year) }\end{array}$ & 0 & data & high & MPA regulations \\
\hline MPA 14 & Zona B & $\begin{array}{l}\text { Partially } \\
\text { protected }\end{array}$ & 1.63 & $\begin{array}{l}\text { Recreational } \\
\text { fishing: hook } \\
\text { and line }\end{array}$ & $\begin{array}{l}\text { Number of } \\
\text { people (nb/year) }\end{array}$ & 0 & data & high & MPA regulations \\
\hline MPA 14 & Zona B & $\begin{array}{l}\text { Partially } \\
\text { protected }\end{array}$ & 1.63 & $\begin{array}{l}\text { Recreational } \\
\text { fishing: } \\
\text { spearfishing }\end{array}$ & $\begin{array}{l}\text { Number of } \\
\text { people (nb/year) }\end{array}$ & 0 & data & high & MPA regulations \\
\hline MPA 14 & Zona B & $\begin{array}{l}\text { Partially } \\
\text { protected }\end{array}$ & 1.63 & $\begin{array}{l}\text { Tourism: } \\
\text { bathing/trampl } \\
\text { ing }\end{array}$ & $\begin{array}{l}\text { Number of } \\
\text { people (nb/year) }\end{array}$ & 120000 & data & high & $\begin{array}{l}\text { Just snorkeling linked to } \\
\text { environmental education } \\
\text { activities (nb of visitors) }\end{array}$ \\
\hline MPA 14 & Zona B & $\begin{array}{l}\text { Partially } \\
\text { protected }\end{array}$ & 1.63 & $\begin{array}{l}\text { Tourism: } \\
\text { commercial } \\
\text { boating }\end{array}$ & $\begin{array}{l}\text { Number of } \\
\text { commercial } \\
\text { touristic boats } \\
\text { (nb/year) }\end{array}$ & 0 & data & high & MPA regulations \\
\hline MPA 14 & Zona B & $\begin{array}{l}\text { Partially } \\
\text { protected }\end{array}$ & 1.63 & $\begin{array}{l}\text { Tourism: } \\
\text { private } \\
\text { boating }\end{array}$ & $\begin{array}{l}\text { Number of } \\
\text { private boats } \\
\text { (nb/year) }\end{array}$ & 0 & data & high & MPA regulations \\
\hline MPA 14 & Zona B & $\begin{array}{l}\text { Partially } \\
\text { protected }\end{array}$ & 1.63 & $\begin{array}{l}\text { Tourism: } \\
\text { scuba-diving }\end{array}$ & $\begin{array}{l}\text { Number of } \\
\text { dives (nb/year) }\end{array}$ & 80 & data & high & $\begin{array}{l}\text { Curtesy of Torre Guaceto } \\
\text { Management Consortium - Just } \\
\text { snorkeling linked to }\end{array}$ \\
\hline
\end{tabular}




\begin{tabular}{|c|c|c|c|c|c|c|c|c|c|}
\hline & & & & & & & & & $\begin{array}{l}\text { environmental education } \\
\text { activities (nb of visitors) }\end{array}$ \\
\hline MPA 14 & Zona B & $\begin{array}{l}\text { Partially } \\
\text { protected }\end{array}$ & 1.63 & $\begin{array}{l}\text { Trawlers/purse } \\
\text {-seiners }\end{array}$ & $\begin{array}{l}\text { Number of } \\
\text { boats (nb/year) }\end{array}$ & 0 & data & high & MPA regulations \\
\hline MPA 14 & Zona C & $\begin{array}{l}\text { Partially } \\
\text { protected }\end{array}$ & 18.85 & $\begin{array}{l}\text { Artisanal } \\
\text { fishing }\end{array}$ & $\begin{array}{l}\text { Number of } \\
\text { boats (nb/year) }\end{array}$ & 5 & data & high & $\begin{array}{l}\text { Curtesy of Torre Guaceto } \\
\text { Management Consortium - Just } \\
\text { snorkeling linked to } \\
\text { environmental education } \\
\text { activities (nb of visitors) }\end{array}$ \\
\hline MPA 14 & Zona C & $\begin{array}{l}\text { Partially } \\
\text { protected }\end{array}$ & 18.85 & $\begin{array}{l}\text { Recreational } \\
\text { fishing: hook } \\
\text { and line }\end{array}$ & $\begin{array}{l}\text { Number of } \\
\text { people (nb/year) }\end{array}$ & 323 & data & high & $\begin{array}{l}\text { Curtesy of Torre Guaceto } \\
\text { Management Consortium - Just } \\
\text { snorkeling linked to } \\
\text { environmental education } \\
\text { activities (nb of visitors) }\end{array}$ \\
\hline MPA 14 & Zona $\mathrm{C}$ & $\begin{array}{l}\text { Partially } \\
\text { protected }\end{array}$ & 18.85 & $\begin{array}{l}\text { Recreational } \\
\text { fishing: } \\
\text { spearfishing }\end{array}$ & $\begin{array}{l}\text { Number of } \\
\text { people (nb/year) }\end{array}$ & 0 & data & high & MPA regulations \\
\hline MPA 14 & Zona $\mathrm{C}$ & $\begin{array}{l}\text { Partially } \\
\text { protected }\end{array}$ & 18.85 & $\begin{array}{l}\text { Tourism: } \\
\text { bathing/trampl } \\
\text { ing }\end{array}$ & $\begin{array}{l}\text { Number of } \\
\text { people (nb/year) }\end{array}$ & 180000 & $\begin{array}{l}\text { expert } \\
\text { opinion }\end{array}$ & medium & $\begin{array}{l}\text { Estimated on the basis of beach } \\
\text { surface and number of visitors } \\
\text { in the B zone. In this case } \\
\text { people doesn't have to pay!!!! }\end{array}$ \\
\hline MPA 14 & Zona $\mathrm{C}$ & $\begin{array}{l}\text { Partially } \\
\text { protected }\end{array}$ & 18.85 & $\begin{array}{l}\text { Tourism: } \\
\text { commercial } \\
\text { boating }\end{array}$ & $\begin{array}{l}\text { Number of } \\
\text { commercial } \\
\text { touristic boats } \\
\text { (nb/year) }\end{array}$ & 0 & data & high & $\begin{array}{l}\text { Based on Historical images of } \\
\text { google earth }\end{array}$ \\
\hline MPA 14 & Zona C & $\begin{array}{l}\text { Partially } \\
\text { protected }\end{array}$ & 18.85 & $\begin{array}{l}\text { Tourism: } \\
\text { private } \\
\text { boating }\end{array}$ & $\begin{array}{l}\text { Number of } \\
\text { private boats } \\
\text { (nb/year) }\end{array}$ & 0 & data & medium & $\begin{array}{l}\text { Based on Historical images of } \\
\text { google earth }\end{array}$ \\
\hline MPA 14 & Zona $\mathrm{C}$ & $\begin{array}{l}\text { Partially } \\
\text { protected }\end{array}$ & 18.85 & $\begin{array}{l}\text { Tourism: } \\
\text { scuba-diving }\end{array}$ & $\begin{array}{l}\text { Number of } \\
\text { dives (nb/year) }\end{array}$ & 80 & $\begin{array}{l}\text { expert } \\
\text { opinion }\end{array}$ & medium & $\begin{array}{l}\text { Assumed on the basis of nb of } \\
\text { divers in B zone. Also for C } \\
\text { zone divers need autorization } \\
\text { of MPA. }\end{array}$ \\
\hline MPA 14 & Zona $\mathrm{C}$ & $\begin{array}{l}\text { Partially } \\
\text { protected }\end{array}$ & 18.85 & $\begin{array}{l}\text { Trawlers/purse } \\
\text {-seiners }\end{array}$ & $\begin{array}{l}\text { Number of } \\
\text { boats (nb/year) }\end{array}$ & 0 & data & high & MPA regulations \\
\hline MPA 14 & Outside & Outside & 76.87 & $\begin{array}{l}\text { Artisanal } \\
\text { fishing }\end{array}$ & $\begin{array}{l}\text { Number of } \\
\text { boats (nb/year) }\end{array}$ & 95 & data & high & $\begin{array}{l}\text { Curtesy of Torre Guaceto } \\
\text { Management Consortium }\end{array}$ \\
\hline
\end{tabular}




\begin{tabular}{|c|c|c|c|c|c|c|c|c|c|}
\hline MPA 14 & Outside & Outside & 76.87 & $\begin{array}{l}\text { Recreational } \\
\text { fishing: hook } \\
\text { and line }\end{array}$ & $\begin{array}{l}\text { Number of } \\
\text { people (nb/year) }\end{array}$ & 365 & $\begin{array}{l}\text { expert } \\
\text { opinion }\end{array}$ & low & Estimated \\
\hline MPA 14 & Outside & Outside & 76.87 & $\begin{array}{l}\text { Recreational } \\
\text { fishing: } \\
\text { spearfishing }\end{array}$ & $\begin{array}{l}\text { Number of } \\
\text { people (nb/year) }\end{array}$ & 365 & $\begin{array}{l}\text { expert } \\
\text { opinion }\end{array}$ & low & Estimated \\
\hline MPA 14 & Outside & Outside & 76.87 & $\begin{array}{l}\text { Tourism: } \\
\text { bathing/trampl } \\
\text { ing }\end{array}$ & $\begin{array}{l}\text { Number of } \\
\text { people (nb/year) }\end{array}$ & 300000 & $\begin{array}{l}\text { expert } \\
\text { opinion }\end{array}$ & low & Estimated \\
\hline MPA 14 & Outside & Outside & 76.87 & $\begin{array}{l}\text { Tourism: } \\
\text { commercial } \\
\text { boating }\end{array}$ & $\begin{array}{l}\text { Number of } \\
\text { commercial } \\
\text { touristic boats } \\
\text { (nb/year) }\end{array}$ & 0 & $\begin{array}{l}\text { expert } \\
\text { opinion }\end{array}$ & low & $\begin{array}{l}\text { Based on Historical images of } \\
\text { google earth }\end{array}$ \\
\hline MPA 14 & Outside & Outside & 76.87 & $\begin{array}{l}\text { Tourism: } \\
\text { private } \\
\text { boating }\end{array}$ & $\begin{array}{l}\text { Number of } \\
\text { private boats } \\
\text { (nb/year) }\end{array}$ & 8 & $\begin{array}{l}\text { expert } \\
\text { opinion }\end{array}$ & low & $\begin{array}{l}\text { Based on Historical images of } \\
\text { google earth }\end{array}$ \\
\hline MPA 14 & Outside & Outside & 76.87 & $\begin{array}{l}\text { Tourism: } \\
\text { scuba-diving }\end{array}$ & $\begin{array}{l}\text { Number of } \\
\text { dives (nb/year) }\end{array}$ & 100 & $\begin{array}{l}\text { expert } \\
\text { opinion }\end{array}$ & low & Estimated \\
\hline MPA 14 & Outside & Outside & 282.03 & $\begin{array}{l}\text { Trawlers/purse } \\
\text {-seiners }\end{array}$ & $\begin{array}{l}\text { Number of } \\
\text { boats (nb/year) }\end{array}$ & 1 & data & high & $\begin{array}{l}\text { Curtesy of Torre Guaceto } \\
\text { Management Consortium }\end{array}$ \\
\hline MPA 15 & $\begin{array}{l}\text { Very strict } \\
\text { protection } \\
\text { subzone } \\
\text { (1a) }\end{array}$ & No-entry & 18.64 & $\begin{array}{l}\text { Artisanal } \\
\text { fishing }\end{array}$ & $\begin{array}{l}\text { Number of } \\
\text { boats (nb/year) }\end{array}$ & 0 & data & high & MPA regulations \\
\hline MPA 15 & $\begin{array}{l}\text { Very strict } \\
\text { protection } \\
\text { subzone } \\
\text { (1a) }\end{array}$ & No-entry & 18.64 & $\begin{array}{l}\text { Recreational } \\
\text { fishing: hook } \\
\text { and line }\end{array}$ & $\begin{array}{l}\text { Number of } \\
\text { people (nb/year) }\end{array}$ & 0 & data & high & MPA regulations \\
\hline MPA 15 & $\begin{array}{l}\text { Very strict } \\
\text { protection } \\
\text { subzone } \\
\text { (1a) }\end{array}$ & No-entry & 18.64 & $\begin{array}{l}\text { Recreational } \\
\text { fishing: } \\
\text { spearfishing }\end{array}$ & $\begin{array}{l}\text { Number of } \\
\text { people (nb/year) }\end{array}$ & 0 & data & high & MPA regulations \\
\hline MPA 15 & $\begin{array}{l}\text { Very strict } \\
\text { protection } \\
\text { subzone } \\
\text { (1a) }\end{array}$ & No-entry & 18.64 & $\begin{array}{l}\text { Tourism: } \\
\text { bathing/trampl } \\
\text { ing }\end{array}$ & $\begin{array}{l}\text { Number of } \\
\text { people (nb/year) }\end{array}$ & 0 & $\begin{array}{l}\text { expert } \\
\text { opinion }\end{array}$ & medium & MPA regulations \\
\hline
\end{tabular}




\begin{tabular}{|c|c|c|c|c|c|c|c|c|c|}
\hline MPA 15 & $\begin{array}{l}\text { Very strict } \\
\text { protection } \\
\text { subzone } \\
\text { (1a) }\end{array}$ & No-entry & 18.64 & $\begin{array}{l}\text { Tourism: } \\
\text { commercial } \\
\text { boating }\end{array}$ & $\begin{array}{l}\text { Number of } \\
\text { commercial } \\
\text { touristic boats } \\
\text { (nb/year) }\end{array}$ & 0 & data & low & MPA regulations \\
\hline MPA 15 & $\begin{array}{l}\text { Very strict } \\
\text { protection } \\
\text { subzone } \\
\text { (1a) }\end{array}$ & No-entry & 18.64 & $\begin{array}{l}\text { Tourism: } \\
\text { private } \\
\text { boating }\end{array}$ & $\begin{array}{l}\text { Number of } \\
\text { private boats } \\
\text { (nb/year) }\end{array}$ & 0 & data & low & MPA regulations \\
\hline MPA 15 & $\begin{array}{l}\text { Very strict } \\
\text { protection } \\
\text { subzone } \\
\text { (1a) }\end{array}$ & No-entry & 18.64 & $\begin{array}{l}\text { Tourism: } \\
\text { scuba-diving }\end{array}$ & $\begin{array}{l}\text { Number of } \\
\text { dives (nb/year) }\end{array}$ & 0 & data & high & MPA regulations \\
\hline MPA 15 & $\begin{array}{l}\text { Very strict } \\
\text { protection } \\
\text { subzone } \\
\text { (1a) }\end{array}$ & No-entry & 18.64 & $\begin{array}{l}\text { Trawlers/purse } \\
\text {-seiners }\end{array}$ & $\begin{array}{l}\text { Number of } \\
\text { boats (nb/year) }\end{array}$ & 0 & data & high & MPA regulations \\
\hline MPA 15 & $\begin{array}{l}\text { Strict } \\
\text { protection } \\
\text { subzone } \\
\text { (1b) }\end{array}$ & No-take & 111.52 & $\begin{array}{l}\text { Artisanal } \\
\text { fishing }\end{array}$ & $\begin{array}{l}\text { Number of } \\
\text { boats (nb/year) }\end{array}$ & 0 & data & medium & MPA regulations \\
\hline MPA 15 & $\begin{array}{l}\text { Strict } \\
\text { protection } \\
\text { subzone } \\
(1 b)\end{array}$ & No-take & 111.52 & $\begin{array}{l}\text { Recreational } \\
\text { fishing: hook } \\
\text { and line }\end{array}$ & $\begin{array}{l}\text { Number of } \\
\text { people (nb/year) }\end{array}$ & 0 & data & medium & MPA regulations \\
\hline MPA 15 & $\begin{array}{l}\text { Strict } \\
\text { protection } \\
\text { subzone } \\
(1 b)\end{array}$ & No-take & 111.52 & $\begin{array}{l}\text { Recreational } \\
\text { fishing: } \\
\text { spearfishing }\end{array}$ & $\begin{array}{l}\text { Number of } \\
\text { people (nb/year) }\end{array}$ & 0 & data & high & MPA regulations \\
\hline MPA 15 & $\begin{array}{l}\text { Strict } \\
\text { protection } \\
\text { subzone } \\
(1 b)\end{array}$ & No-take & 111.52 & $\begin{array}{l}\text { Tourism: } \\
\text { bathing/trampl } \\
\text { ing }\end{array}$ & $\begin{array}{l}\text { Number of } \\
\text { people (nb/year) }\end{array}$ & 0 & data & medium & MPA regulations \\
\hline MPA 15 & $\begin{array}{l}\text { Strict } \\
\text { protection } \\
\text { subzone } \\
(1 b)\end{array}$ & No-take & 111.52 & $\begin{array}{l}\text { Tourism: } \\
\text { commercial } \\
\text { boating }\end{array}$ & $\begin{array}{l}\text { Number of } \\
\text { commercial } \\
\text { touristic boats } \\
\text { (nb/year) }\end{array}$ & 591 & data & high & $\begin{array}{l}\text { Number of ticket sold to } \\
\text { commercial touristic boats }\end{array}$ \\
\hline
\end{tabular}




\begin{tabular}{|c|c|c|c|c|c|c|c|c|c|}
\hline MPA 15 & $\begin{array}{l}\text { Strict } \\
\text { protection } \\
\text { subzone } \\
(1 \mathrm{~b})\end{array}$ & No-take & 111.52 & $\begin{array}{l}\text { Tourism: } \\
\text { private } \\
\text { boating }\end{array}$ & $\begin{array}{l}\text { Number of } \\
\text { private boats } \\
\text { (nb/year) }\end{array}$ & 12803 & data & high & $\begin{array}{l}\text { Number of ticket sold to small } \\
\text { boats }\end{array}$ \\
\hline MPA 15 & $\begin{array}{l}\text { Strict } \\
\text { protection } \\
\text { subzone } \\
(1 \mathrm{~b})\end{array}$ & No-take & 111.52 & $\begin{array}{l}\text { Tourism: } \\
\text { scuba-diving }\end{array}$ & $\begin{array}{l}\text { Number of } \\
\text { dives (nb/year) }\end{array}$ & 0 & data & high & MPA regulations \\
\hline MPA 15 & $\begin{array}{l}\text { Strict } \\
\text { protection } \\
\text { subzone } \\
(1 \mathrm{~b})\end{array}$ & No-take & 111.52 & $\begin{array}{l}\text { Trawlers/purse } \\
\text {-seiners }\end{array}$ & $\begin{array}{l}\text { Number of } \\
\text { boats (nb/year) }\end{array}$ & 0 & data & high & MPA regulations \\
\hline MPA 15 & $\begin{array}{l}\text { Tradition } \\
\text { and culture } \\
\text { subzone } \\
\text { (2a) }\end{array}$ & $\begin{array}{l}\text { Partially } \\
\text { protected }\end{array}$ & 82.22 & $\begin{array}{l}\text { Artisanal } \\
\text { fishing }\end{array}$ & $\begin{array}{l}\text { Number of } \\
\text { boats (nb/year) }\end{array}$ & 107 & $\begin{array}{l}\text { expert } \\
\text { opinion }\end{array}$ & low & $\begin{array}{l}\text { There is } 107 \text { licences for } \\
\text { artizanal fisheries for people } \\
\text { who have properties in NP } \\
\text { Kornati. Licences include } \\
\text { trammel nets, long lines and } \\
\text { hook and line fishing gear but } \\
\text { they are not allowed to sell } \\
\text { fish. }\end{array}$ \\
\hline MPA 15 & $\begin{array}{l}\text { Tradition } \\
\text { and culture } \\
\text { subzone } \\
\text { (2a) }\end{array}$ & $\begin{array}{l}\text { Partially } \\
\text { protected }\end{array}$ & 82.22 & $\begin{array}{l}\text { Recreational } \\
\text { fishing: hook } \\
\text { and line }\end{array}$ & $\begin{array}{l}\text { Number of } \\
\text { people (nb/year) }\end{array}$ & 0 & data & medium & MPA regulations \\
\hline MPA 15 & $\begin{array}{l}\text { Tradition } \\
\text { and culture } \\
\text { subzone } \\
\text { (2a) }\end{array}$ & $\begin{array}{l}\text { Partially } \\
\text { protected }\end{array}$ & 82.22 & $\begin{array}{l}\text { Recreational } \\
\text { fishing: } \\
\text { spearfishing }\end{array}$ & $\begin{array}{l}\text { Number of } \\
\text { people (nb/year) }\end{array}$ & 0 & data & medium & MPA regulations \\
\hline MPA 15 & $\begin{array}{l}\text { Tradition } \\
\text { and culture } \\
\text { subzone } \\
(2 \mathrm{a})\end{array}$ & $\begin{array}{l}\text { Partially } \\
\text { protected }\end{array}$ & 82.22 & $\begin{array}{l}\text { Tourism: } \\
\text { bathing/trampl } \\
\text { ing }\end{array}$ & $\begin{array}{l}\text { Number of } \\
\text { people (nb/year) }\end{array}$ & 50000 & $\begin{array}{l}\text { expert } \\
\text { opinion }\end{array}$ & low & $\begin{array}{l}\text { There is estimation that half of } \\
\text { the guests go swiming and } \\
\text { walking arround the park }\end{array}$ \\
\hline MPA 15 & $\begin{array}{l}\text { Tradition } \\
\text { and culture } \\
\text { subzone } \\
(2 \mathrm{a}) \\
\end{array}$ & $\begin{array}{l}\text { Partially } \\
\text { protected }\end{array}$ & 82.22 & $\begin{array}{l}\text { Tourism: } \\
\text { commercial } \\
\text { boating }\end{array}$ & $\begin{array}{l}\text { Number of } \\
\text { commercial } \\
\text { touristic boats } \\
\text { (nb/year) }\end{array}$ & 591 & data & high & $\begin{array}{l}\text { Number of ticket sold to } \\
\text { commercial touristic boats }\end{array}$ \\
\hline
\end{tabular}




\begin{tabular}{|c|c|c|c|c|c|c|c|c|c|}
\hline MPA 15 & $\begin{array}{l}\text { Tradition } \\
\text { and culture } \\
\text { subzone } \\
(2 \mathrm{a})\end{array}$ & $\begin{array}{l}\text { Partially } \\
\text { protected }\end{array}$ & 82.22 & $\begin{array}{l}\text { Tourism: } \\
\text { private } \\
\text { boating }\end{array}$ & $\begin{array}{l}\text { Number of } \\
\text { private boats } \\
\text { (nb/year) }\end{array}$ & 12803 & data & high & $\begin{array}{l}\text { Number of ticket sold to small } \\
\text { boats }\end{array}$ \\
\hline MPA 15 & $\begin{array}{l}\text { Tradition } \\
\text { and culture } \\
\text { subzone } \\
(2 \mathrm{a})\end{array}$ & $\begin{array}{l}\text { Partially } \\
\text { protected }\end{array}$ & 82.22 & $\begin{array}{l}\text { Tourism: } \\
\text { scuba-diving }\end{array}$ & $\begin{array}{l}\text { Number of } \\
\text { dives (nb/year) }\end{array}$ & 0 & data & high & MPA regulations \\
\hline MPA 15 & $\begin{array}{l}\text { Tradition } \\
\text { and culture } \\
\text { subzone } \\
(2 \mathrm{a})\end{array}$ & $\begin{array}{l}\text { Partially } \\
\text { protected }\end{array}$ & 82.22 & $\begin{array}{l}\text { Trawlers/purse } \\
\text {-seiners }\end{array}$ & $\begin{array}{l}\text { Number of } \\
\text { boats (nb/year) }\end{array}$ & 0 & data & high & MPA regulations \\
\hline MPA 15 & $\begin{array}{l}\text { Recreation } \\
\text { subzone } \\
(2 b)\end{array}$ & $\begin{array}{l}\text { Partially } \\
\text { protected }\end{array}$ & 2.36 & $\begin{array}{l}\text { Artisanal } \\
\text { fishing }\end{array}$ & $\begin{array}{l}\text { Number of } \\
\text { boats (nb/year) }\end{array}$ & 0 & data & medium & MPA regulations \\
\hline MPA 15 & $\begin{array}{l}\text { Recreation } \\
\text { subzone } \\
(2 b)\end{array}$ & $\begin{array}{l}\text { Partially } \\
\text { protected }\end{array}$ & 2.36 & $\begin{array}{l}\text { Recreational } \\
\text { fishing: hook } \\
\text { and line }\end{array}$ & $\begin{array}{l}\text { Number of } \\
\text { people (nb/year) }\end{array}$ & 0 & data & medium & MPA regulations \\
\hline MPA 15 & $\begin{array}{l}\text { Recreation } \\
\text { subzone } \\
(2 b)\end{array}$ & $\begin{array}{l}\text { Partially } \\
\text { protected }\end{array}$ & 2.36 & $\begin{array}{l}\text { Recreational } \\
\text { fishing: } \\
\text { spearfishing }\end{array}$ & $\begin{array}{l}\text { Number of } \\
\text { people (nb/year) }\end{array}$ & 0 & data & medium & MPA regulations \\
\hline MPA 15 & $\begin{array}{l}\text { Recreation } \\
\text { subzone } \\
(2 b)\end{array}$ & $\begin{array}{l}\text { Partially } \\
\text { protected }\end{array}$ & 2.36 & $\begin{array}{l}\text { Tourism: } \\
\text { bathing/trampl } \\
\text { ing }\end{array}$ & $\begin{array}{l}\text { Number of } \\
\text { people (nb/year) }\end{array}$ & 50000 & $\begin{array}{l}\text { expert } \\
\text { opinion }\end{array}$ & low & $\begin{array}{l}\text { There is estimation that half of } \\
\text { the guests go swiming and } \\
\text { walking arround the park }\end{array}$ \\
\hline MPA 15 & $\begin{array}{l}\text { Recreation } \\
\text { subzone } \\
(2 b)\end{array}$ & $\begin{array}{l}\text { Partially } \\
\text { protected }\end{array}$ & 2.36 & $\begin{array}{l}\text { Tourism: } \\
\text { commercial } \\
\text { boating }\end{array}$ & $\begin{array}{l}\text { Number of } \\
\text { commercial } \\
\text { touristic boats } \\
\text { (nb/year) }\end{array}$ & 591 & data & high & $\begin{array}{l}\text { Number of ticket sold to } \\
\text { commercial touristic boats }\end{array}$ \\
\hline MPA 15 & $\begin{array}{l}\text { Recreation } \\
\text { subzone } \\
(2 b)\end{array}$ & $\begin{array}{l}\text { Partially } \\
\text { protected }\end{array}$ & 2.36 & $\begin{array}{l}\text { Tourism: } \\
\text { private } \\
\text { boating }\end{array}$ & $\begin{array}{l}\text { Number of } \\
\text { private boats } \\
\text { (nb/year) }\end{array}$ & 591 & data & high & $\begin{array}{l}\text { Number of ticket sold to small } \\
\text { boats }\end{array}$ \\
\hline MPA 15 & $\begin{array}{l}\text { Recreation } \\
\text { subzone } \\
(2 b)\end{array}$ & $\begin{array}{l}\text { Partially } \\
\text { protected }\end{array}$ & 2.36 & $\begin{array}{l}\text { Tourism: } \\
\text { scuba-diving }\end{array}$ & $\begin{array}{l}\text { Number of } \\
\text { dives (nb/year) }\end{array}$ & 12803 & $\begin{array}{l}\text { expert } \\
\text { opinion }\end{array}$ & low & Estimated \\
\hline MPA 15 & $\begin{array}{l}\text { Recreation } \\
\text { subzone } \\
(2 b)\end{array}$ & $\begin{array}{l}\text { Partially } \\
\text { protected }\end{array}$ & 2.36 & $\begin{array}{l}\text { Trawlers/purse } \\
\text {-seiners }\end{array}$ & $\begin{array}{l}\text { Number of } \\
\text { boats (nb/year) }\end{array}$ & 0 & data & high & MPA regulations \\
\hline
\end{tabular}




\begin{tabular}{|c|c|c|c|c|c|c|c|c|c|}
\hline MPA 15 & $\begin{array}{l}\text { Anchoring } \\
\text { subzone } \\
\text { (3a) }\end{array}$ & $\begin{array}{l}\text { Partially } \\
\text { protected }\end{array}$ & 1.41 & $\begin{array}{l}\text { Artisanal } \\
\text { fishing }\end{array}$ & $\begin{array}{l}\text { Number of } \\
\text { boats (nb/year) }\end{array}$ & 0 & data & medium & MPA regulations \\
\hline MPA 15 & $\begin{array}{l}\text { Anchoring } \\
\text { subzone } \\
\text { (3a) }\end{array}$ & $\begin{array}{l}\text { Partially } \\
\text { protected }\end{array}$ & 1.41 & $\begin{array}{l}\text { Recreational } \\
\text { fishing: hook } \\
\text { and line }\end{array}$ & $\begin{array}{l}\text { Number of } \\
\text { people (nb/year) }\end{array}$ & 0 & data & medium & MPA regulations \\
\hline MPA 15 & $\begin{array}{l}\text { Anchoring } \\
\text { subzone } \\
\text { (3a) }\end{array}$ & $\begin{array}{l}\text { Partially } \\
\text { protected }\end{array}$ & 1.41 & $\begin{array}{l}\text { Recreational } \\
\text { fishing: } \\
\text { spearfishing }\end{array}$ & $\begin{array}{l}\text { Number of } \\
\text { people (nb/year) }\end{array}$ & 0 & data & medium & MPA regulations \\
\hline MPA 15 & $\begin{array}{l}\text { Anchoring } \\
\text { subzone } \\
\text { (3a) }\end{array}$ & $\begin{array}{l}\text { Partially } \\
\text { protected }\end{array}$ & 1.41 & $\begin{array}{l}\text { Tourism: } \\
\text { bathing/trampl } \\
\text { ing }\end{array}$ & $\begin{array}{l}\text { Number of } \\
\text { people (nb/year) }\end{array}$ & 50000 & $\begin{array}{l}\text { expert } \\
\text { opinion }\end{array}$ & low & $\begin{array}{l}\text { There is estimation that half of } \\
\text { the guests go swiming and } \\
\text { walking arround the park }\end{array}$ \\
\hline MPA 15 & $\begin{array}{l}\text { Anchoring } \\
\text { subzone } \\
\text { (3a) }\end{array}$ & $\begin{array}{l}\text { Partially } \\
\text { protected }\end{array}$ & 1.41 & $\begin{array}{l}\text { Tourism: } \\
\text { commercial } \\
\text { boating }\end{array}$ & $\begin{array}{l}\text { Number of } \\
\text { commercial } \\
\text { touristic boats } \\
\text { (nb/year) }\end{array}$ & 591 & data & high & $\begin{array}{l}\text { Number of ticket sold to } \\
\text { commercial touristic boats }\end{array}$ \\
\hline MPA 15 & $\begin{array}{l}\text { Anchoring } \\
\text { subzone } \\
\text { (3a) }\end{array}$ & $\begin{array}{l}\text { Partially } \\
\text { protected }\end{array}$ & 1.41 & $\begin{array}{l}\text { Tourism: } \\
\text { private } \\
\text { boating }\end{array}$ & $\begin{array}{l}\text { Number of } \\
\text { private boats } \\
\text { (nb/year) }\end{array}$ & 12803 & data & high & $\begin{array}{l}\text { Number of ticket sold to small } \\
\text { boats }\end{array}$ \\
\hline MPA 15 & $\begin{array}{l}\text { Anchoring } \\
\text { subzone } \\
\text { (3a) }\end{array}$ & $\begin{array}{l}\text { Partially } \\
\text { protected }\end{array}$ & 1.41 & $\begin{array}{l}\text { Tourism: } \\
\text { scuba-diving }\end{array}$ & $\begin{array}{l}\text { Number of } \\
\text { dives (nb/year) }\end{array}$ & 0 & data & high & MPA regulations \\
\hline MPA 15 & $\begin{array}{l}\text { Anchoring } \\
\text { subzone } \\
\text { (3a) }\end{array}$ & $\begin{array}{l}\text { Partially } \\
\text { protected }\end{array}$ & 1.41 & $\begin{array}{l}\text { Trawlers/purse } \\
\text {-seiners }\end{array}$ & $\begin{array}{l}\text { Number of } \\
\text { boats (nb/year) }\end{array}$ & 0 & data & high & MPA regulations \\
\hline MPA 15 & $\begin{array}{l}\text { Settlement } \\
\text { subzone } \\
(3 \mathrm{~b})\end{array}$ & $\begin{array}{l}\text { Partially } \\
\text { protected }\end{array}$ & 0.64 & $\begin{array}{l}\text { Artisanal } \\
\text { fishing }\end{array}$ & $\begin{array}{l}\text { Number of } \\
\text { boats (nb/year) }\end{array}$ & 0 & data & medium & MPA regulations \\
\hline MPA 15 & $\begin{array}{l}\text { Settlement } \\
\text { subzone } \\
(3 \mathrm{~b})\end{array}$ & $\begin{array}{l}\text { Partially } \\
\text { protected }\end{array}$ & 0.64 & $\begin{array}{l}\text { Recreational } \\
\text { fishing: hook } \\
\text { and line }\end{array}$ & $\begin{array}{l}\text { Number of } \\
\text { people (nb/year) }\end{array}$ & 0 & data & medium & MPA regulations \\
\hline MPA 15 & $\begin{array}{l}\text { Settlement } \\
\text { subzone } \\
(3 \mathrm{~b})\end{array}$ & $\begin{array}{l}\text { Partially } \\
\text { protected }\end{array}$ & 0.64 & $\begin{array}{l}\text { Recreational } \\
\text { fishing: } \\
\text { spearfishing }\end{array}$ & $\begin{array}{l}\text { Number of } \\
\text { people (nb/year) }\end{array}$ & 0 & data & medium & MPA regulations \\
\hline MPA 15 & $\begin{array}{l}\text { Settlement } \\
\text { subzone } \\
(3 \mathrm{~b})\end{array}$ & $\begin{array}{l}\text { Partially } \\
\text { protected }\end{array}$ & 0.64 & $\begin{array}{l}\text { Tourism: } \\
\text { bathing/trampl } \\
\text { ing }\end{array}$ & $\begin{array}{l}\text { Number of } \\
\text { people (nb/year) }\end{array}$ & 50000 & $\begin{array}{l}\text { expert } \\
\text { opinion }\end{array}$ & low & $\begin{array}{l}\text { There is estimation that half of } \\
\text { the guests go swiming and } \\
\text { walking arround the park }\end{array}$ \\
\hline
\end{tabular}




\begin{tabular}{|c|c|c|c|c|c|c|c|c|c|}
\hline MPA 15 & $\begin{array}{l}\text { Settlement } \\
\text { subzone } \\
(3 b)\end{array}$ & $\begin{array}{l}\text { Partially } \\
\text { protected }\end{array}$ & 0.64 & $\begin{array}{l}\text { Tourism: } \\
\text { commercial } \\
\text { boating }\end{array}$ & $\begin{array}{l}\text { Number of } \\
\text { commercial } \\
\text { touristic boats } \\
\text { (nb/year) }\end{array}$ & 0 & data & high & MPA regulations \\
\hline MPA 15 & $\begin{array}{l}\text { Settlement } \\
\text { subzone } \\
(3 \mathrm{~b})\end{array}$ & $\begin{array}{l}\text { Partially } \\
\text { protected }\end{array}$ & 0.64 & $\begin{array}{l}\text { Tourism: } \\
\text { private } \\
\text { boating }\end{array}$ & $\begin{array}{l}\text { Number of } \\
\text { private boats } \\
\text { (nb/year) }\end{array}$ & 0 & data & high & MPA regulations \\
\hline MPA 15 & $\begin{array}{l}\text { Settlement } \\
\text { subzone } \\
(3 \mathrm{~b})\end{array}$ & $\begin{array}{l}\text { Partially } \\
\text { protected }\end{array}$ & 0.64 & $\begin{array}{l}\text { Tourism: } \\
\text { scuba-diving }\end{array}$ & $\begin{array}{l}\text { Number of } \\
\text { dives (nb/year) }\end{array}$ & 0 & data & high & MPA regulations \\
\hline MPA 15 & $\begin{array}{l}\text { Settlement } \\
\text { subzone } \\
(3 \mathrm{~b})\end{array}$ & $\begin{array}{l}\text { Partially } \\
\text { protected }\end{array}$ & 0.64 & $\begin{array}{l}\text { Trawlers/purse } \\
\text {-seiners }\end{array}$ & $\begin{array}{l}\text { Number of } \\
\text { boats (nb/year) }\end{array}$ & 0 & data & high & MPA regulations \\
\hline MPA 15 & Outside & Outside & 462.13 & $\begin{array}{l}\text { Artisanal } \\
\text { fishing }\end{array}$ & $\begin{array}{l}\text { Number of } \\
\text { boats (nb/year) }\end{array}$ & 160 & data & medium & MPA regulations \\
\hline MPA 15 & Outside & Outside & 462.13 & $\begin{array}{l}\text { Recreational } \\
\text { fishing: hook } \\
\text { and line }\end{array}$ & $\begin{array}{l}\text { Number of } \\
\text { people (nb/year) }\end{array}$ & 1500 & $\begin{array}{l}\text { expert } \\
\text { opinion }\end{array}$ & low & Estimated \\
\hline MPA 15 & Outside & Outside & 462.13 & $\begin{array}{l}\text { Recreational } \\
\text { fishing: } \\
\text { spearfishing }\end{array}$ & $\begin{array}{l}\text { Number of } \\
\text { people (nb/year) }\end{array}$ & 500 & $\begin{array}{l}\text { expert } \\
\text { opinion }\end{array}$ & low & Estimated \\
\hline MPA 15 & Outside & Outside & 462.13 & $\begin{array}{l}\text { Tourism: } \\
\text { bathing/trampl } \\
\text { ing }\end{array}$ & $\begin{array}{l}\text { Number of } \\
\text { people (nb/year) }\end{array}$ & 40000 & $\begin{array}{l}\text { expert } \\
\text { opinion }\end{array}$ & low & Estimated \\
\hline MPA 15 & Outside & Outside & 462.13 & $\begin{array}{l}\text { Tourism: } \\
\text { commercial } \\
\text { boating }\end{array}$ & $\begin{array}{l}\text { Number of } \\
\text { commercial } \\
\text { touristic boats } \\
\text { (nb/year) }\end{array}$ & 700 & $\begin{array}{l}\text { expert } \\
\text { opinion }\end{array}$ & low & Estimated \\
\hline MPA 15 & Outside & Outside & 462.13 & $\begin{array}{l}\text { Tourism: } \\
\text { private } \\
\text { boating }\end{array}$ & $\begin{array}{l}\text { Number of } \\
\text { private boats } \\
\text { (nb/year) }\end{array}$ & 17000 & $\begin{array}{l}\text { expert } \\
\text { opinion }\end{array}$ & low & Estimated \\
\hline MPA 15 & Outside & Outside & 462.13 & $\begin{array}{l}\text { Tourism: } \\
\text { scuba-diving }\end{array}$ & $\begin{array}{l}\text { Number of } \\
\text { dives (nb/year) }\end{array}$ & 33270 & $\begin{array}{l}\text { expert } \\
\text { opinion }\end{array}$ & medium & Estimated \\
\hline MPA 15 & Outside & Outside & 1269.35 & $\begin{array}{l}\text { Trawlers/purse } \\
\text {-seiners }\end{array}$ & $\begin{array}{l}\text { Number of } \\
\text { boats (nb/year) }\end{array}$ & 70 & $\begin{array}{l}\text { expert } \\
\text { opinion }\end{array}$ & medium & Estimated \\
\hline
\end{tabular}




\section{References}

Association AGIR. 2013. Appui et accompagnement à la création/post création d'activités génératrices de revenus et de coopérative les pêcheurs néo-alphabétisés au sein du littoral du Rif centrale et orientale Marocain. Rapport global final. 120p.

http://panorama.solutions/sites/default/files/rapport-final-projet-agir_-app.pdf

Cappanera, V., Venturini, S., \& Campodonico, P., Blini, V., Ortenzi, 2010. Valutazione dell'impatto antropico legato alle attività svolte nell'Area Marina protetta Portofino (AMP). Le attività di fruizione 2010-2011. Rapporto tecnico: 194 pp.

Cappanera, V., Venturini, S., \& Campodonico, P. 2014. Valutazione dell'impatto antropico e socio-economico nell'Area Marina Protetta del Promontorio di Portofino. Portofino MPA, Annual Report, 1-51 pp.

Cattaneo-Vietti, R. (ed.). 2013. La pesca ricreativa nel Mar Ligure. In Modelli di governante e monitoraggio e valorizzazione delle risorse ittiche (pp. 1-84). Regione Liguria: Progetto strategico MARTE+.

Franzosini, C., Limam, A. 2006. Plan de gestion de la composante marine du Parc National d'Al Hoceima. Rapport du Projet Régional pour le Développement d'Aires Protégées Marines et Côtières dans la Région Méditerranéenne (Projet MedMPA). 92 p.

Font, T., Lloret, J., Piante, C. 2012. Recreational fishing within Marine Protected Areas in the Mediterranean. MedPAN North Project. WWFFrance: $168 \mathrm{pp}$

Nibani, H. 2010. Rapport des ateliers de communication sur la gestion du Parc Nationale d'Al Hoceima. Rapport final, 31 p. http://www.mapama.gob.es/es/parques-nacionales-oapn.

Sacanell, M. 2010. Avaluació de les captures de la pesca artesanal en la zona d'influència de l'Àrea Protegida de les Illes Medes. 


\section{Appendix C}

\section{Supplementary Figure and Descriptive Statistics}

\section{Supplementary Figures}

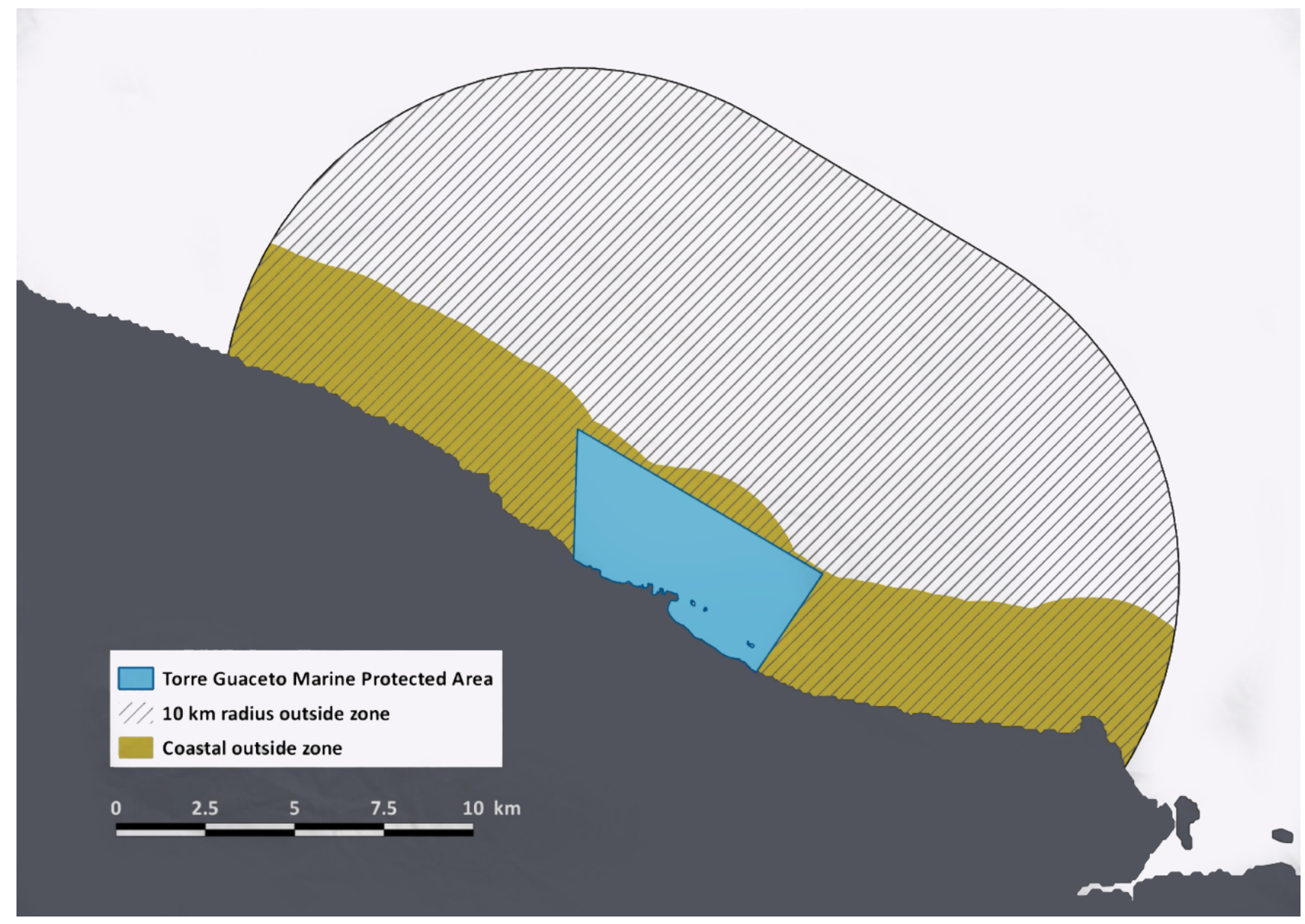

Fig. C.1. Example of outside areas of a marine protected area, as used for the study. We used two approaches to delineate the outside area, depending on the characteristics of the threat: 1) for commercial fishing with trawlers and purse seiners a $10 \mathrm{~km}$ radius surrounding the MPAs was applied (dashed area), while 2) for all other threats originating closer to the shore we considered the coastal section up to a maximum distance from the shore equal to the MPAs most offshore limit (brown area). 


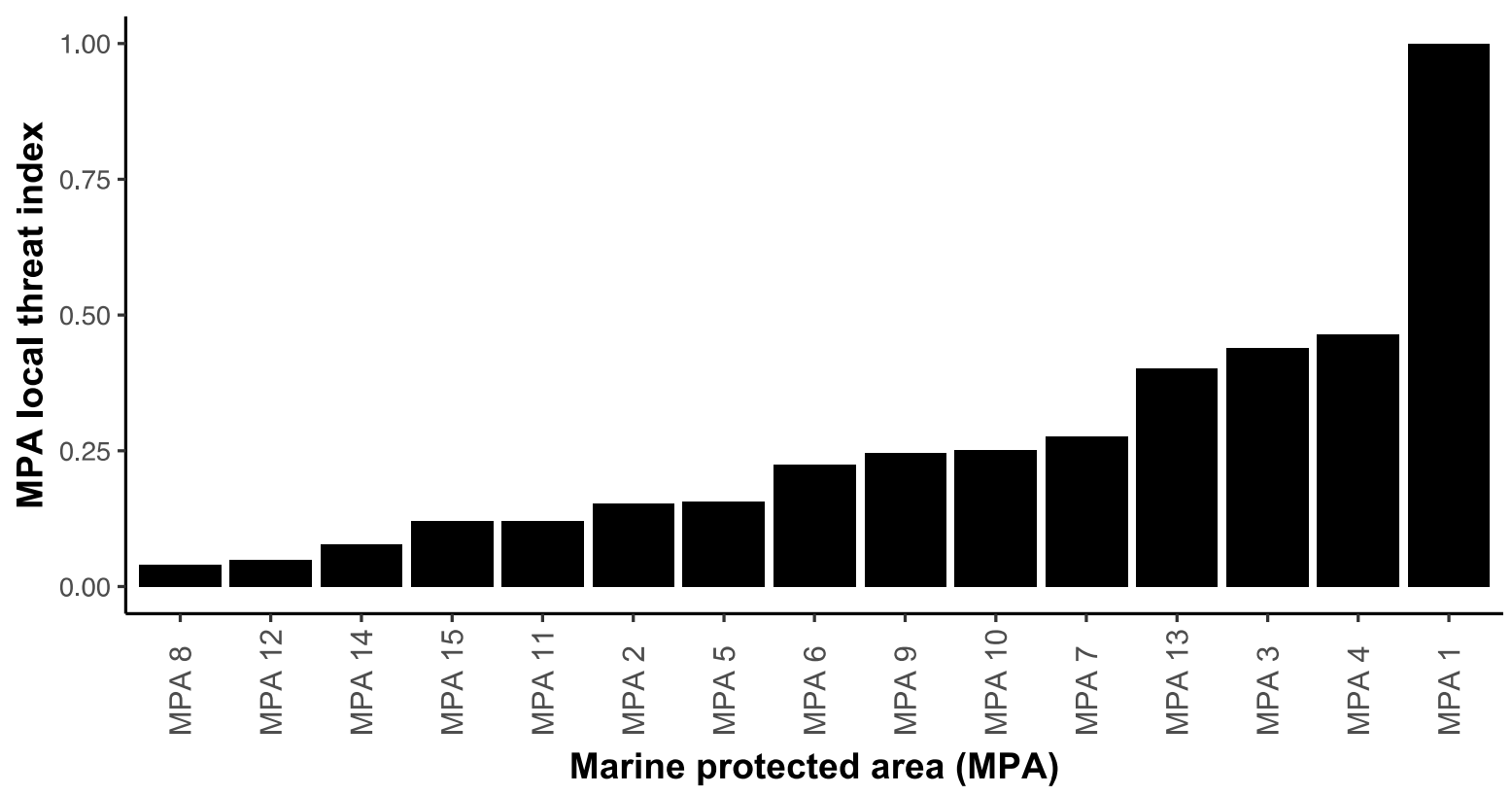

Non-extractive threats

Extractive threats

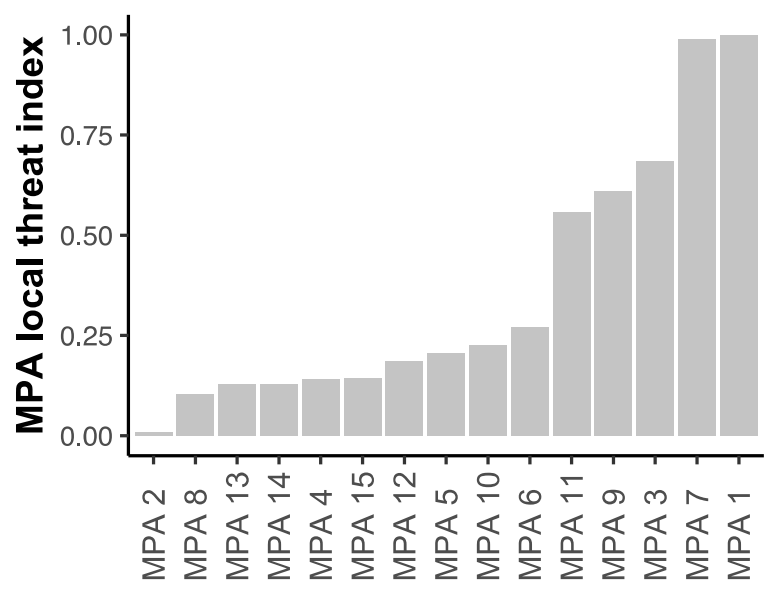

Marine protected area (MPA)

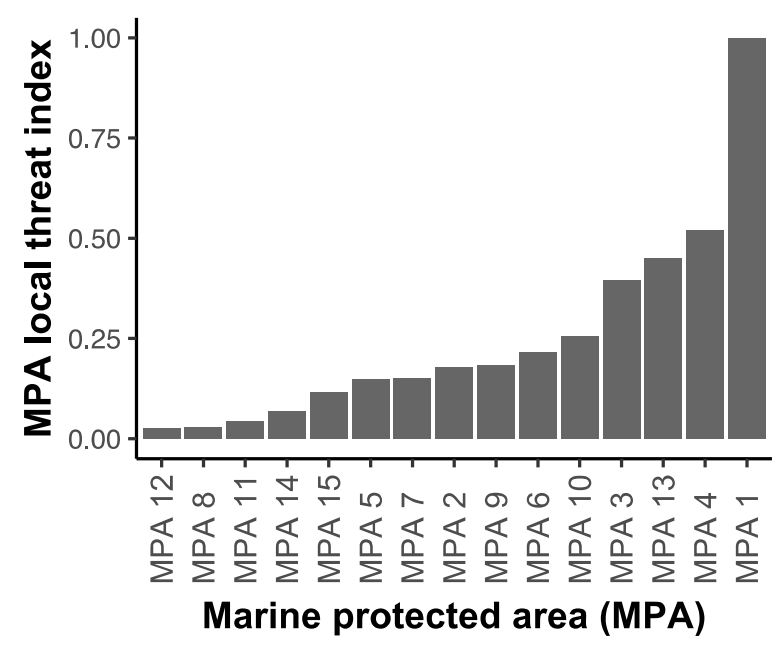

Fig. C.2. Local threat index of marine protected areas (MPAs) for all threats combined (top panel), extractive (bottom left panel) and non-extractive threats (bottom right panel). A low/high index mean that the MPA have a low/high threat intensities in its outside area, when compared to the threat intensities found in the outside areas of the other MPAs included in this study. 

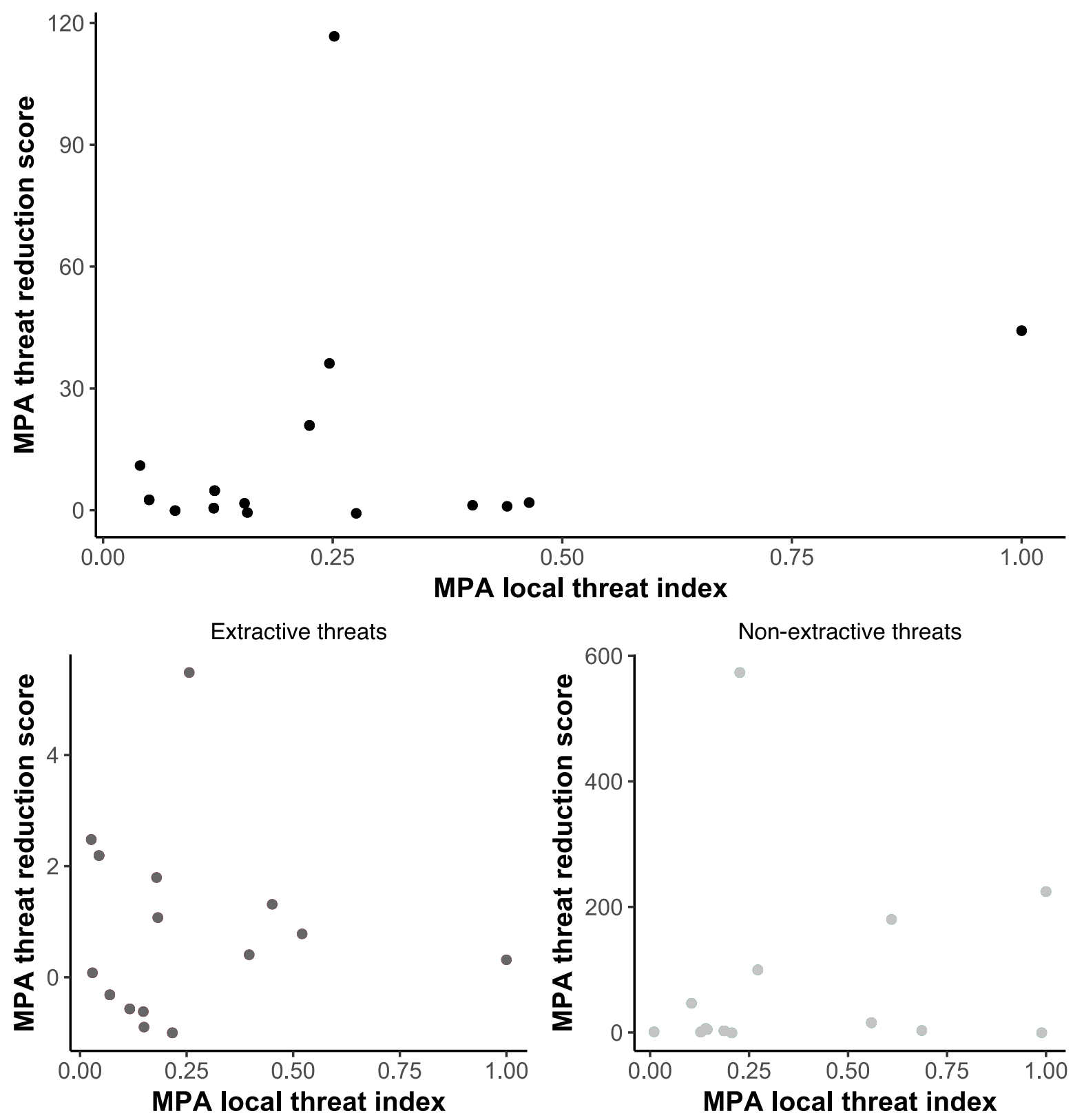

Fig. C.3. Relationships between the marine protected area (MPA) threat reduction score and the MPA local threat index for all threats combined (top panel), extractive (bottom left panel) and non-extractive threats (bottom right panel). No significant linear relationships were found $(\mathrm{p}>0.05)$. 
All threats
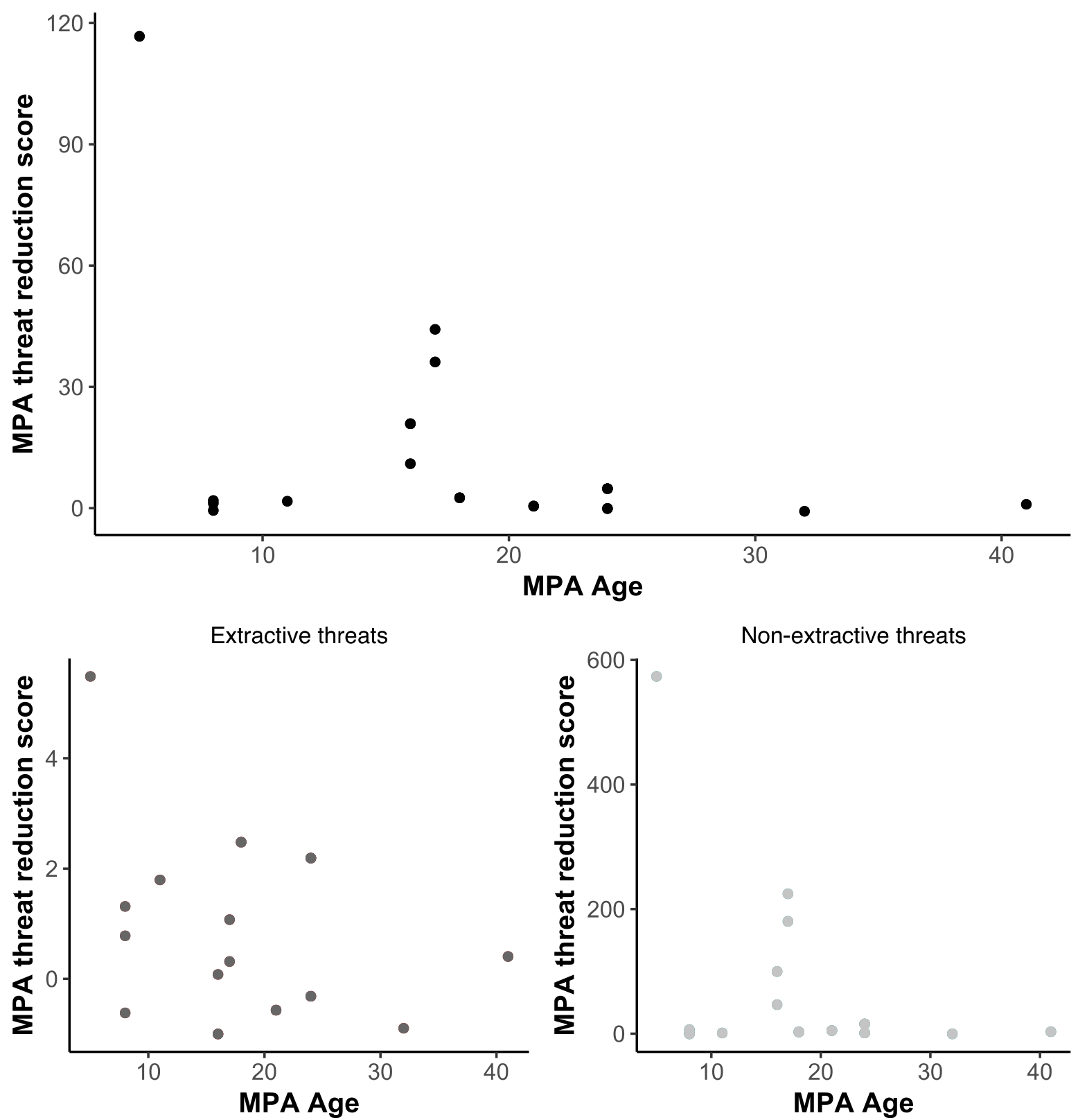

Fig. C.4. Relationships between the threat reduction score and the age of the marine protected areas (MPAs) for all threats combined (top panel), extractive (bottom left panel) and non-extractive threats (bottom right panel). No significant linear relationships were found $(\mathrm{p}>0.05)$. 

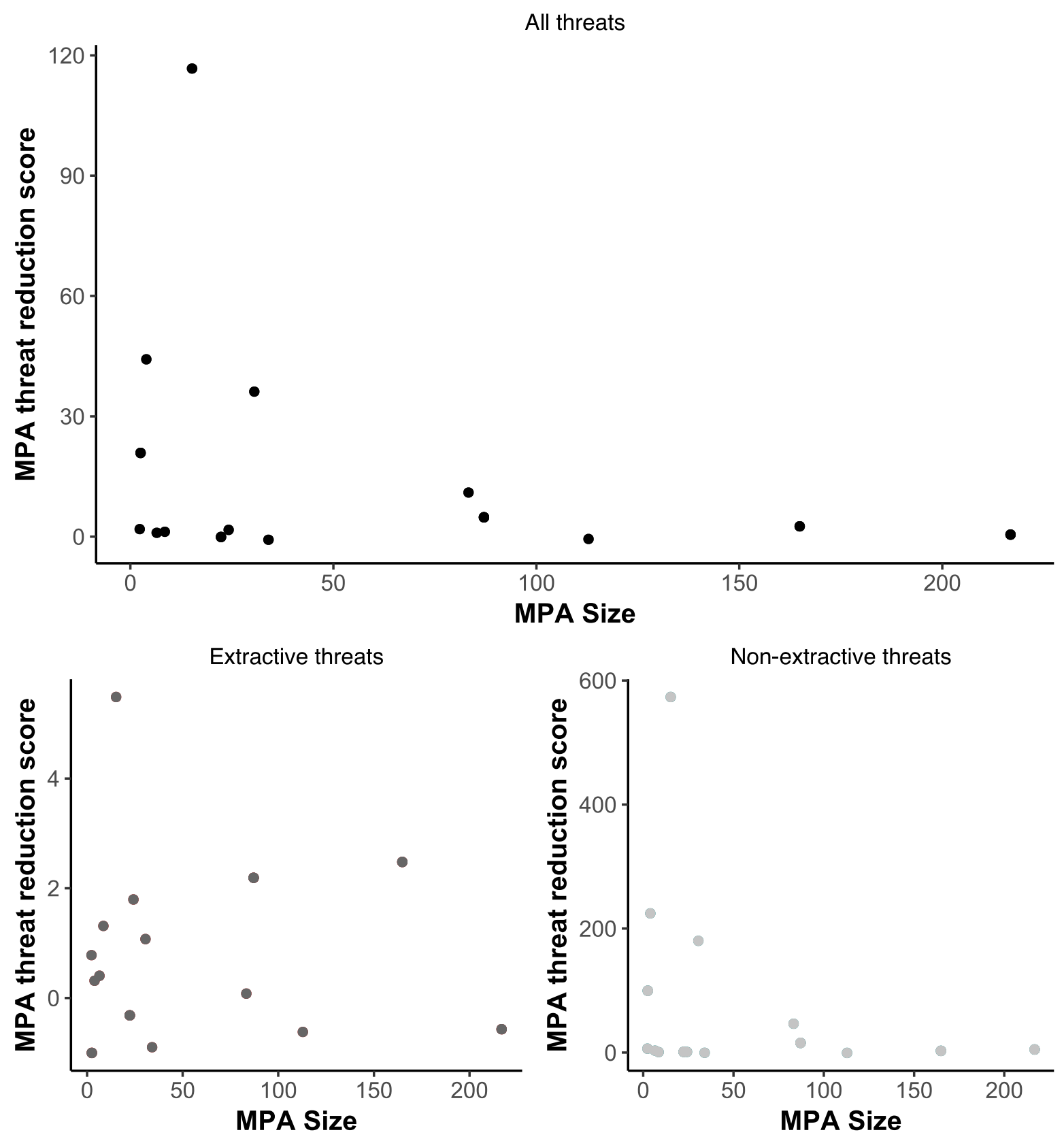

Fig. C.5. Relationships between the threat reduction score and the size of the marine protected areas (MPAs) for all threats combined (top panel), extractive (bottom left panel) and non-extractive threats (bottom right panel). No significant linear relationships were found $(\mathrm{p}>0.05)$. 


\section{Descriptive statistics for the threat intensity index and threat reduction capacity index}

Table C.1. Descriptive statistics for the standardized threat intensity index. The standardized threat intensity values were obtained by diving with the maximum threat intensity of each threat. This resulted in a standardized scale of $0-1$. These normalized values were then used to calculate the mean threat intensity of each threat in each protection level to explore the variability of threat intensity amongst protection levels (Fig. 2).

\begin{tabular}{|c|c|c|c|c|c|c|c|c|c|c|c|c|}
\hline $\begin{array}{l}\text { Protection } \\
\text { level }\end{array}$ & Threats & Type & Mean & $\begin{array}{l}\text { Standard } \\
\text { deviation }\end{array}$ & $\begin{array}{l}\text { Sample } \\
\text { Size }\end{array}$ & $\begin{array}{l}\text { Standard } \\
\text { error }\end{array}$ & $\begin{array}{l}\text { Medi } \\
\text { an }\end{array}$ & Min & Max & $25 \%$ & $50 \%$ & $75 \%$ \\
\hline $\begin{array}{l}\text { Fully } \\
\text { Protected }\end{array}$ & Artisanal fishing & extractive & 0 & 0 & 18 & - & 0 & 0 & 0 & 0 & 0 & 0 \\
\hline $\begin{array}{l}\text { Fully } \\
\text { Protected }\end{array}$ & $\begin{array}{l}\text { Recreational fishing: hook } \\
\text { and line }\end{array}$ & extractive & 0 & 0 & 18 & - & 0 & 0 & 0 & 0 & 0 & 0 \\
\hline $\begin{array}{l}\text { Fully } \\
\text { Protected }\end{array}$ & $\begin{array}{l}\text { Recreational fishing: } \\
\text { spearfishing }\end{array}$ & extractive & 0 & 0 & 18 & - & 0 & 0 & 0 & 0 & 0 & 0 \\
\hline $\begin{array}{l}\text { Fully } \\
\text { Protected }\end{array}$ & Trawlers/purse-seiners & extractive & 0 & 0 & 18 & - & 0 & 0 & 0 & 0 & 0 & 0 \\
\hline $\begin{array}{l}\text { Fully } \\
\text { Protected }\end{array}$ & Tourism: bathing/trampling & $\begin{array}{l}\text { non- } \\
\text { extractive }\end{array}$ & $\begin{array}{r}0.087 \\
50 \\
\end{array}$ & 0.23875 & 18 & 0.05627 & $\begin{array}{r}0.000 \\
57 \\
\end{array}$ & 0 & 1 & 0 & $\begin{array}{r}0.000 \\
57 \\
\end{array}$ & $\begin{array}{r}0.018 \\
45 \\
\end{array}$ \\
\hline $\begin{array}{l}\text { Fully } \\
\text { Protected }\end{array}$ & $\begin{array}{l}\text { Tourism: commercial } \\
\text { boating }\end{array}$ & $\begin{array}{l}\text { non- } \\
\text { extractive }\end{array}$ & $\begin{array}{r}0.066 \\
59 \\
\end{array}$ & 0.23437 & 18 & 0.05524 & 0 & 0 & 1 & 0 & 0 & $\begin{array}{r}0.020 \\
05 \\
\end{array}$ \\
\hline $\begin{array}{l}\text { Fully } \\
\text { Protected }\end{array}$ & Tourism: private boating & $\begin{array}{l}\text { non- } \\
\text { extractive }\end{array}$ & $\begin{array}{r}0.112 \\
40 \\
\end{array}$ & 0.27257 & 18 & 0.06425 & $\begin{array}{r}0.003 \\
10 \\
\end{array}$ & 0 & 1 & 0 & $\begin{array}{r}0.003 \\
10 \\
\end{array}$ & $\begin{array}{r}0.042 \\
81 \\
\end{array}$ \\
\hline $\begin{array}{l}\text { Fully } \\
\text { Protected }\end{array}$ & Tourism: scuba-diving & $\begin{array}{l}\text { non- } \\
\text { extractive }\end{array}$ & $\begin{array}{r}0.059 \\
26 \\
\end{array}$ & 0.23529 & 18 & 0.05546 & $\begin{array}{r}0.000 \\
00 \\
\end{array}$ & 0 & 1 & 0 & $\begin{array}{r}0.000 \\
00\end{array}$ & $\begin{array}{r}0.000 \\
00 \\
\end{array}$ \\
\hline $\begin{array}{l}\text { Partially } \\
\text { protected }\end{array}$ & Artisanal fishing & extractive & $\begin{array}{r}0.190 \\
81 \\
\end{array}$ & 0.27044 & 32 & 0.04781 & $\begin{array}{r}0.098 \\
77 \\
\end{array}$ & 0 & 1 & $\begin{array}{r}0.027 \\
18 \\
\end{array}$ & $\begin{array}{r}0.098 \\
77 \\
\end{array}$ & $\begin{array}{r}0.208 \\
50 \\
\end{array}$ \\
\hline $\begin{array}{l}\text { Partially } \\
\text { protected }\end{array}$ & $\begin{array}{l}\text { Recreational fishing: hook } \\
\text { and line }\end{array}$ & extractive & $\begin{array}{r}0.171 \\
45 \\
\end{array}$ & 0.29805 & 32 & 0.05269 & $\begin{array}{r}0.031 \\
82 \\
\end{array}$ & 0 & 1 & 0 & $\begin{array}{r}0.031 \\
82 \\
\end{array}$ & $\begin{array}{r}0.159 \\
75 \\
\end{array}$ \\
\hline $\begin{array}{l}\text { Partially } \\
\text { protected }\end{array}$ & $\begin{array}{l}\text { Recreational fishing: } \\
\text { spearfishing }\end{array}$ & extractive & $\begin{array}{r}0.043 \\
62 \\
\end{array}$ & 0.18155 & 32 & 0.03209 & 0 & 0 & 1 & 0 & 0 & $\begin{array}{r}0.001 \\
91 \\
\end{array}$ \\
\hline $\begin{array}{l}\text { Partially } \\
\text { protected }\end{array}$ & Trawlers/purse-seiners & extractive & $\begin{array}{r}0.001 \\
44 \\
\end{array}$ & 0.00817 & 32 & 0.00144 & 0 & 0 & $\begin{array}{r}0.046 \\
21 \\
\end{array}$ & 0 & 0 & 0 \\
\hline $\begin{array}{l}\text { Partially } \\
\text { protected }\end{array}$ & Tourism: bathing/trampling & $\begin{array}{l}\text { non- } \\
\text { extractive }\end{array}$ & $\begin{array}{r}0.044 \\
23 \\
\end{array}$ & 0.07340 & 32 & 0.01298 & $\begin{array}{r}0.008 \\
22 \\
\end{array}$ & 0 & $\begin{array}{r}0.237 \\
99 \\
\end{array}$ & $\begin{array}{r}0.002 \\
22 \\
\end{array}$ & $\begin{array}{r}0.008 \\
22 \\
\end{array}$ & $\begin{array}{r}0.042 \\
45 \\
\end{array}$ \\
\hline $\begin{array}{l}\text { Partially } \\
\text { protected }\end{array}$ & $\begin{array}{l}\text { Tourism: commercial } \\
\text { boating }\end{array}$ & $\begin{array}{l}\text { non- } \\
\text { extractive }\end{array}$ & $\begin{array}{r}0.034 \\
48 \\
\end{array}$ & 0.12059 & 32 & 0.02132 & $\begin{array}{r}0.003 \\
51 \\
\end{array}$ & 0 & $\begin{array}{r}0.598 \\
78 \\
\end{array}$ & 0 & $\begin{array}{r}0.003 \\
51 \\
\end{array}$ & $\begin{array}{r}0.008 \\
14 \\
\end{array}$ \\
\hline
\end{tabular}




\begin{tabular}{|c|c|c|c|c|c|c|c|c|c|c|c|c|}
\hline $\begin{array}{l}\text { Partially } \\
\text { protected }\end{array}$ & Tourism: private boating & $\begin{array}{l}\text { non- } \\
\text { extractive }\end{array}$ & $\begin{array}{r}0.056 \\
24 \\
\end{array}$ & 0.11317 & 32 & 0.02001 & $\begin{array}{r}0.009 \\
19 \\
\end{array}$ & 0 & $\begin{array}{r}0.535 \\
73 \\
\end{array}$ & $\begin{array}{r}0.000 \\
76 \\
\end{array}$ & $\begin{array}{r}0.009 \\
19 \\
\end{array}$ & $\begin{array}{r}0.055 \\
91 \\
\end{array}$ \\
\hline $\begin{array}{l}\text { Partially } \\
\text { protected }\end{array}$ & Tourism: scuba-diving & $\begin{array}{l}\text { non- } \\
\text { extractive }\end{array}$ & $\begin{array}{r}0.024 \\
45 \\
\end{array}$ & 0.05391 & 32 & 0.00953 & $\begin{array}{r}0.000 \\
70\end{array}$ & 0 & $\begin{array}{r}0.248 \\
01\end{array}$ & 0 & $\begin{array}{r}0.000 \\
70\end{array}$ & $\begin{array}{r}0.020 \\
99 \\
\end{array}$ \\
\hline Outside & Artisanal fishing & extractive & $\begin{array}{r}0.077 \\
81 \\
\end{array}$ & 0.12497 & 15 & 0.03227 & $\begin{array}{r}0.033 \\
57 \\
\end{array}$ & $\begin{array}{r}0.004 \\
29 \\
\end{array}$ & $\begin{array}{r}0.487 \\
99 \\
\end{array}$ & $\begin{array}{r}0.016 \\
11 \\
\end{array}$ & $\begin{array}{r}0.033 \\
57 \\
\end{array}$ & $\begin{array}{r}0.081 \\
27 \\
\end{array}$ \\
\hline Outside & $\begin{array}{l}\text { Recreational fishing: hook } \\
\text { and line }\end{array}$ & extractive & $\begin{array}{r}0.072 \\
10\end{array}$ & 0.10633 & 15 & 0.02745 & $\begin{array}{r}0.030 \\
70\end{array}$ & 0 & $\begin{array}{r}0.398 \\
42\end{array}$ & $\begin{array}{r}0.015 \\
08\end{array}$ & $\begin{array}{r}0.030 \\
70\end{array}$ & $\begin{array}{r}0.054 \\
84\end{array}$ \\
\hline Outside & $\begin{array}{l}\text { Recreational fishing: } \\
\text { spearfishing }\end{array}$ & extractive & $\begin{array}{r}0.009 \\
82 \\
\end{array}$ & 0.02336 & 15 & 0.00603 & $\begin{array}{r}0.002 \\
58 \\
\end{array}$ & 0 & $\begin{array}{r}0.092 \\
36 \\
\end{array}$ & $\begin{array}{r}0.001 \\
01 \\
\end{array}$ & $\begin{array}{r}0.002 \\
58 \\
\end{array}$ & $\begin{array}{r}0.004 \\
58 \\
\end{array}$ \\
\hline Outside & Trawlers/purse-seiners & extractive & $\begin{array}{r}0.263 \\
77 \\
\end{array}$ & 0.27445 & 15 & 0.07086 & $\begin{array}{r}0.185 \\
72 \\
\end{array}$ & 0 & $\begin{array}{r}1.000 \\
00 \\
\end{array}$ & $\begin{array}{r}0.032 \\
96 \\
\end{array}$ & $\begin{array}{r}0.185 \\
72 \\
\end{array}$ & $\begin{array}{r}0.422 \\
19 \\
\end{array}$ \\
\hline Outside & Tourism: bathing/trampling & $\begin{array}{l}\text { non- } \\
\text { extractive }\end{array}$ & $\begin{array}{r}0.011 \\
39 \\
\end{array}$ & 0.00824 & 15 & 0.00213 & $\begin{array}{r}0.011 \\
21\end{array}$ & $\begin{array}{r}0.000 \\
07\end{array}$ & $\begin{array}{r}0.025 \\
97 \\
\end{array}$ & $\begin{array}{r}0.005 \\
25 \\
\end{array}$ & $\begin{array}{r}0.011 \\
21 \\
\end{array}$ & $\begin{array}{r}0.017 \\
57 \\
\end{array}$ \\
\hline Outside & $\begin{array}{l}\text { Tourism: commercial } \\
\text { boating }\end{array}$ & $\begin{array}{l}\text { non- } \\
\text { extractive }\end{array}$ & $\begin{array}{r}0.004 \\
96 \\
\end{array}$ & 0.01089 & 15 & 0.00281 & $\begin{array}{r}0.000 \\
67 \\
\end{array}$ & 0 & $\begin{array}{r}0.041 \\
96 \\
\end{array}$ & $\begin{array}{r}0.000 \\
17 \\
\end{array}$ & $\begin{array}{r}0.000 \\
67 \\
\end{array}$ & $\begin{array}{r}0.002 \\
73 \\
\end{array}$ \\
\hline Outside & Tourism: private boating & $\begin{array}{l}\text { non- } \\
\text { extractive }\end{array}$ & $\begin{array}{r}0.003 \\
26\end{array}$ & 0.00449 & 15 & 0.00116 & $\begin{array}{r}0.001 \\
26\end{array}$ & $\begin{array}{r}0.000 \\
01\end{array}$ & $\begin{array}{r}0.014 \\
04\end{array}$ & $\begin{array}{r}0.000 \\
23\end{array}$ & $\begin{array}{r}0.001 \\
26\end{array}$ & $\begin{array}{r}0.003 \\
91\end{array}$ \\
\hline Outside & Tourism: scuba-diving & $\begin{array}{l}\text { non- } \\
\text { extractive }\end{array}$ & $\begin{array}{r}0.001 \\
74 \\
\end{array}$ & 0.00438 & 15 & 0.00113 & $\begin{array}{r}0.000 \\
12 \\
\end{array}$ & $\begin{array}{r}0.000 \\
01 \\
\end{array}$ & $\begin{array}{r}0.017 \\
32 \\
\end{array}$ & $\begin{array}{r}0.000 \\
06\end{array}$ & $\begin{array}{r}0.000 \\
12 \\
\end{array}$ & $\begin{array}{r}0.001 \\
09 \\
\end{array}$ \\
\hline
\end{tabular}

Table C.2. Descriptive statistics for the threat reduction capacity index. A negative value of index indicates that the threat intensity is reduced inside the protected area relative to the outside; a positive value of index indicates that the threat intensity is higher inside the MPA relative to the outside. The mean threat reduction capacity values were used to compare the reduction capacity of the fully and partially protected zones for every threat (Fig. 3).

\begin{tabular}{|c|c|c|c|c|c|c|c|c|c|c|c|c|}
\hline $\begin{array}{l}\text { Protection } \\
\text { level }\end{array}$ & Threats & Type & Mean & $\begin{array}{l}\text { Standard } \\
\text { deviation }\end{array}$ & $\begin{array}{l}\text { Sample } \\
\text { Size } \\
\end{array}$ & $\begin{array}{l}\text { Standard } \\
\text { error }\end{array}$ & Median & Min & $\operatorname{Max}$ & $25 \%$ & $50 \%$ & $75 \%$ \\
\hline Fully Protected & Artisanal fishing & extractive & -1 & 0 & 18 & 0 & -1 & -1 & -1 & -1 & -1 & -1 \\
\hline Fully Protected & $\begin{array}{l}\text { Recreational fishing: hook } \\
\text { and line }\end{array}$ & extractive & -1 & 0 & 18 & 0 & -1 & -1 & -1 & -1 & -1 & -1 \\
\hline Fully Protected & $\begin{array}{l}\text { Recreational fishing: } \\
\text { spearfishing }\end{array}$ & extractive & -1 & $\overline{0}$ & 18 & 0 & -1 & -1 & -1 & -1 & -1 & $\overline{-1}$ \\
\hline
\end{tabular}




\begin{tabular}{|c|c|c|c|c|c|c|c|c|c|c|c|c|}
\hline Fully Protected & Trawlers/purse-seiners & extractive & -1 & 0 & 18 & 0 & -1 & -1 & -1 & -1 & -1 & -1 \\
\hline Fully Protected & Tourism: bathing/trampling & $\begin{array}{l}\text { non- } \\
\text { extractive }\end{array}$ & 8.41 & 23.12 & 18 & 5.45 & -0.94 & -1 & 83.52 & -1 & -0.94 & 2.17 \\
\hline Fully Protected & $\begin{array}{l}\text { Tourism: commercial } \\
\text { boating }\end{array}$ & $\begin{array}{l}\text { non- } \\
\text { extractive }\end{array}$ & 28.36 & 79.61 & 18 & 18.76 & -1 & -1 & $\begin{array}{r}301.9 \\
1\end{array}$ & -1 & -1 & 2.91 \\
\hline Fully Protected & Tourism: private boating & $\begin{array}{l}\text { non- } \\
\text { extractive }\end{array}$ & $\begin{array}{r}237.5 \\
6\end{array}$ & 763.16 & 18 & 179.88 & 1.11 & -1 & $\begin{array}{r}3197 . \\
31\end{array}$ & -1 & 1.11 & 18.46 \\
\hline Fully Protected & Tourism: scuba-diving & $\begin{array}{l}\text { non- } \\
\text { extractive }\end{array}$ & $\begin{array}{r}2386 . \\
14\end{array}$ & 7752.38 & 18 & 1827.25 & -1 & -1 & $\begin{array}{r}3151 \\
1.71\end{array}$ & -1 & -1 & -1 \\
\hline $\begin{array}{l}\text { Partially } \\
\text { protected }\end{array}$ & Artisanal fishing & extractive & 4.93 & 9.33 & 32 & 1.65 & 2.65 & -1 & 47.12 & 0.22 & 2.65 & 5.28 \\
\hline $\begin{array}{l}\text { Partially } \\
\text { protected }\end{array}$ & $\begin{array}{l}\text { Recreational fishing: hook } \\
\text { and line }\end{array}$ & extractive & 2.39 & 5.54 & 32 & 0.98 & 0.52 & -1 & 21.96 & -1 & 0.52 & 2.70 \\
\hline $\begin{array}{l}\text { Partially } \\
\text { protected }\end{array}$ & $\begin{array}{l}\text { Recreational fishing: } \\
\text { spearfishing }\end{array}$ & extractive & 1.97 & 6.31 & 32 & 1.12 & -1 & -1 & 24.51 & -1 & -1 & 0.63 \\
\hline $\begin{array}{l}\text { Partially } \\
\text { protected }\end{array}$ & Trawlers/purse-seiners & extractive & -0.95 & 0.27 & 32 & 0.05 & -1 & -1 & 0.47 & -1 & -1 & -1 \\
\hline $\begin{array}{l}\text { Partially } \\
\text { protected }\end{array}$ & Tourism: bathing/trampling & $\begin{array}{l}\text { non- } \\
\text { extractive }\end{array}$ & 50.55 & 175.82 & 32 & 31.08 & -0.11 & -1 & $\begin{array}{r}901.6 \\
0\end{array}$ & -0.87 & -0.11 & 6.66 \\
\hline $\begin{array}{l}\text { Partially } \\
\text { protected }\end{array}$ & $\begin{array}{l}\text { Tourism: commercial } \\
\text { boating }\end{array}$ & $\begin{array}{l}\text { non- } \\
\text { extractive }\end{array}$ & 45.74 & 100.08 & 32 & 17.69 & 9.04 & -1 & $\begin{array}{r}461.2 \\
4\end{array}$ & -0.67 & 9.04 & 27.34 \\
\hline $\begin{array}{l}\text { Partially } \\
\text { protected }\end{array}$ & Tourism: private boating & $\begin{array}{l}\text { non- } \\
\text { extractive }\end{array}$ & 26.35 & 80.78 & 32 & 14.28 & 4.49 & -1 & $\begin{array}{r}400.4 \\
9 \\
\end{array}$ & -0.43 & 4.49 & 9.68 \\
\hline $\begin{array}{l}\text { Partially } \\
\text { protected }\end{array}$ & Tourism: scuba-diving & $\begin{array}{l}\text { non- } \\
\text { extractive }\end{array}$ & $\begin{array}{r}413.8 \\
5\end{array}$ & 1129.49 & 32 & 199.67 & 4.32 & -1 & $\begin{array}{r}5904 . \\
77\end{array}$ & -1 & 4.32 & $\begin{array}{r}217.3 \\
1\end{array}$ \\
\hline
\end{tabular}

